\title{
Analyzing the Function of PTK7 in Cell Migration
}

\section{Doctoral Thesis}

In partial fulfillment of the requirements for the degree

"Doctor rerum naturalium (Dr. rer. nat.)"

in the Molecular Medicine Study Program

at the Georg-August University Göttingen

submitted by

\author{
Martina Christine Podleschny \\ born in Osterode am Harz, Germany
}

Göttingen, 30. September 2011 
Members of the Thesis Committee:

Supervisor

Dr. Annette Borchers, Developmental Biochemistry

Second member of the thesis committee

Prof. Dr. Heidi Hahn, Human Genetics

Third member of the thesis committee

Prof. Dr. Andreas Wodarz, Stem Cell Biology

Date of Disputation: 09.11.2011 
AFFIDAVIT

I hereby declare that my doctoral thesis entitled

"Analyzing the Function of PTK7 in Cell Migration"

has been written independently with no other sources and aids than quoted.

Göttingen, September 2011 


\section{Table of Contents}

I. Table of Contents.................................................................. 4

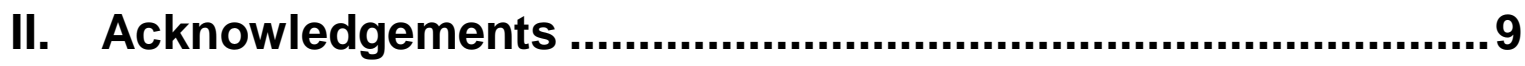

III. Abstract ............................................................................. 10

IV. List of Figures ..................................................................11

V. List of Tables......................................................................... 14

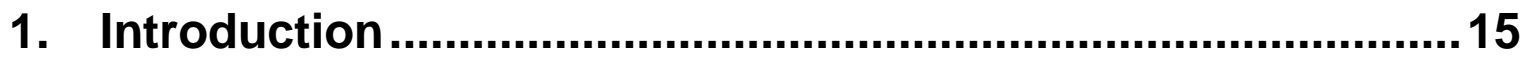

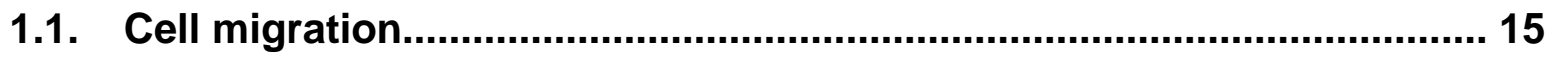

1.1.1. Current knowledge of single cell migration....................................... 16

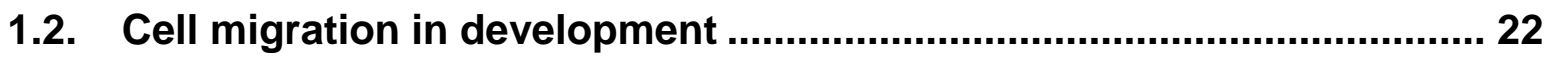

1.2.1. Cell migration during gastrulation.................................................. 22

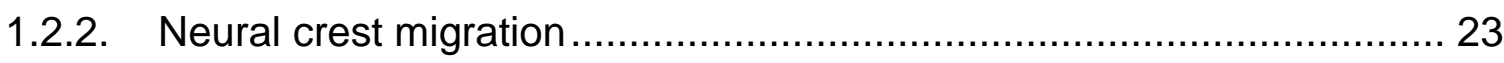

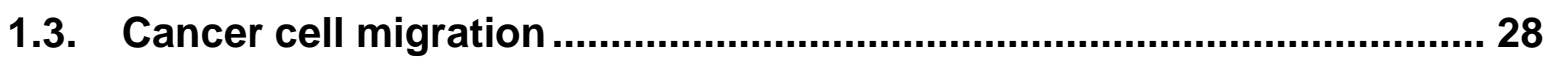

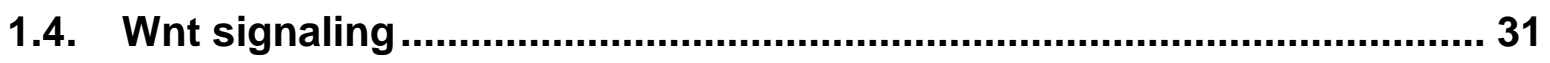

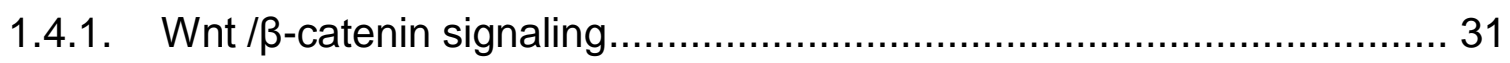

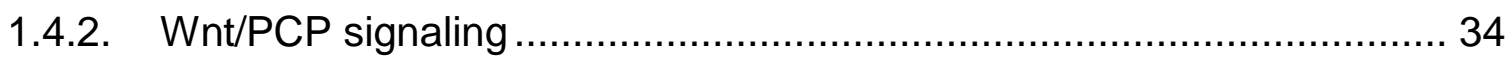


1.5. Protein Tyrosine Kinase 7 signaling 39

1.5.1. PTK7 is a regulator of PCP signaling 39

1.5.2. PTK7 in cancer 41

1.5.3. PTK7 increases cell migration and inhibits apoptosis 42

1.5.4. PTK7 is a target for proteolytic cleavage by MT1MMP 42

1.6. Ror2 signaling... 45

1.6.1. Ror2 is a Wnt co-receptor...... 45

1.6.2. Ror2 regulates convergent extension during development 46

1.6.3. Wnt5a Ror2 signaling in cell migration 46

1.6.4. Wnt5a Ror2 signaling in tumor invasion 47

1.7. Aim of the study 49

2. Materials and Methods 50

2.1. Materials. 50

2.1.1. Bacteria 50

2.1.2. Cell lines 50

2.1.3. Model Organism. 50

2.1.4. Chemicals, Buffer and Media . 51

2.1.5. Constructs 55 
2.1.6. Oligonucleotides 59

2.1.7. Antibodies 62

2.2. Methods 64

2.2.1. Techniques using DNA 64

2.2.2. Techniques using RNA 65

2.2.3. Cell culture techniques. 66

2.2.4. Protein techniques 70

2.2.5. Xenopus techniques 72

3. Results 73

3.1. PTK7 phenotypes in human cell lines 73

3.1.1. PTK7 overexpression increases cell protrusions 73

3.1.2. Stable overexpression of PTK7. 75

3.1.3. Inducible overexpression of PTK7 78

3.1.4. PTK7 overexpression did not increase proliferation 81

3.1.5. PTK7 overexpression does not promote MCF7 migration in scratch assays 83

3.1.6. PTK7 overexpression improves invasiveness of MCF7 cells 85

3.2. Signaling mechanisms 87

3.2.1. PTK7 is a Wnt co-receptor 87 
3.2.2. PTK7 inhibits canonical Wnt signaling 90

3.2.3. siRNA knockdown of PTK7 in human cell lines 92

3.2.4. siRNA knockdown of PTK7 cannot abolish canonical Wnt signaling in TOPflash reporter assays 94

3.2.5. PTK7 activates downstream targets of PCP signaling 95

3.2.6. PTK7 showed no indication for activation of JNK 96

3.3. PTK7- Ror2 interaction 97

3.3.1. The PTK7 overexpression phenotype resembles the Ror2 phenotype. 97

3.3.2. PTK7 and Ror2 co-precipitate each other in cell lysates 99

3.3.3. Ror2 rescues PTK7 knockdown in Xenopus laevis neural crest cell migration 105

4. Discussion 108

4.1. PTK7 induces filopodia formation 108

4.2. PTK7 does not influence cell proliferation 108

4.3. PTK7 increases invasiveness of MCF7 cells 109

4.4. PTK7 is a Wnt co-receptor 111

4.5. PTK7 activates PCP downstream signaling 112

4.6. PTK7/Ror2 interaction 113

4.6.1. Biochemical evidence for PTK7/Ror2 interaction 113 
4.6.2. PTK7 and Ror2 interact functionally in Xenopus neural crest migration 114

5. Summary and Conclusions ..............................................116

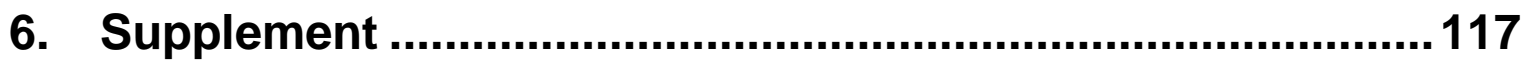

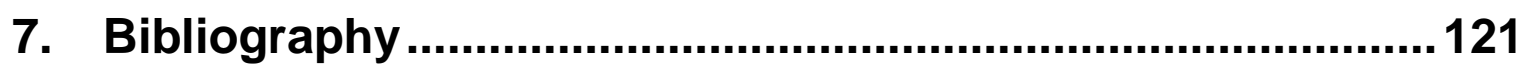




\section{Acknowledgements}

First of all I would like to thank my supervisor, Dr. Annette Borchers, for providing the opportunity to do my thesis work in her group. She entrusted me with this interesting project and was a motivating and encouraging teacher who patiently answered all my questions. I am grateful for her continuous support and advice during the process of learning how to work as a scientist.

I would like to thank Prof. Dr. Tomas Pieler for giving me the opportunity to work in his department and for offering a scientific environment.

The members of my thesis committee, Prof. Dr. Heidi Hahn and Prof. Dr. Andreas Wodarz I would like to thank for co-supervising my project and being involved in helpful discussions.

Furthermore, I want to thank my collaboration partners Prof. Dr. Klaudia Giehl (Giessen), Prof. Dr. Claudia Binder and Dr. Tobias Pukrop (Goettingen), who provided their techniques and knowledge and contributed important results to my work.

Many people from different departments in Goettingen provided access to their instruments or reagents and plasmids and shared their knowledge to use them. I would like to thank Prof. Dr Andreas Wodarz and his group members for providing the laser scanning microscope. Prof. Dr. Matthias Dobbelstein and Ulrike Keitel I would like to thank for providing the Celigo ${ }^{\mathrm{TM}}$ instrument. The group of Prof. Dr. Claudia Binder and Dr. Tobias Pukrop I want to thank for help with Boyden Chambers (Matthias Schulz) and flow cytometry analysis (Dr. Florian Klemm).

Furthermore, I want to thank the current and former members of the "morphogenesis group" - Hanna, llona, Iryna and Peter - for being nice and helpful colleagues and generating a pleasant working atmosphere.

I also thank all members of the department for Developmental Biochemistry for their helpful and friendly support.

Finally, I would like to thank my family and all my friends who helped, supported and motivated me in various ways. I am very grateful for your great encouragement. 


\section{Abstract}

Cell migration is very important for embryonic development and maintenance of the adult organism. During development cell migration processes are involved in gastrulation, convergent extension movements and neural crest cell migration. PTK7 (protein tyrosine kinase 7) regulates embryonic cell migration and its expression correlates with the metastatic potential of different tumor cell lines, suggesting that it might play a role in tumor cell migration. In vertebrates PTK7 is required for cell movements like neural tube closure and neural crest migration. As the human ortholog of PTK7 was identified in colon carcinoma cell lines we wanted to analyze whether it also affects tumor migration and invasion. To investigate the function of PTK7 in the context of tumor cells and metastatic behavior we established inducible expression of PTK7 in the low-invasive breast cancer cell line MCF7. Analyzing the morphology of these cells and performing functional assays revealed that PTK7 overexpression led to an increase in filopodia-like cell protrusions and increased the invasiveness of MCF7 cells. As a very similar filopodia phenotype for overexpression of Ror2 was previously described we analyzed the relationship between PTK7 and Ror2 in vitro and in vivo in Xenopus neural crest migration. Indeed, we could show an interaction of PTK7 and Ror2 in immunoprecipitation experiments, which is also conserved in Xenopus neural crest migration. As it was shown for Xenopus PTK7 and its Drosophila ortholog otk (offtrack) to bind Wnt proteins we confirmed that PTK7 functions as a Wnt co-receptor to bind canonical Wnt3a and inhibits canonical Wnt signaling. With the knowledge we gained and the tools, which were established, our work opens further possibilities to study aspects of cell migration and invasion in development and cancer metastasis. 


\section{List of Figures}

Figure 1.1. The cycle of cell migration.

Figure 1.2. Phosphatidyl inositol phosphate signaling in the regulation of cell polarity.

Figure 1.3. Steps in cell migration.

Figure 1.4. Transformation from epithelial to migrating cells.

Figure 1.5. Gastrulation process in Xenopus laevis gastrulation.

Figure 1.6. Migrating neural crest cells in Xenopus laevis.

Figure 1.7. Pluripotent neural crest cells give rise to a variety of cell types.

Figure 1.8. Comparison of EMT steps in neural crest cell migration and cancer metastasis.

Figure 1.9. Figure summarizes molecules involved in regulation of neural crest migration.

Figure 1.10. Tight regulation of Wnt signaling is essential.

Figure 1.11. Wnt induces a second axis in Xenopus embryos.

Figure 1.12. $\beta$-catenin dependent Wnt signaling.

Figure 1.13. PCP signaling.

Figure 1.14. Schematic representation of convergent extension.

Figure 1.15. PCP regulates contact inhibition of locomotion.

Figure 1.16. PTK7 is required for neural crest cell migration. 
Figure 1.17. Structure of PTK7.

Figure 1.18. Structure model of PTK7 shows the MT1MMP cleavage sites.

Figure 1.19. Wnt/Ror2 signaling.

Figure 3.1. PTK7 overexpression increases number of cell protrusions.

Figure 3.2. Stable overexpression of PTK7-EGFP in MCF7 cells.

Figure 3.3. Flow cytometry analysis of PTK7-EGFP expressing MCF7 cells.

Figure 3.4. Inducible expression of PTK7.

Figure 3.5. Doxycycline induction of PTK7GFP in MCF7 cells results in filopodia formation.

Figure 3.6. PTK7 overexpression does not influence the cell proliferation.

82

Figure 3.7. PTK7 overexpression in MCF7 cells cannot increase the speed of migration in scratch assays.

Figure 3.8. PTK7 overexpression in MCF7 cells doubles their invasiveness in Boyden chamber assays.

Figure 3.9. PTK7 and Wnt3a do not interact directly.

Figure 3.10. PTK7 and Fz7 directly interact.

Figure 3.11. PTK7 and Fz7 form a receptor complex that is required for binding Wnt.

Figure 3.12. PTK7 inhibits canonical Wnt signaling.

Figure 3.13. The expression of PTK7 can be effectively downregulated by siRNA transfection.

Figure 3.14. Activation of canonical Wnt signaling does not require PTK7. 
Figure 3.15. PTK7 activates the small GTPases RhoA and Rac1.

Figure 3.16. PTK7 overexpression does not activate JNK.

Figure 3.17. Overexpression of Ror2 in MCF7 cells resembles the PTK7 overexpression phenotype.

Figure 3.18. PTK7 and Ror2 co-precipitate each other in cell lysates.

Figure 3.19. Full-length and deletion constructs of Ror2.

Figure 3.20. Deletion mutants of Ror2 co-precipitate PTK7.

Figure 3.21. Ror2 co-precipitates deletion mutants of PTK7.

Figure 3.22. Summary of the interacting domains of PTK7 and Ror2.

Figure 3.23. Ror2 rescues the PTK7 loss of function phenotype in Xenopus neural crest migration. 


\section{List of Tables}

Table 2.1. Summarizes the expression plasmids that were used during this study.

Table 2.2. Summarizing the restriction enzymes used for linearization of plasmids and polymerases used for in vitro transcription.

Table 2.3. Summarizes antibodies and working concentrations used in this study.

Table 2.4. Volumes of culture medium, amount of DNA/RNA and Lipofectamin. 


\section{Introduction}

\subsection{Cell migration}

Cell migration is a crucial process required for embryonic development and maintenance of the adult organism. The process of cell migration starts at early embryogenesis during gastrulation when the three different germ layers are formed (Keller, 1980; Winklbauer and Nagel, 1991). Later on in development cell migration is required for neural tube closure (Wallingford and Harland, 2002) or when cells from former epithelial sheets delaminate and migrate throughout the body to reach their destination such as primordial germ cells (Molyneaux and Wylie, 2004; Molyneaux et al., 2001) or neural crest cells (Serbedzija et al., 1992; Serbedzija et al., 1990; Trainor, 2005). In the adult organism some physiological aspects of cell migration take place. During the turnover of skin and intestinal tissue new epithelial cells migrate upwards from the underlying basal layer or the intestinal crypts (Grose et al., 2002; Ridley et al., 2003). In wound repair, angiogenesis and immune response of the adult organism, cell migration is required (Cotran, 2005; Ley et al., 2007; Werner and Grose, 2003). Leukocytes migrate out of the blood vessels into the infected tissue to apply cellular immune response (Friedl and Weigelin, 2008) and fibroblasts migrate to sites of injuries where they are necessary in tissue repair. In wound repair vascular endothelial cells are motile in order to construct new blood vessels (Korff and Augustin, 1999; Lauffenburger and Horwitz, 1996). However, misregulation of cell migration can also cause serious disease such as cancer metastasis, which is a frequent cause of death in humans (Chambers et al., 2002; Friedl and Wolf, 2003; Yamaguchi et al., 2005). Therefore it is important to understand the mechanisms, which regulate cell migration to obtain tools for treatment of disease. 


\subsubsection{Current knowledge of single cell migration}

The complex process of cell migration -polarization, protrusion formation, adhesion, contraction and retraction- needs controlled signal integration to result in the output of forward movement of single cells. One can mechanically define a sequence of steps, known as the cell motility cycle (Lauffenburger and Horwitz, 1996) (Figure 1.1.). The migrating cell produces a protrusion into the direction of movement. At the site of protrusion a stable adhesion focus is formed to the underlying substratum, contractile components of the cell perform a contraction and the rear of the cells is moved along while the adhesion in the rear is abolished.

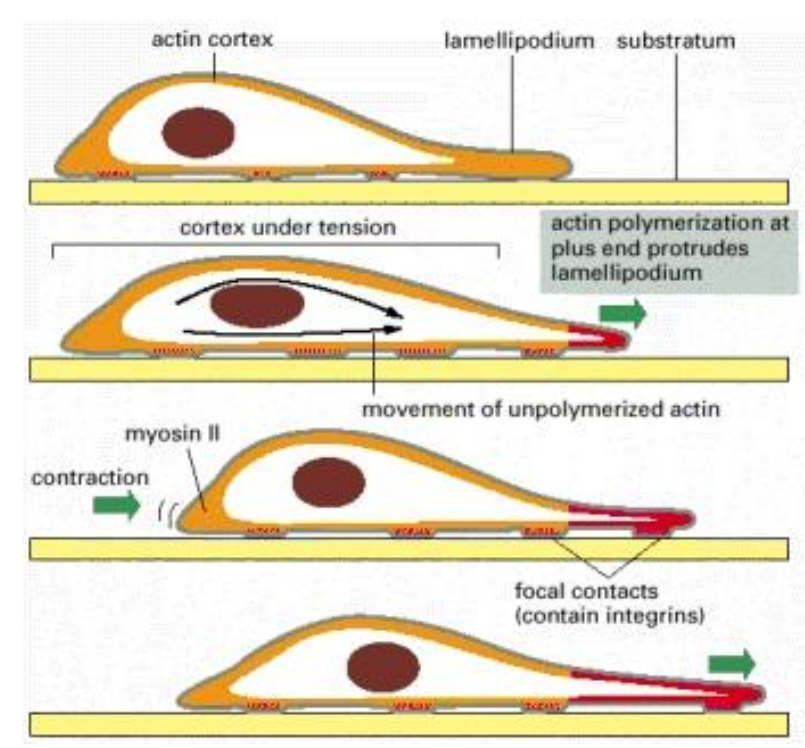

Figure 1.1. The cycle of cell migration. (A) Cell attaches to the substratum. (B) Polarized cell produces a protrusion in form of a lamellipodium at the leading edge. (C) Strong focal contacts arise in the front while the cortex is under tension and the rear contracts. The adhesion in the rear detaches thereby the cell moves forward. (D) A new forward directed protrusion is formed to start the next cycle. Taken from (Molecular Biology of the Cell. 4th edition. Alberts B, Johnson A, Lewis J, et al. New York: Garland Science; 2002.)

Before a cell can start to migrate it needs to be polarized, in a way that a leading edge and a trailing edge are defined. Polarization is established upon stimuli the cell senses from the environment. The triggering events leading to polarization can be either chemotactic if gradients of soluble molecules are present, haptotactic if the cell responds to different adhesion molecules in the substratum or even durotactic in case cells are responding to a mechanical signal from the environment. (Carter, 1965; Lo et al., 2000; 
Petrie et al., 2009). On the molecular level polarity is established if a G-protein coupled receptor senses a chemoattractant molecule (Van Haastert PJ, 2004). Upon activation of a G-protein coupled receptor a variety of downstream molecules can be activated locally (Kolsch et al., 2008; Parent et al., 1998; Servant et al., 2000). As the cells are able to sense very minor differences in concentrations of chemoattractants forming a gradient, this signal needs to be amplified and translated into more pronounced intracellular gradients, which lead to polarization within the cell. Activation of G-protein coupled receptors by a chemokine gradient leads to a localized activation of Ras, which results in activation of phosphatidylinositol 3-kinase (PI3K). PI3K activity results in phosphatidylinositol 3,4 bisphosphate $(\mathrm{PI}(3,4) \mathrm{P} 2)$ or phosphatidyloinositol $3,4,5$ trisphosphate $(\mathrm{PI}(3,4,5) \mathrm{P} 3)$ or short PIP3 at the leading edge of the cell (Figure 1.2.). These molecules are key signaling molecules and become highly polarized at the leading edge while the phosphatase PTEN that can dephosphorylate and inactivate PIP3 is localized at the trailing edge. PIP3 in turn activates the small GTPase Rac1 at the leading edge, which triggers actin polymerization and the formation of lamellipodia (Figure 1.3.A). Furthermore, the Rho family member cdc42, also known as the master regulator of polarity, is active at the front of the migrating cell (Itoh et al., 2002; Ridley et al., 2003). Cdc42 restricts protrusions to the leading edge (Srinivasan et al., 2003) and localizes the microtubule organizing center (MTOC) in front of the nucleus at the leading edge (Etienne-Manneville and Hall, 2002; Ridley et al., 2003; Rodriguez et al., 2003). Rac1 activity at the leading edge is antagonized by RhoA, another member of the Rho family of small GTPases. RhoA localizes to the rear of the cell and mediates actomyosin-based contractility of the cell. Rac1, which is active at the leading edge of the cell, suppresses Rho activity, whereas Rho, which is more active at sides and the rear of a polarized cell, suppresses Rac1 activity. Via this mechanism the formation of Rac1-mediated protrusions apart from the leading edge are inhibited (Ridley et al., 2003; Worthylake and Burridge, 2003; Xu et al., 2003) (Figure 1.3.C). 


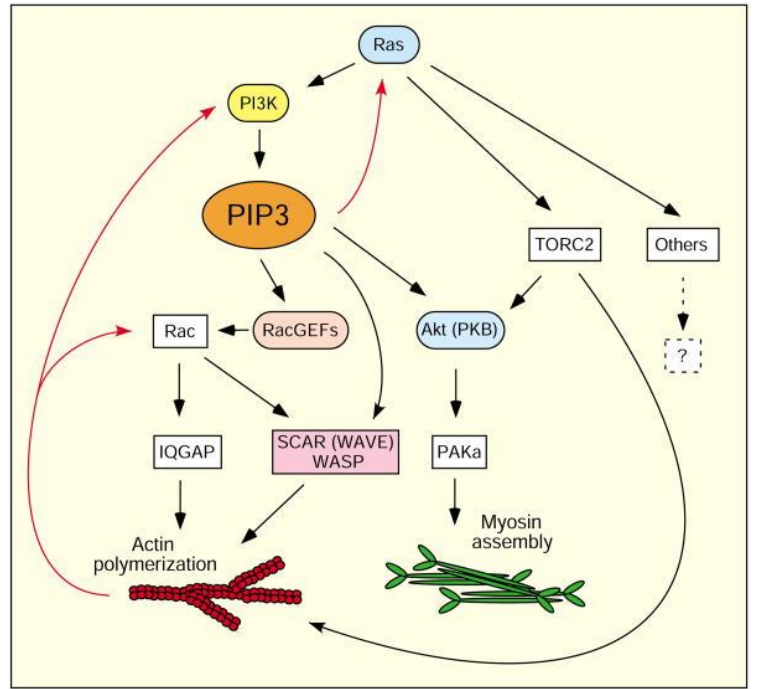

Figure 1.2. Phosphatidyl inositol phosphate signaling in the regulation of cell polarity. Upon chemokine signaling activated Ras activates PI3K. PIP3s are produced, which can activate both actin polymerization and myosin assembly. Taken from V. Kölsch et al. Journal of Cell Science 121, 551-559, 2008 (Kolsch et al., 2008). 


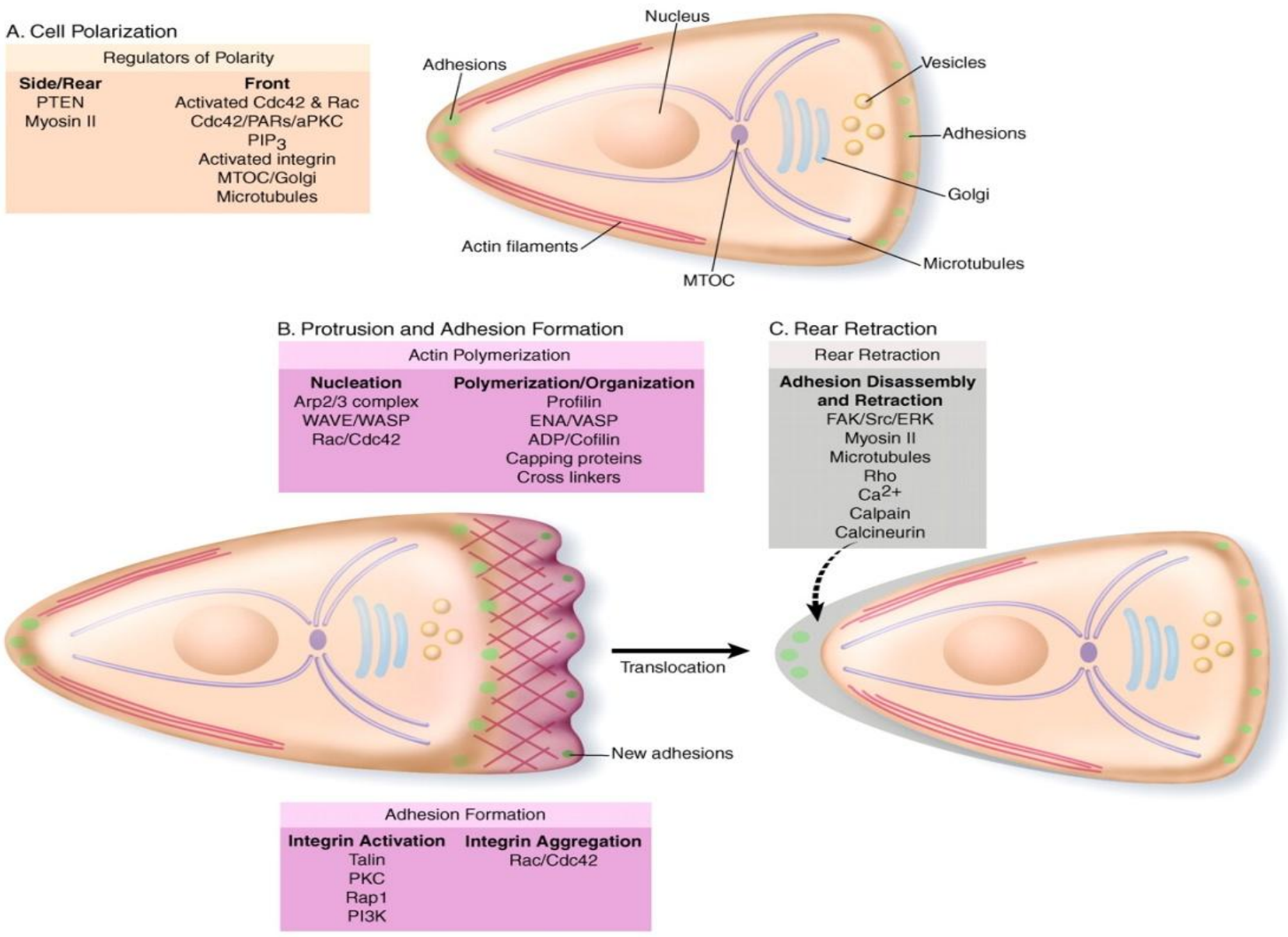

Figure 1.3. Steps in cell migration. (A) Establishment of cell polarity is essential for directed cell migration. The regulators of polarity are summarized in box A. At the leading edge cdc42 Rac, integrins and PIP3 get activated. Activation of PTEN and Myosin II occurs at the sides and the rear of the cell. (B) The polarized cell produces protrusions at the leading edge and modifies cell adhesion. Box B summarizes the regulators of Actin polymerization and organization as well as the actin nucleators. (C) At the rear of the migrating cell retraction and adhesion disassembly take place. Box $C$ summarizes proteins involved in the process of adhesion disassembly and retraction. Taken from A J Ridley et al. Science 2003; 302:1704-1709 (Ridley et al., 2003).

To move forward a polarized cell needs to create protrusions and has to adhere. Therefore actin polymerization (Pollard and Borisy, 2003) and adhesion formation have to take place. Directional protrusion formation is driven by active Rac1. Rac1 activity can promote localized actin polymerization by activating nucleation promoting factor (NPF), proteins like the Wiskott-Aldrich syndrome protein WASp or Scar/WAVE proteins that activate the actin related protein Arp 2/3 complex (Mullins and Pollard, 1999a; Mullins and Pollard, 1999b). Arp2/3 is a nucleator of actin polymerization and produces branched 
filaments, which push lamellipodia forward at the leading edge (Pollard, 2000; Pollard, 2007). The nucleator formin is responsible for the formation of unbranched actin bundles, which are structures generated in filopodia (Wallar and Alberts, 2003). Actin filaments do elongate until a capping protein terminates the growth process (Figure 1.3.B).

For active forward movement the cell has to transmit mechanical force to the underlying substratum. To this end cells form focal contacts at the tips of protrusion sites. Integrin receptors are responsible for stabilizing the focal contact formed through attachment. Tractional forces to move the cell forward are born from integrin binding to ECM with intracellular connection to the cytoskeleton (Lauffenburger and Horwitz, 1996). Integrins are transmembrane receptors that connect the cytoskeleton of intracellular actin filaments to neighboring cells or to molecules of the extracellular matrix (ECM). Integrins are heterodimeric receptors consisting of $\alpha$ and $\beta$ chains; intracellular they only have short domains but large ligand binding domains at their extracellular part (Giancotti and Ruoslahti, 1999; Hynes, 1992). Upon activation of integrin receptors by extracellular ligand binding they undergo conformational changes and cluster (Emsley et al., 2000; Ridley et al., 2003). Integrins do not have any catalytical domains but they transmit signals through interaction with catalytical active partners like ras related protein1 (Rap1) and protein kinase $C$ (PKC), which increase the integrin affinity (Kinbara et al., 2003). Initially formed small focal complexes at the leading edge are further stabilized by the involvement of active Rac and Cdc42 (Ridley et al., 2003). In migrating cells the stability of focal adhesion needs to be in a distinct range because cells with very large integrin clusters are non-migrating or can move only very slowly (Ridley et al., 2003).

The forces inside the cell are driven by an interaction of actin filaments with myosin II. The activity of myosin II is positively regulated by the myosin light chain (MLC) phosphorylation, which gets activated by MLC kinase (MLCK) or Rho kinase (ROCK) (Ridley et al., 2003). To retract the rear of the cell and to release the adhesion in the rear, proteins are involved that are in general known to regulate adhesion turnover. Focal adhesion kinase (FAK), ERK, Src (Alahari et al., 2002; Larsen et al., 2003; Turner et al., 2001) and the protease calpain, which is calcium regulated through stretch activated calcium channels, participate in this process (Glading et al., 2002; Hendey et al., 1992; Lee et al., 1999) (Figure 1.3.C). Upon disassembly of adhesion contacts the cycle of cell migration is completed and the rear of the cell retracts. This migratory cycle continues as long as the cell is polarized. 
A general statement about the regulation of cell migration in vivo is that cell migration has to be controlled at three different levels. At the beginning prior to migration the cell shows an unpolarized morphology. To become migratory, cells form protrusions in all directions before they sense attractant cues and the protrusions become polarized, which means oriented into the direction of migration. And finally the cell starts guided movement to reach the destination (Figure 1.4.).

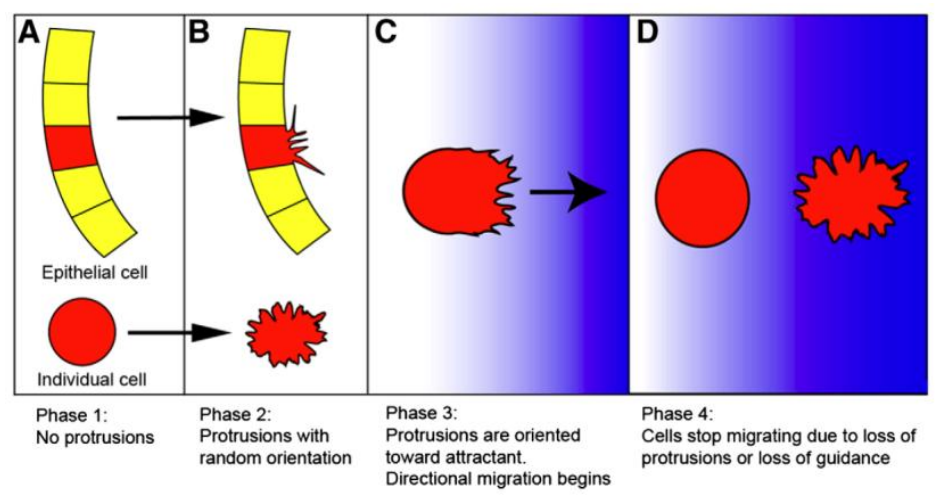

Figure 1.4. Transformation from epithelial to migrating cells. (A) Before migration starts the cell is part of the complex organization of an epithelium. (B) The cell produces random unpolarized protrusions. (C) As the cell senses stimuli, the protrusions are polarized and the cell leaves its former location. (D) The cell stops migration due to lack of attractive guidance cues. Taken from Aman and Piotrowski Developmental Biology 341 (2010) 20-33 (Aman and Piotrowski, 2010).

Two different types of cell migration can be distinguished, individual single cell migration versus collective or cohesive cell migration. Single cell migration is mainly seen for the migration of primordial germ cells, leukocytes and hematopoietic stem cells (Friedl et al. 2001), whereas collective cell migration is required for most of the morphogenetic movements like gastrulation, neural crest migration, vascular sprouting and pronephros development as well as for cell migration in many types of cancer (De Smet et al., 2009; Friedl and Gilmour, 2009; Teddy and Kulesa, 2004; Vasilyev et al., 2009). During collective cell migration the cells remain physically and functionally linked with intact cellcell junctions while polarization is mainly seen at the leading. 


\subsection{Cell migration in development}

\subsubsection{Cell migration during gastrulation}

During early embryogenesis, morphogenetic movements are required to form a threedimensional body plan. An early process to achieve this is gastrulation, when the three germ layers are formed. During amphibian gastrulation, for example, the presumptive mesendodermal cells involute and migrate actively on the blastocoel roof to the direction of the animal pole. These cell movements are driven by directional cell migration. Before cells can start to migrate, FGF (fibroblast growth factor)-induced epithelial mesenchymal transition (EMT), which upregulates Snail that in turn down regulates E-cadherin, is required (Carver et al., 2001; Ciruna and Rossant, 2001). Extracellular signals that give the directionality of cell migration are necessary to result in a properly formed embryo. It is the role of these extracellular signals to activate directed cell motility (Keller, 2005; Kurosaka and Kashina, 2008). Directionality for cell migration in gastrulation is mediated by platelet derived growth factor (PDGF) signaling. The growth factor PDGF is secreted by the blastocoel roof cells in a gradient, which increases in direction of movement, while the corresponding receptor PDGFR is expressed by the mesendodermal cells (Ataliotis and Mercola, 1997; Keller et al., 2003; Nagel et al., 2004) (Figure 1.5.). However, the PDGF signaling seems to be responsible only for guidance and not for motility (Nagel et al., 2004). Additionally, chemokine signaling plays a role for motility in Xenopus anterior mesoderm. The cells of the blastocoel roof express the chemokine cxcl12a while the cxcr4 receptor is expressed at the leading edge of migrating mesodermal cells (Figure 1.5.). If expression of the ligand $\mathrm{cxcl} 12 \mathrm{a}$ is either downregulated or overexpressed the migration of the anterior mesoderm is impaired (Fukui et al., 2007). Recent data suggest that not only guidance molecules and actin regulators but also regulators of cell adhesion are required for the regulation of gastrulation movements (Aman and Piotrowski, 2010; Hammerschmidt and Wedlich, 2008; Solnica-Krezel, 2006; Witzel et al., 2006). The extracellular matrix of the blastocoel roof is fibronectin-rich and the interaction with the mesendodermal cells is mediated by the $\alpha 5 \beta 1$ integrin receptor (Ramos et al., 1996). This mainly summarizes the active migration processes of cell movement during gastrulation. But there are other movement processes happening during gastrulation, which are regulated by other mechanisms for example convergent extension, which is regulated by planar cell polarity and will be explained later. 


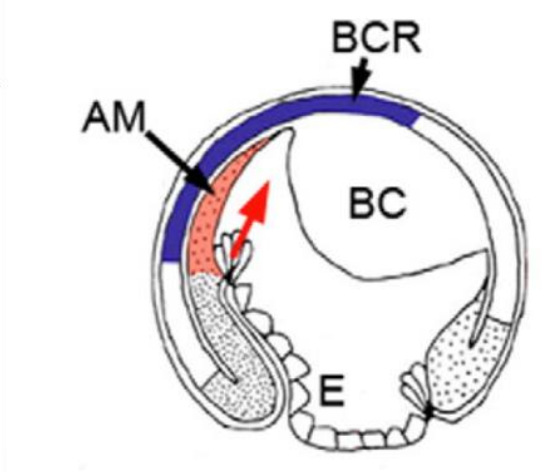

PDGFA, Cxcl12a PDGFR $\alpha$, Cxcr4

Figure 1.5. Gastrulation process in Xenopus laevis gastrulation. Schematic view of a cross section through a gastrulating Xenopus embryo. Anterior mesendodermal (AM) cells imaged in red migrate along the internal surface of the blastocoel roof $(B C R)$ into the direction of the animal pole. The attracting cues and corresponding receptors are indicated by the colors. PDGF and Cxcl 12a are expressed by the BCR (blue), while PDGFR and Cxcr4 are expressed by the AM cells (red). Taken from Aman A. and Piotrowski T. Developmental Biology 341 (2010) 20-33 (Aman and Piotrowski, 2010).

\subsubsection{Neural crest migration}

Neural crest cells are a population of highly migratory cells that have been likened to the migration of malignant tumor cells (Kuriyama and Mayor, 2008). Neural crest cells become induced at the borders of the neural plate and move through the developing embryo to their site of destination (Knecht and Bronner-Fraser, 2002; Scherson et al., 1993; Serbedzija et al., 1989; Serbedzija et al., 1992; Serbedzija et al., 1990) (Figure 1.6.) 

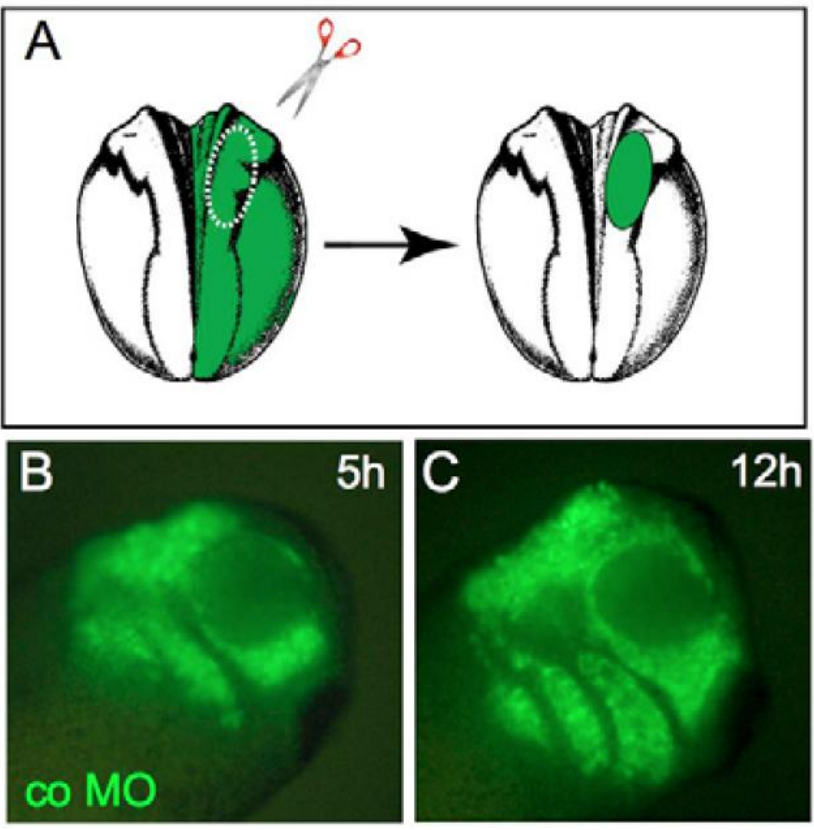

Figure 1.6. Migrating neural crest cells in Xenopus laevis. (A) Transplantation of GFP injected neural crest cells to a receiving embryo. (B,C) The GFP positive cranial neural crest cells migrate and show the typical stream-like formation. Taken from Shnitsar and Borchers, Development 2008 135 4015-4024 (Shnitsar and Borchers, 2008).

The pluripotent neural crest cells give rise to a variety of tissues, for instance facial cartilage, glia cells of cranial nerves, pigment cells or neuro-secretory cells of the adrenal gland (Figure 1.7.). Prior to migration, neural crest cells become induced at the border of the neural plate through signals that are provided by the adjacent tissues like the neural plate, epidermis and mesoderm (Bonstein et al., 1998; Knecht and Bronner-Fraser, 2002; Mancilla and Mayor, 1996; Mayor et al., 1995; Raven, 1945; Selleck and Bronner-Fraser, 1995). Factors involved in neural crest cell induction are bone morphogenic protein (BMP), different Wnts, fibroblast growth factor (FGF) and retinoic acid (RA) (Barembaum and Bronner-Fraser, 2005; Steventon et al., 2005). 


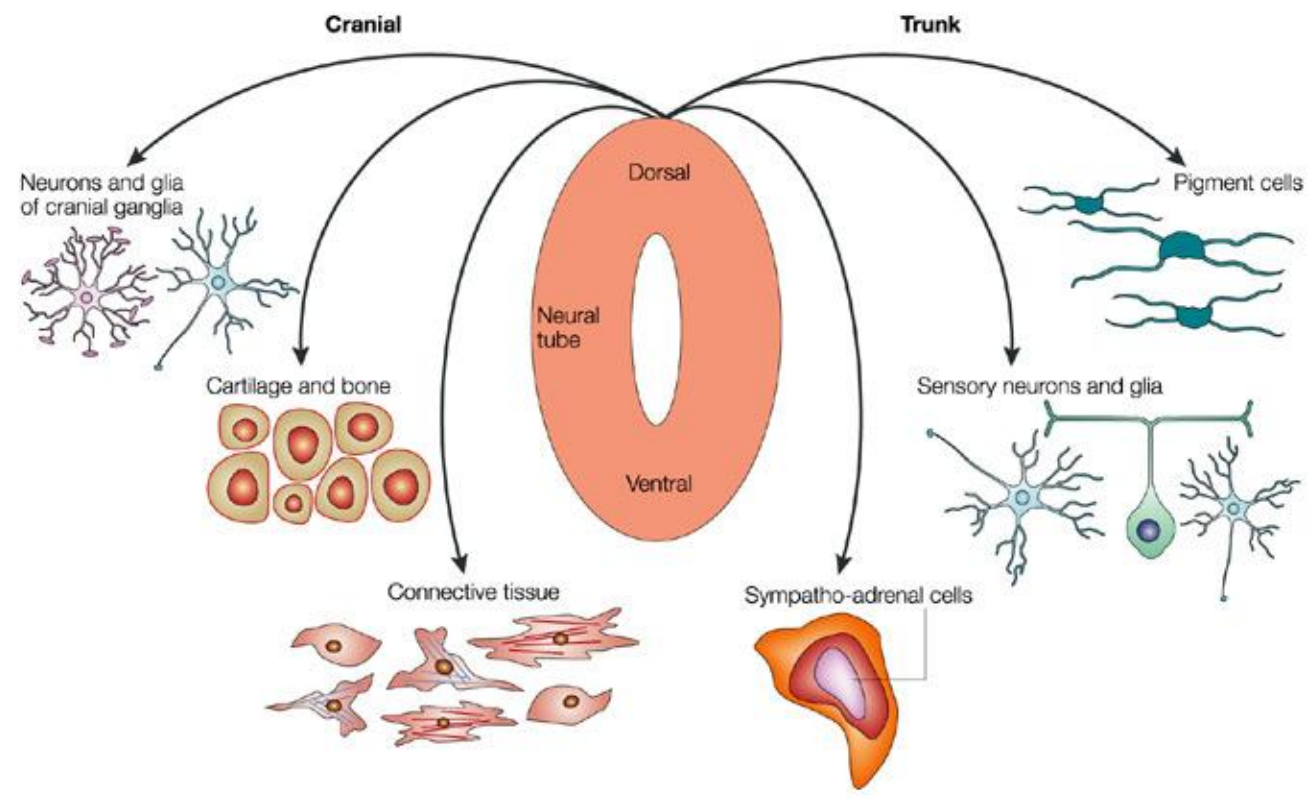

Figure 1.7. Pluripotent neural crest cells give rise to a variety of cell types. Neural crest cells migrate from the borders of the neural plate throughout the body and develop into many different cell types. The cranial neural crest develops into neurons and glia, cartilage and bone as well as connective tissue. The trunk neural crest cells give rise to pigment cells, sensory neurons, glia and sympatho-adrenal cells. Taken from Knecht and Bronner-Fraser Nature Reviews Genetics 2002, 3, 453-461 (Knecht and Bronner-Fraser, 2002).

After their induction at the neural plate border, neural crest cells have to lose their epithelial character before they can start migration. Therefore, like in cancer cell migration they undergo a process called epithelial-mesenchymal-transition (EMT) (Figure 1.8.). Cells of an epithelial tissue are strictly arranged and share tight junctions with their direct neighbors. In this respect epithelial tissues are highly polar in the apical basal direction. It is the first step of EMT to lose this apical basal polarity by breaking cellular junctions. The type of cellular junctions is exchanged at the beginning of the EMT process. Occludin, which is a typical component of tight junctions, is replaced by Connexin-43, a representative for gap-junctions (Aaku-Saraste et al., 1996; Li and Mrsny, 2000; Lo et al., 1997; Wang and Nathans, 2007). At the next step in EMT, cells exchange their adhesion molecules from an epithelial towards a mesenchymal composition. From the onset of EMT one can detect a decrease in the expression of type I cadherins and an 
increase in the expression of type II cadherins (DeLuca et al., 1999). Furthermore, it has been shown that factors, like members of the Snail family, which are required to induce the neural crest fate actively repress the expression of E-cadherin (Aybar et al., 2003; Batlle et al., 2000; Cano et al., 2000; Carl et al., 1999; Elloul et al., 2005; LaBonne and Bronner-Fraser, 2000; Mayor et al., 2000).To finally reach a mesenchymal character neural crest cells additionally require the gain of proteolytic activity. Proteolytic activity is mainly achieved by the expression of matrix metalloproteases (MMPs). These proteins are serine proteases that can perform metal ion dependent cleavages of extracellular matrix proteins. Intriguingly, MMP expression is also regulated by Snail expression (Kuphal et al., 2005) and overexpression of MMPs has also been detected in various cancers (Nomura et al., 1995; Springman et al., 1990; Stetler-Stevenson et al., 1989).

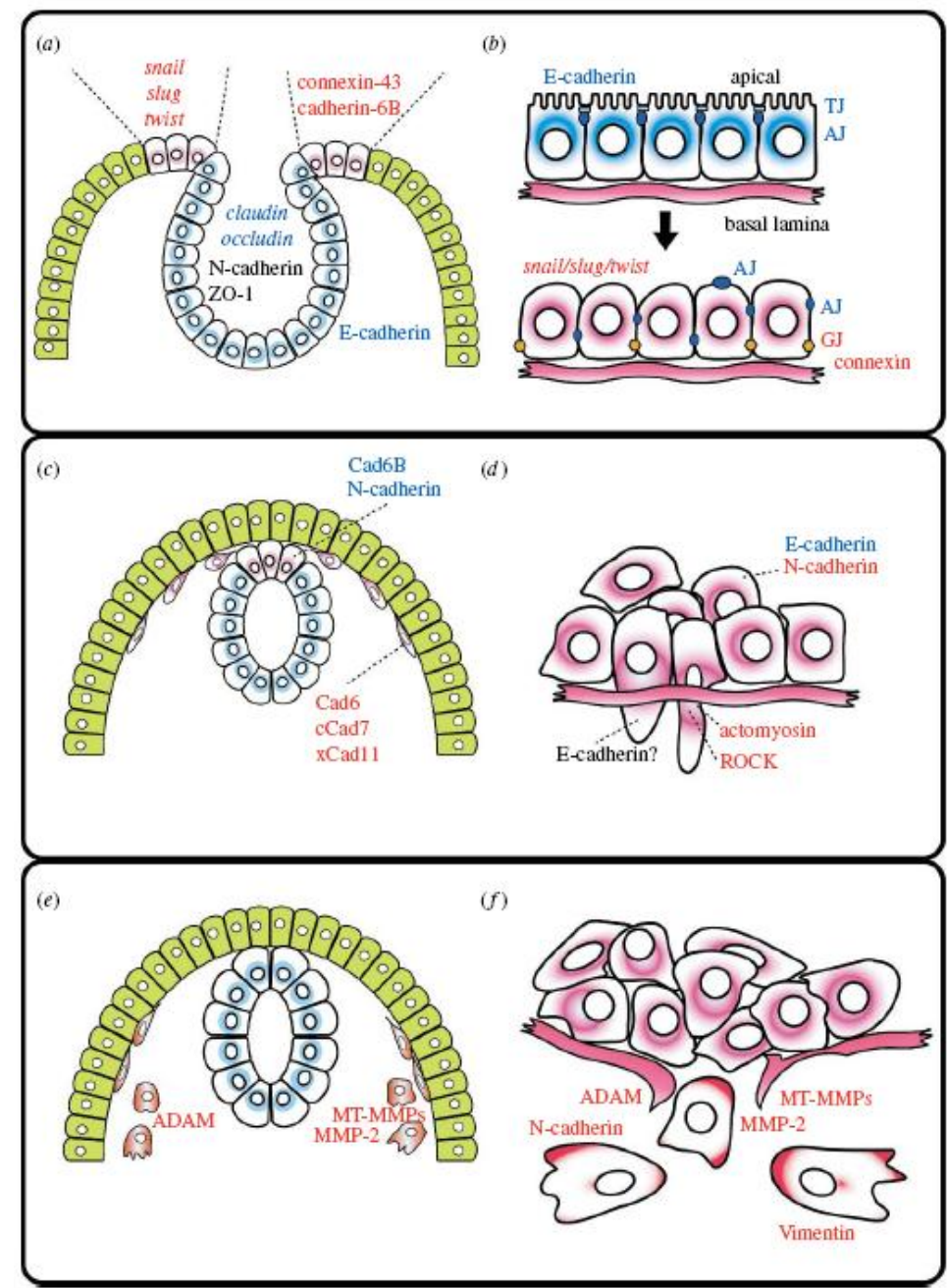

Figure 1.8. Comparison of EMT steps in neural crest cell migration and cancer metastasis. $(\mathbf{a}, \mathbf{b})$ The cells lose apical basal polarity. (c,d) The composition of cell adherence molecules changes from epithelial to mescenchymal. (e,f) The migrating neural crest cells and tumor cells gain functions to cleave extracellular matrix structures. Taken from Kuriyama and Mayor 
Philosophical Transactions of the Royal Society B (2008) 363, 1349-1362 (Kuriyama and Mayor, 2008).

Neural crest cells induced at the region of the neural plate have to find their specific way through the embryo. To reach their final destination they need various signaling molecules for guidance (Figure 1.9.). Surprisingly, so far mainly repellent cues have been identified (Figure 1.9.(3)). The repellent cues include different ligand receptor pairs: firstly, Ephrins and Eph receptors, which belong to the family of receptor tyrosine kinases that are activated by the binding of their specific ligand. On the cellular level they regulate motility (Davy et al., 2004; Kuriyama and Mayor, 2008). Secondly, there is the group of neuropilins and plexins with class3 semaphorins as their ligands. These ligand-receptor pairs are also known from their role in axon guidance (Kolodkin, 1998). Actin filaments of the cytoskeleton can be altered upon semaphoring signaling (Yu et al., 1998). It has been shown that semaphorins are required for the correct migration pattern of neural crest cells (Brown et al., 2001; Eickholt et al., 1999; Gitler et al., 2004; Lepore et al., 2006; Sato et al., 2006). There is also a third family of repulsive regulation involved in neural crest migration, which are the Robo receptor and its ligand Slit. Like the semaphorins they are well known from Drosophila axonal guidance (Dickson and Gilestro, 2006). The role of the Slit /Robo duo in neural crest migration is to keep the migrating trunk neural crest cells on a specific track (Jia et al., 2005). As mentioned earlier mainly repellent factors are known, which restrict the migration of neural crest cells into limited areas. But quite recently the work from Theveneau et al. 2010 described the stroma-cell derived factor 1 (Sdf1) as a potent attracting factor, which binds to the cxcr4 receptor, and thereby stimulates the migration of neural crest cells. They showed a strong chemoattractant effect in vivo and their in vitro data also showed that expression of Sdf1 is crucial for proper neural crest migration (Theveneau et al., 2010; Theveneau and Mayor, 2011) (Figure 1.9.(2)). This tells us that cell migration during development needs to be highly regulated by attractants and repellents to end up in a normally developed animal. 


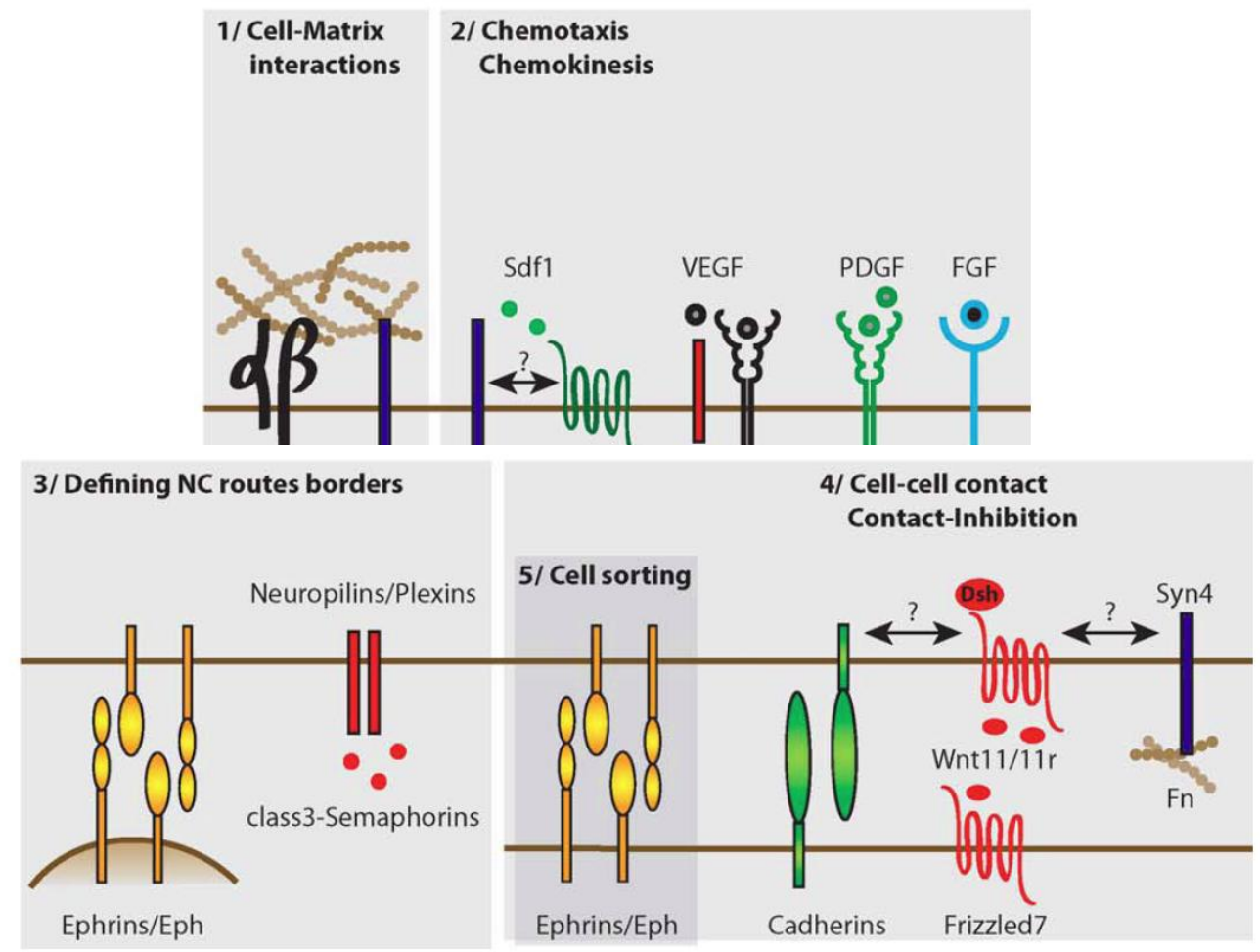

Figure 1.9. Figure summarizes molecules involved in regulation of neural crest migration. (1) For cell matrix interaction, (2) for chemokinesis, (3) to define the routes of migration and (4/5) cell contact and contact inhibition. Taken from Theveneau and Mayor Genesis 49; 164-176 (2011)(Theveneau and Mayor, 2011).

\subsection{Cancer cell migration}

"Although cell migration is crucial for normal development and morphogenesis of animal body plans and organ systems, abnormal cell migration during adult life underlies pathological states such as invasion and metastasis of cancer" (Aman and Piotrowski, 2010).

We saw already that the ability to migrate is restricted to a distinct population of cells in the adult organism. If cells gain this ability by mistake the pathological situation of cancer metastasis occurs. During the process of metastasis the cancer cells spread from the primary tumor and give rise to additional tumors in distant organs. This ability of cancer cells is the most frequent cause of death for cancer patients (Yamaguchi et al., 2005). 
During cancer metastasis the cells of the primary tumor, which originally were of epithelial character, gain the ability to leave the former tight connections of the tissue organization. Furthermore, they acquire a migratory phenotype and gain proteolytic activity to cross the barrier of the basement membrane to intravasate into blood or lymph vessels (Chambers et al., 2002; Friedl and Wolf, 2003; Yamaguchi et al., 2005). This transformation to a migratory state resembles very much what is seen in neural crest cell migration, where the cells need to undergo EMT before starting to migrate (Kuriyama and Mayor, 2008) (Figure 1.8.). Cancers, which metastasize seem to reactivate embryonic skills of cell motility (Friedl and Gilmour, 2009). For cancer cell migration, the same features of cell motility apply as described before: active extension of protrusions in form of lamellipodia or fillopodia and their retraction, which results in net movement. But there are also additional types of movements described for cancer cell migration, for instance amoeboid movement (Friedl and Wolf, 2003). Contradictory observations have been published concerning solitary migrating tumor cells (Wang et al., 2002) versus collective cell migration (Friedl and Gilmour, 2009). However, evidence from colorectal cancer, melanoma or breast cancer gained through in vitro explants show a predominantly collective cell invasion (Friedl et al., 1995; Hegerfeldt et al., 2002; Nabeshima et al., 2000). A similar behavior has been observed for breast cancer or colorectal cancer cell lines in 2D wound assays or 3D invasion cultures (Friedl and Gilmour, 2009). The hallmarks of collective cell migration are that the cells stay physically and functionally connected with intact cell-cell contacts during the process of movement (CarmonaFontaine et al., 2008; Friedl et al., 2004; Montell, 2008). The migration force is generated by multicellular polarity and a "supracellular" organization of the cytoskeleton and finally the surrounding tissue.The ECM are structurally modified along the route of migration from a moving group of cells (Friedl and Gilmour, 2009). The polarization of migrating cells in a group resembles the situation in neural crest cell migration. A clear hierarchy exists that defines leaders and followers in a so-called front rear asymmetry. Leaders and followers can be distinguished by morphology and gene expression differences. The front cells show more mesenchymal qualities, extending lamellipdia and filopodia whereas the rear cells are more epithelial-like tightly packed and rarely show protrusions (Diz-Munoz et al., 2010; Friedl and Gilmour, 2009).

Cancer cells also react on chemoattractants to gain directionality for movement. It has been shown for breast cancer cells that signals of epidermal growth factors (EGF), which diffuse from blood vessels, attract cancer cells, which express EGF receptors, to migrate in the direction of blood vessels (Wang et al., 2004; Wang et al., 2002). Additionally, a paracrine interaction with stromal cells comes into play. Different studies showed that 
tumor cells and tumor associated macrophages generate a paracrine loop that potentiates invasion of cancer cells (Pollard, 2004; Wyckoff et al., 2004). To improve cell motility in cancer cells, gene upregulation also takes place. A study was performed to investigate the gene expression differences between migrating and stationary cancer cells with a focus on genes relevant for motility. The study showed that many regulators of the cytoskeleton and actin polymerization are upregulated in the metastatic group (Wang et al., 2005).

As seen in neural crest migration during development, the cells need the help of proteolytic enzymes, which are able to modify the extracellular environment by degrading the ECM barrier, for migration through neighboring tissues. The membrane anchored membrane type matrix metalloproteinase 1 (MT1MMP) has been shown to promote cell migration (Seiki, 2002; Seiki et al., 2003; Wolf et al., 2007). Nabeshima et al. 2000 showed a front-cell specific expression of MT1MMP during collective cell migration in colon carcinoma cells (Nabeshima et al., 2000). However, there is also evidence that not the cancer cell itself but the inflammatory cells that assemble at boundaries of tumors caused by chemoattractant secretion by the cancer cells produce the enzymes for degradation of ECM (Hanahan and Weinberg, 2011; Joyce and Pollard, 2009; Kessenbrock et al., 2010; Qian and Pollard, 2010). Furthermore, a specific type of protrusion is associated with proteolytic activities in cancer cell invasion. The so-called invadopodia, first described as actin-rich matrix-degrading protrusions in Rous sarcoma virus transformed fibroblasts (Chen, 1989), are fundamental for degradation of ECM during cell invasion, especially for pathing through the basement membrane (Buccione et al., 2009; Ridley, 2011; Schoumacher et al., 2011). In principle, the regulation of filopodia and lamellipodia is similar to the situation in invadopodia; the main difference is the capability of invadopodia to degrade ECM. To fulfill this requirement, vesicles, which contain the matrix degrading proteases, need to be delivered to the protrusion sites. This delivery is administered by the vesicle tethering exocyst complex (Poincloux et al., 2009) and the vesicle trafficking is driven by microtubles (Ridley, 2011; Schoumacher et al., 2010). One can summarize here that the processes of neural crest migration and cancer cell migration are highly similar, which could mean that in this aspect tumor cells reactivated embryonic features to become malignant. 


\subsection{Wnt signaling}

Wnt signaling is a complex signaling network that is required during development as well as for the proper function of adult organisms. During development Wnt signaling is crucial for cell fate determination, axis formation, cell polarity and migration (Raible and Ragland, 2005; Wodarz and Nusse, 1998). For the proper maintenance of cells and tissues in adult organisms, Wnt signaling is involved in adult stem cell self-renewal, proliferation and regeneration (Kuhnert et al., 2004; Pinto et al., 2003). This requires a strict homeostatic regulation as exceeding signaling levels result in cancer formation and progression whereas limited levels of Wnt signaling lead to degenerative conditions (Figure 1.10.) (Angers and Moon, 2009).

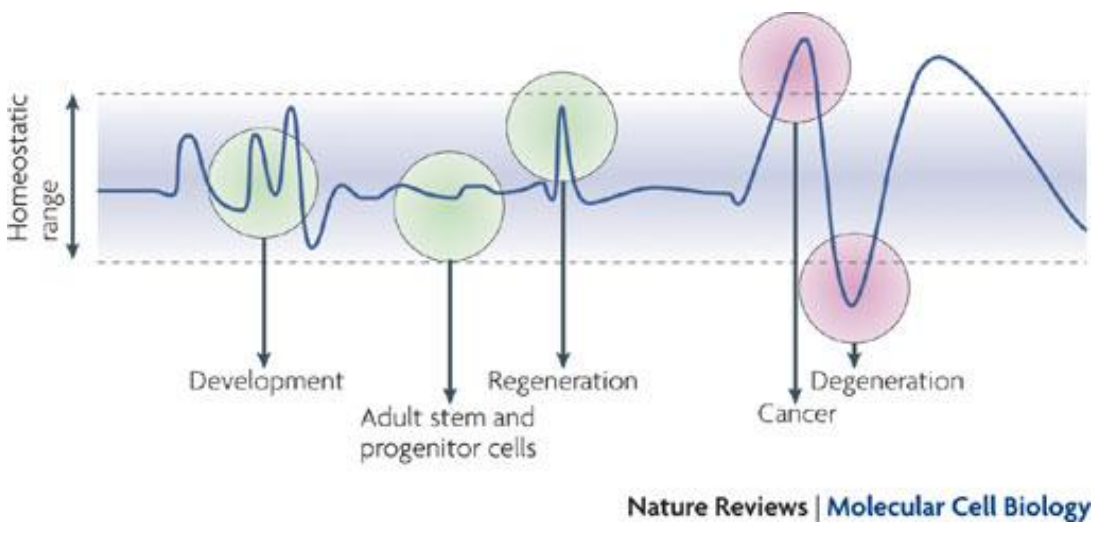

Figure 1.10. Tight regulation of Wnt signaling is essential. The scheme visualizes the narrow homeostatic range of Wnt signaling in development and adult progenitors. Taken from Angers and Moon Nature Reviews Molecular Cell Biology advance online publication Published online 17 June 2009doi:10.1038/nrm2717 (Angers and Moon, 2009).

\subsubsection{Wnt / $\beta$-catenin signaling}

Historically, the nomenclature Wnt was established after the mouse Int-1 gene originally identified as the integration site for the mouse mammary tumor virus in breast tumors (Nusse and Varmus, 1982) and the Drosophila wingless ( $w g$ ) were shown to be homologs of a secreted cysteine rich protein (Cabrera et al., 1987; Rijsewijk et al., 1987). 
This was the first evidence that a gene, known as a developmental regulator, functions to promote cancer.

The Drosophila wg controls segment polarity during the development of the embryo and larvae (Nusslein-Volhard and Wieschaus, 1980). wg mutant flies showed a severely impaired segmentation of the larval epidermis, which is normally covered with nakedcuticle and denticle in an alternating way. Mutations in the genes porcupine, dishevelled and armadillo showed the same phenotype and epistatic studies revealed that these genes were core members of a newly identified signaling pathway (Noordermeer et al., 1994; Peifer et al., 1994; Siegfried et al., 1992). Studies in vertebrates showed that mRNA of mouse Wnt1, injected into the ventral blastomers of 4-cell stage Xenopus embryos, could induce a duplicated body axis (McMahon and Moon, 1989). This finding was interesting in two aspects: Firstly, it documented that the signaling cascade was shared in vertebrates and invertebrates and, secondly, it provided a simple assay to test the function of other possible members of the signaling pathway for their potency to induce second axes (Clevers, 2006). The family of Wnt proteins includes 19 members of highly conserved, secreted glycoproteins (Angers and Moon, 2009; Logan and Nusse, 2004), which became classified according to their ability to induce double axes in Xenopus embryos like Wnt1, Wnt3a and Wnt8, whereas other members such as Wnt4, Wnt5a and Wnt11 could not (Du et al., 1995; Olson and Papkoff, 1994; Shimizu et al., 1997). The ability to induce axis duplication was also seen for Dishevelled, $\beta$-catenin, the vertebrate homolog of armadillo and a dominant negative mutant of Glycogen Synthase Kinase 3 (GSK3) (Clevers, 2006; Dominguez et al., 1995; Guger and Gumbiner, 1995; He et al., 1995) (Figure 1.11.).

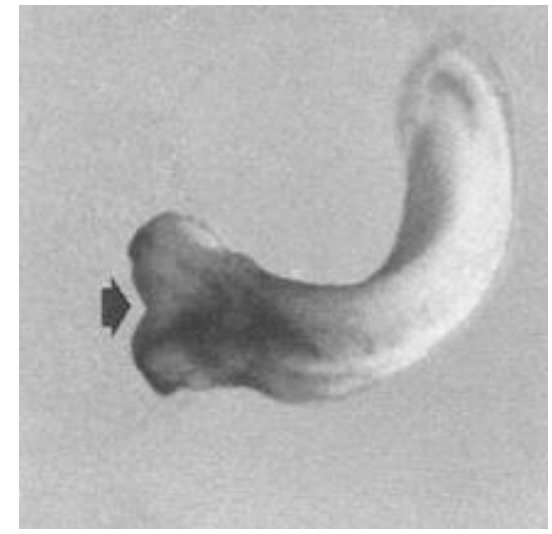

Figure 1.11. Wnt induces a second axis in Xenopus embryos. The figure shows a Xenopus embryo after ventral injection of Wnt1 mRNA. The arrow points to the bifurcation between the two head structures. Taken from McMahon and Moon Cell, Vol. 58, 1075-1084. September 22, 1989 (McMahon and Moon, 1989). 
From these and additional findings, a highly conserved pathway - the so-called $\beta$-catenin dependent or canonical Wnt signaling pathway - emerged (Figure 1.12.). This pathway is activated after Wnt ligand binding to a 7-transmembrane Frizzled receptor (Fz) (Bhanot et al., 1996) and its co-receptor LRP5/6 (Pinson et al., 2000; Tamai et al., 2000) (Arrow in Drosophila (Wehrli et al., 2000)). After Wnt binding Fz can bind to Dishevelled (Dsh) and Dsh gets phosphorylated. At the intracellular C-terminal part of the LRP receptor, Wnt binding leads to phosphorylation by GSK3 and Casein Kinase IY (CK1Y). Phosphorylated LRP can recruit Axin to the plasma membrane (Davidson et al., 2005; Zeng et al., 2005). In the absence of a Wnt ligand a cytoplasmic destruction complex is formed, consisting of Axin, CKI $\alpha$, GSK3, APC (adenomatous polyposis of the colon) and $\beta$-catenin (Price, 2006). This complex is responsible for the degradation of cytoplasmic $\beta$-catenin. $\beta$ catenin is phosphorylated, subsequently ubiquitinated and targeted for proteasomal degradation (Aberle et al., 1997). Following pathway activation by Wnt ligands, Axin can leave this destruction complex to bind to phosphorylated LRP at the plasma membrane. As a result, $\beta$-catenin cannot be phosphorylated and translocates to the nucleus where it activates gene transcription by binding to the N-terminus of LEF/TCF (lymphoid enhancer factor / T cell factor) (Behrens et al., 1996; Molenaar et al., 1996; van de Wetering et al., 1997). TCF becomes converted from a transcriptional repressor into a transactivator upon $\beta$-catenin binding (Cavallo et al., 1998; Roose et al., 1998). Transcriptional activation downstream of $\beta$-catenin, similar to the axis induction, can be used as readout to study $\beta$-catenin dependent Wnt signaling. Korinek et al. designed a reporter plasmid that expresses three copies of the conserved TCF DNA binding motif upstream of a minimal promoter to drive luciferase activity and thereby measures Wnt pathway activation (Korinek et al., 1997). 


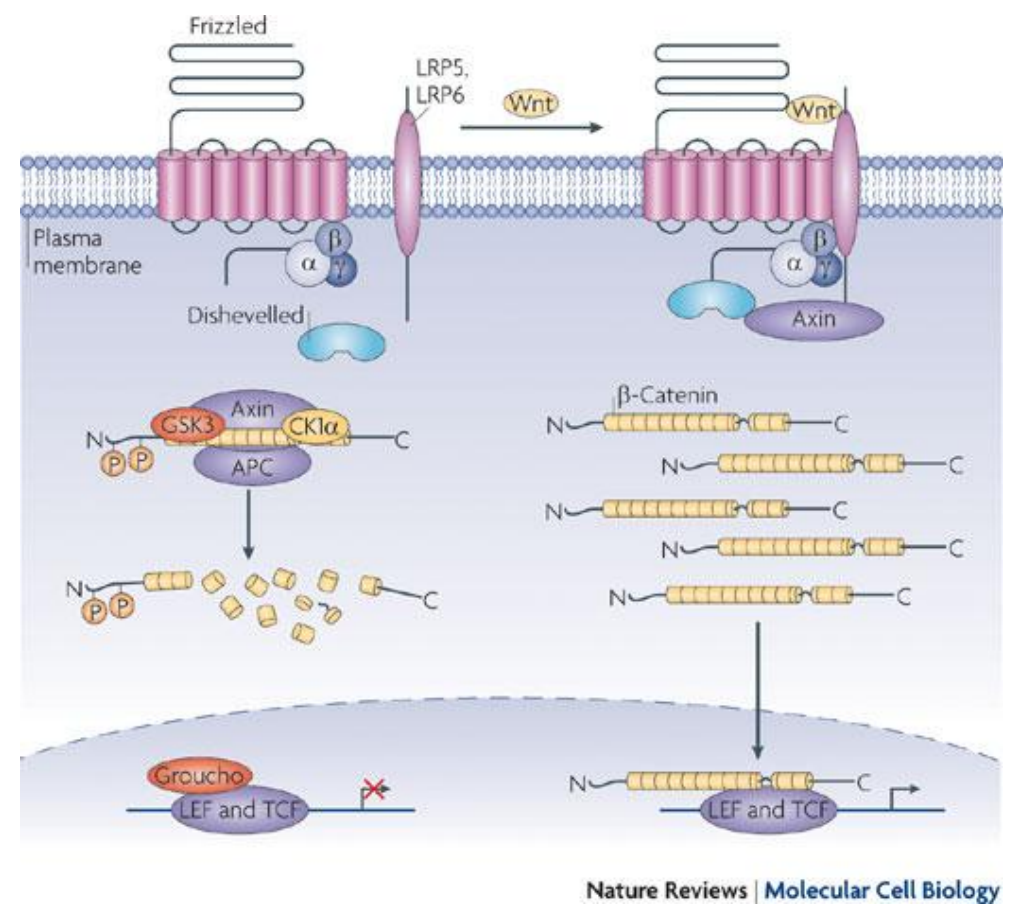

Figure 1.12. $\beta$-catenin dependent Wnt signaling. Left panel: in the absence of Wnt signals at the Frizzled and LRP5/6 receptors Dishevelled is cytoplasmically localized and the destruction complex composed of Axin and APC is active to degrade phosphorylated $\beta$-catenin. Transcription is inactive. Right panel: Upon Wnt ligand binding to the Frizzled LRP5/6 receptors, Disheveled gets recruited to the plasma membrane and phosphorylated LRP recruits Axin. Thereby the destruction complex is non-functional, $\beta$-catenin can accumulate in the cell and translocates to the nucleus where transcriptional activation of target genes is initiated. Taken from Angers and Moon Nature Reviews Molecular Cell Biology advance online publication published online 17 June 2009doi:10.1038/nrm2717 (Angers and Moon, 2009).

\subsubsection{Wnt/PCP signaling}

In addition to the so-called canonical Wnt signaling, there are other Wnt signaling pathways, which act independently of $\beta$-catenin. One is the so-called planar cell polarity pathway (PCP). PCP was initially studied in Drosophila, where it was shown to be responsible for establishing the polarity of cells in the plane of an epithelium perpendicular to the typical apico-basal polarization of epithelial cells (Bayly and Axelrod, 2011; Klein and Mlodzik, 2005; Seifert and Mlodzik, 2007) (Figure 1.13.A). Planar cell polarity is required for collective cell movement and tissue organization. Members of the PCP pathway have been identified based on typical phenotypes in Drosophila. Gubb and Garcia-Bellido described mutations of PCP genes that were causing default organization 
of cuticular structures and the compound eye (Gubb and Garcia-Bellido, 1982). PCP mutants such as frizzled ( $f z)$, disheveled (dsh) and prickle (pk) showed a disorganized patterning of the wing hairs and omatidia in the fly (Figure 1.13.B) (Klein and Mlodzik, 2004; Wong and Adler, 1993). Fz and Dsh are the key players in the PCP pathway. Surprisingly, in Drosophila Wnt proteins do not participate in PCP. Contrary to what is seen in Drosophila, an involvement of Wnt is seen in higher vertebrates. Mouse Wnt5 knockout and zebrafish Wnt11 mutations show defects in convergence extension movements (Heisenberg et al., 2000; Qian et al., 2007). Furthermore, inhibition of Wnt signaling can disrupt PCP signaling and affect the orientation of the sensory bristles in the cochlea inner ear cells (Dabdoub et al., 2003; Dabdoub and Kelley, 2005; Qian et al., 2007). These findings provide evidence for a common pathway where members of the conserved Frizzeld/PCP pathway interact with a variant Wnt signaling pathway to establish PCP in vertebrates (Figure 1.13.C) (van Amerongen and Berns, 2008; Wallingford et al., 2002; Wallingford and Harland, 2002; Wang and Nathans, 2007). Activation of the PCP pathway by the binding of a Wnt ligand to the Fz transmembrane receptor results in Dsh recruitment to the plasma membrane (Boutros et al., 1998; Strutt et al., 1997). Dsh is involved in both $\beta$-catenin-dependent and PCP pathways, but the outcome is dependent on the downstream regulators. The Dsh protein consists of three conserved major domains, which are the DIX, the PDZ and the DEP domain (Figure 1.13.D). The DIX domain forms homo-dimers or binds to canonical molecules like Axin (Itoh et al., 2000; Julius et al., 2000; Kishida et al., 1999; Rothbacher et al., 2000; Smalley et al., 1999). The PDZ domain can interact with both canonical (Li et al., 1999a; Li et al., 1999b; Peters et al., 1999; Sakanaka et al., 1999; Willert et al., 1997; Yost et al., 1996) and PCP members (Bastock et al., 2003; Jenny et al., 2005; Jessen et al., 2002; Park and Moon, 2002; Wallingford and Habas, 2005). The DEP domain is regulating PCP by mediating PCP signaling downstream of Dsh. It associates and activates the small GTPase Rac, which activates the N-terminal jun kinase (JNK) (Boutros et al., 1998; Habas et al., 2003; Li et al., 1999b). In a second parallel branch of PCP signaling, DAAM1 (Disheveled Associated Activator of Morphogenesis) activates RhoA, which in turn activates the Rho associated kinase (ROCK). This then affects reorganization of the cytoskeleton and actin polymerization (Habas et al., 2001). 
A
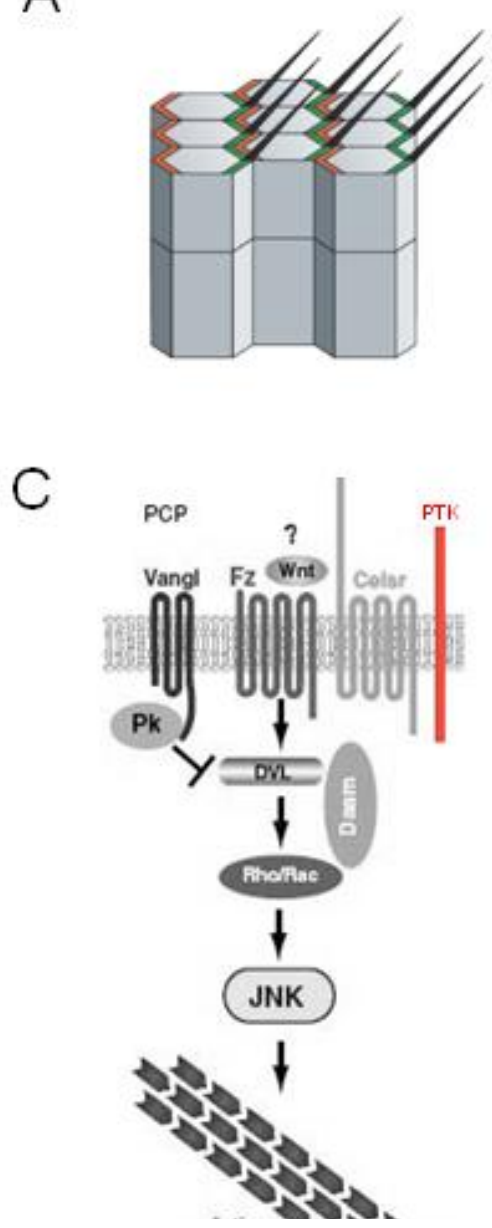

$B$ wildtype PCP mutant

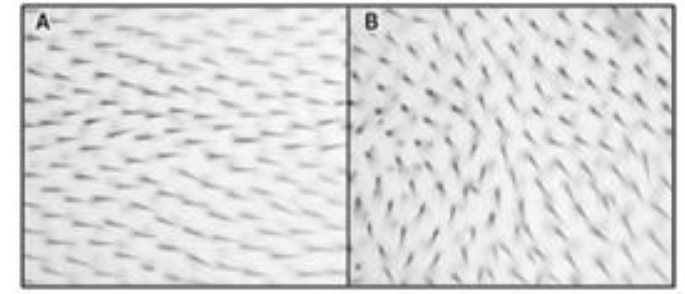

$D$

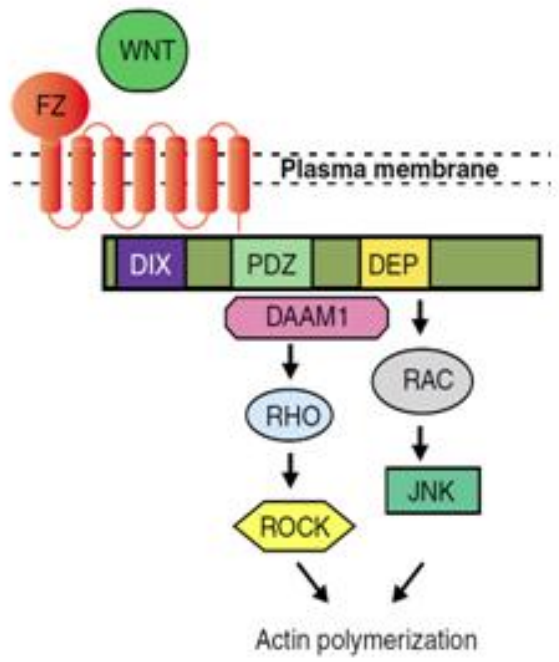

Figure 1.13. PCP signaling. (A) $3 D$ model of Drosophila wing explains that PCP proteins are localized asymmetrically either proximal in red or distal in green. The localization of the proteins produces polarity in the plane of the epithelium. Modified from Bayly and Axelrod Nature Reviews Genetics 201112 385-391 (Bayly and Axelrod, 2011). (B) Example of PCP mutant. In the left panel wildtype Drosophila wing hairs are depicted. All hairs point distally. The right panel shows a wing of a frizzled mutant where the organization of the wing hairs is disturbed. Modified from Zallen, Cell 129, June 15, 2007 (Zallen, 2007). (C)The Wnt PCP pathway. Depicted are the transmembrane molecules Van Gogh like (vangl), Frizzled (Fz) Celsr and PTK7. The pathway is activated upon Wnt Fz binding. Subsequently, Dsh is trans-localized to the membrane. Dsh downstream signaling activates the small GTPases Rho and Rac, whereby actin cytoskeleton rearrangement takes place. Modified from Montcouquiol et al. Annual Reviews of Neuroscience 2006, 29:363-386 (Montcouquiol et al., 2006). (D) Dishevelled in non-canonical Wnt signaling. The schema illustrates the domain structure of Dishevelled and the associated downstream proteins. In PCP signaling, the PDZ/DEP domains mainly participate and activate the actin polymerization by activation of Rho or Rac. Modified from Wallingford and Habas Development 132, 4421-4436 2005 (Wallingford and Habas, 2005). 
In vertebrates, PCP signaling was shown to be required for different kinds of cell movements such as convergent extension (CE) in the mesoderm, neural tube formation and orientation of the cochlear stereocilia bundles (Goodrich, 2008; Jones and Chen, 2007; Karner et al., 2006; Tada and Kai, 2009). An important aspect of PCP regulated cell movement happens during gastrulation, which is the so-called convergent extension movement. During this process the paraxial and axial mesoderm converges medially and extends longitudinally to elongate the anterior-posterior axis (Keller et al., 2000). Due to this action, the tissue of the embryo narrows and extends without any cell divisions to form the future anterior-posterior body axis (Keller, 2002) (Figure 1.14.). While convergent extension movements happen in Xenopus embryos the mesenchymal cells intercalate and thereby form a narrower elongated structure. To reach this condition the cells become polarized, elongate themselves, and the resulting forces pull them between each other (Keller et al., 2003). In the regulation of convergent extension movements the Wnt/PCP pathway is relevant for activating downstream Rho family GTPases, which have cytoskeleton rearranging effects on cells (Tahinci and Symes, 2003).
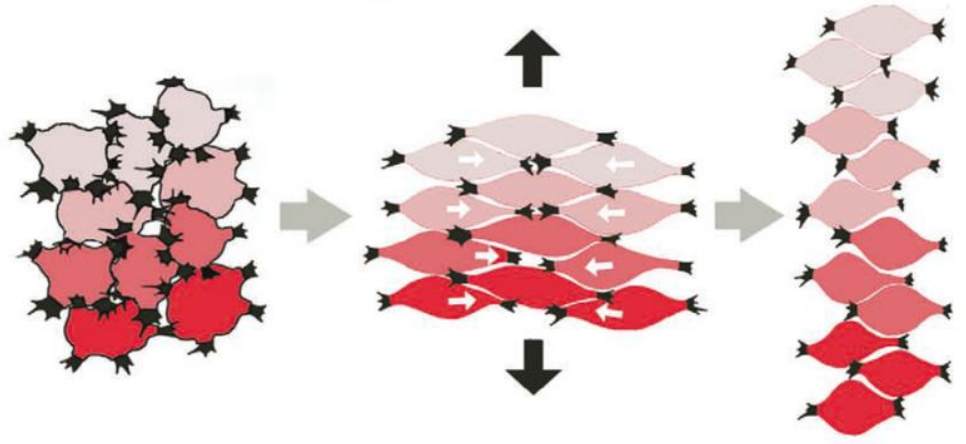

Figure 1.14. Schematic representation of convergent extension. The body axis of an embryo elongates during gastrulation through convergent extension movements. The cells undergo a mediolateral intercalation and thereby elongate the structure. Taken from Ray Keller Current Opinion in Cell Biology 2005, 17:533-541 (Keller, 2005).

A further prominent example of a PCP regulated migration process is neural crest cell migration. PCP signaling, regulating polarity in epithelia and non-epithelial cell sheets, is important for migrating neural crest cells. It has been shown that repression of PCP 
molecules like Wnt11, Fz7 or Dsh leads to a disruption of neural crest migration (De Calisto et al., 2005; Kuriyama and Mayor, 2008). Studies on the function of PCP in neural crest migration revealed that PCP regulates a process called contact inhibition of locomotion. The PCP molecules Fz7 and Dsh are localized to the cell contacts between neural crest cells and activate RhoA in a localized fashion at the lateral and backward cell contacts (Carmona-Fontaine et al., 2008; Matthews et al., 2008; Theveneau and Mayor, 2011). Rac1, which is activated at the leading edge and results in protrusion formation, is antagonized by RhoA at the contact sites, in the case of collisions between neural crest cells. The formation of protrusions at lateral positions of the cell is thereby prevented. This leads to a discontinuation of the previous direction and further migration in different directions (Carmona-Fontaine et al., 2008). PCP signaling regulates directional neural crest cell migration by this mechanism (Figure 1.15.).
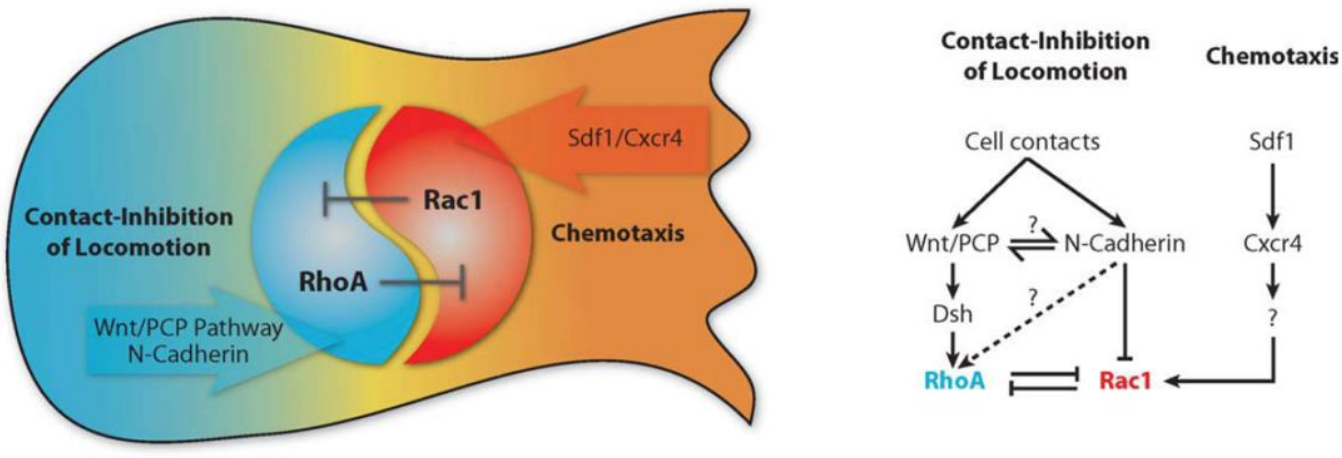

Figure 1.15. PCP regulates contact inhibition of locomotion. Illustration of the antagonistic representation of chemotaxis at the leading edge and Rac1 activity versus contact inhibition of locomotion and RhoA activation at the trailing edge and the signaling cascade involved. Cell contacts activate the Wnt PCP pathway at the rear, whereas chemokines activate Rac1 at the leading edge. Taken from Theveneau and Mayor Genesis 49; 164-176 (2011) (Theveneau and Mayor, 2011). 


\subsection{Protein Tyrosine Kinase 7 signaling}

\subsubsection{PTK7 is a regulator of PCP signaling}

In addition to the key players in PCP signaling such as Fz and Dsh, other transmembrane and cytoplasmic proteins are involved in modulating the signaling (Figure 1.13.C). Protein tyrosine kinase 7 (PTK7) is one important member of PCP regulators, which is required for cell polarity and movement in development and cancer. PTK7 loss of function mutation in mice resulted in a combined phenotype of severe neural tube closure defect and disorientation of the stereociliary bundles at the cochlea in mouse embryos. In Xenopus embryos the knockdown of PTK7 also resulted in a PCP phenotype. The embryos showed the typical picture of defective convergent extension movements like shortened body axes and incomplete closure of the neural tube (Lu et al., 2004; Paudyal et al., 2010; Yen et al., 2009). A mouse phenotype very similar to PTK7 null mutants (Lu et al.2004), which was seen due to conditional double knockout of the caudal type homeobox transcription factors $(\mathrm{Cdx}) \quad c d x 1$ and $c d x 2$, revealed them to be the transcriptional regulators of PTK7 during mouse development (Savory et al., 2011). That PTK7 recruits Dsh to the plasma membrane by an interaction with the Dsh PDZ domain was shown in a study, designed to elucidate the downstream events of PTK7 activated PCP signaling (Figure 1.16.C). PTK7 is expressed in Xenopus neural crest cells and crucial for neural crest migration as knockdown of PTK7 resulted in an impaired migration pattern. (Shnitsar and Borchers, 2008) (Figure 1.16.). Additional analysis showed that PTK7 acts together with the adaptor protein RACK1 (receptor of activated protein kinase C) for proper function of neural tube closure. RACK1 is also required for PTK7-mediated Dsh membrane recruitment (Wehner et al., 2010). A recent study identified PTK7 as an interaction partner for Wnt proteins in Drosophila and Xenopus and demonstrated that PTK7 inhibits canonical Wnt signaling (Peradziryi et al., 2011). Taken together, PTK7 plays an important role during development to regulate polarity and cell migration by activating PCP signaling and inhibiting $\beta$-catenin signaling. 


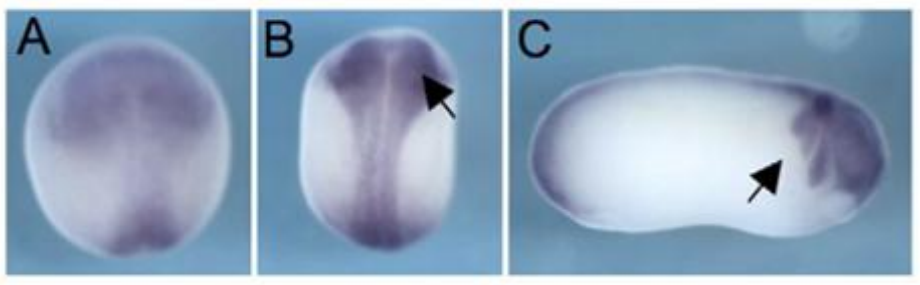

D

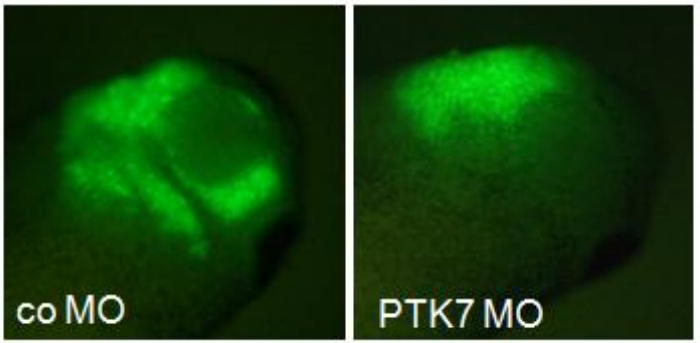

$\mathrm{E}$

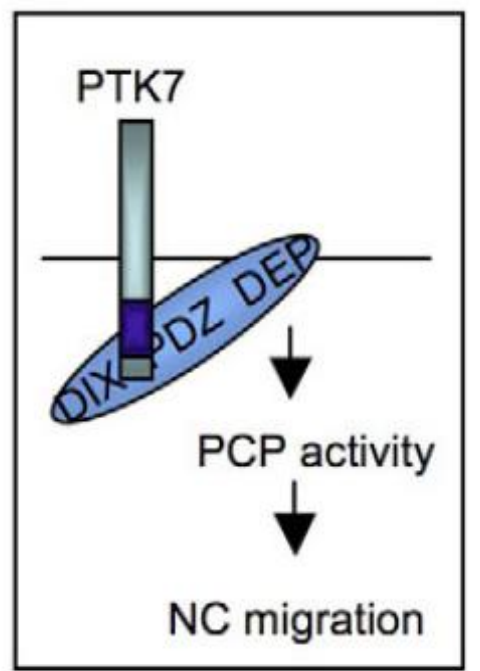

Figure 1.16. PTK7 is required for neural crest cell migration. (A-C) PTK7 is expressed at the area of the migrating neural crest. Whole mount in situ hybridization using PTK7 antisense RNA as a probe. $(\mathbf{A}, \mathbf{B})$ At early neurula stages PTK7 is expressed in pre-migratory neural crest cells. (C) At stage 26 PTK7 is expressed in the migratory cranial neural crest cells. (D) PTK7 knockdown inhibits neural crest cell migration. Xenopus embryos were either injected with control morpholino or PTK7 morpholino together with GFP mRNA. The neural crest cells of the injected embryos were transplanted into receiving embryos and the GFP expressing neural crest cells were visualized. The left panel shows the normal migration pattern of control morpholino injected embryos; the right panel shows the migratory impaired neural crest cells after PTK7 morpholino injection. (E) The model illustrates that PTK7 needs to bind Dsh for activation of PCP and this is crucial for normal neural crest migration. Taken from Shnitsar and Borchers, Development 2008135 40154024 (Shnitsar and Borchers, 2008).

Structurally, PTK7 is a transmembrane molecule; it consists of seven extracellular immunoglobuline-like domains, a single transmembrane region and, intracellularly, a kinase homology domain (Figure 1.17.). Although PTK7 is a member of the receptor tyrosine kinase family, PTK7 is catalytically inactive because of a mutation in the active 
DFG triplet to coordinate ATP binding during phosphorylation. In the species tested so far no kinase activity was detected, in Hydra (Miller and Steele, 2000), chicken (Chou and Hayman, 1991), mouse (Jung et al., 2004) and human (Mossie et al., 1995). Only for the Drosphila homolog Dtrk/otk was kinase activity seen but this could be very likely due to contamination with other catalytically active molecules (Pulido et al., 1992). Functional relevance of the Drosophila protein Dtrk/otk was described for cell adhesion (Pulido et al., 1992) and axonal guidance regulation (Winberg et al., 2001).

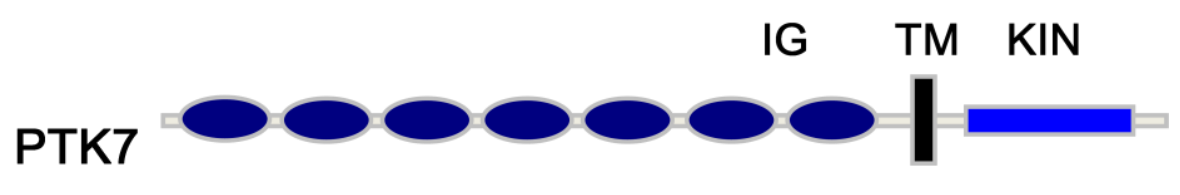

Figure 1.17. Structure of PTK7. Schematic view of the PTK7 structure immunoglobuline-like domains (IG) in dark blue, transmembrane domain (TM) and kinase like-homology domain (KIN).

\subsubsection{PTK7 in cancer}

The human homolog of PTK7 was cloned from colon carcinoma cells and therefore first named Colon carcinoma kinase-4 (CCK-4) (Mossie et al., 1995). Elevated RNA levels of PTK7 were detected in samples of colon carcinoma cell lines but not in colon tissues of healthy adults (Mossie et al., 1995). Upregulation of PTK7 was also seen during a global gene expression analysis in metastatic colon cancer compared to non-metastasized colon cancer (Saha et al., 2001). In gastric cancer the PTK7 locus on human chromosome 6 (6p21.1) was found to be amplified in array comparative genomic hybridization (CGH) analysis (Banga et al., 1997; Gorringe et al., 2005). In acute myeloid leukemia (AML) elevated PTK7 expression levels were found (Muller-Tidow et al., 2004; Prebet et al., 2010). Prebet et al. detected PTK7 expression in $72 \%$ of AML. Even though the AML patients with PTK7 expression showed lower white blood cell counts and lower frequency of extra medullar disease at time of diagnosis, the overall survival and the leukemia free survival were significantly reduced in PTK7+ AML's (Prebet et al., 2010). Furthermore, down regulation of PTK7 has also been reported in different human malignancies (Easty et al., 1997; Endoh et al., 2004). 


\subsubsection{PTK7 increases cell migration and inhibits apoptosis}

AML in vitro data showed that PTK7 ectopic or endogenous expression significantly increased the spontaneous, un-stimulated cell migration while the migratory response to stem cell factor (SCF) stimulation could be inhibited by PTK7 shRNA knockdown (Prebet et al., 2010). Similar results were seen before for endothelia cell migration in angiogenesis (Shin et al., 2008). Interestingly, in both models - AML and endothelial cells- the secreted extracellular fragment of PTK7 is able to inhibit induced cell migration (Prebet et al., 2010; Shin et al., 2008). In the endothelia study the authors describe an inhibition of VEGF induced tube formation, wound healing, migration and invasion of HUVECs and suggest a specific counteraction of the endogenous PTK7 by the secreted PTK7 (Shin et al., 2008). In addition to the finding of induced migration in PTK7 expressing AML cells the authors also document increased survival rates under serum starved conditions in case of PTK7 expression. They further show that PTK7 expression increases the survival rates after doxorubicin chemotherapeutic treatment, which could be reversed by either PTK7 shRNA knockdown or incubation with the secreted PTK7 prior to doxorubicin application. The resistance to chemotherapy in AML cells is due to less caspase 3 and 7 driven apoptosis in presence of PTK7 (Prebet et al., 2010). The inhibitory influence of PTK7 on apoptosis seen in AML goes along with data observed in the colon cancer cell line HCT116. Meng at al. showed reduced cell viability and BrdU incorporation as well as an increase of apoptosis in HCT116 cells after siRNA knockdown of PTK7 (Meng et al., 2010). Since so far no one has shown an increased proliferation rate upon overexpression of PTK7 (Prebet et al., 2010; Shin et al., 2008) the advantage of tumor cells expressing PTK7 might be due to resistance to apoptosis.

\subsubsection{PTK7 is a target for proteolytic cleavage by MT1MMP}

Recent data functionally connect the PCP molecule Van-Gogh like 2 (vangl2) with MT1MMP/MMP14 activity during zebrafish gastrulation (Coyle et al., 2008) and further demonstrates that vangl2 knockdown in cells results in higher levels of MMP14 protein and increased cell migration (Cantrell and Jessen, 2010). Golubkov et al. 2010 identified a MT1MMP/MMP14 cleavage site in the extracellular domain of PTK7 between the sixth and seventh immunoglobuline domain (Figure 1.18.). MT1MMP activity in cells expressing PTK7 resulted in $70 \mathrm{kDa}$ extracellular and $50 \mathrm{kDa}$ intracellular fragments. By introducing an amino acid mutation at this specific site they could prevent the cleavage and show that PTK7 is indeed a target for MT1MMP. They further linked their findings for 
the functional interaction of MT1MMP and PTK7 to the development of zebrafish embryos. PTK7 knockdown and inhibition of MT1MMP activity result in the same phenotype showing major PCP defects during convergent extension movements such as shorter body axes and wider lateral axes. From the results of transwell invasion essays they conclude that MT1MMP activity is required to increase cell invasion which can also be triggered by the soluble non-membrane-bound fragment of PTK7 alone (Golubkov et al., 2010). Recently the N-ethyl-N-nitrosourea (ENU)-induced mouse mutant chuzhoi (chz) was identified to be a mutant form of PTK7 with a three amino acid insert in the extracellular protein domain. This mutant induced a severe PCP phenotype in mouse embryos (Paudyal et al., 2010). In silico analysis hypothesized that this mutation generates an additional MT1MMP cleavage site between the fifth and sixth immunoglobuline domain, which could be experimentally verified (Figure 1.18.). In MT1MMP expressing cells the surface expression of chz was strongly reduced while increased levels of shed chz protein were detected in culture supernatants. Thereby they demonstrated that levels of surface chz expression inversely correlate with the expression of MT1MMP. The invasion increasing influence of the soluble extracellular PTK7 domain of $c h z$ was significantly stronger than that of wildtype PTK7 (Golubkov et al., 2011). From these findings it can be concluded that for the proper function of PTK7 in early embryogenesis and cell migration a tightly balanced ratio of membrane bound and soluble fractions is required. 


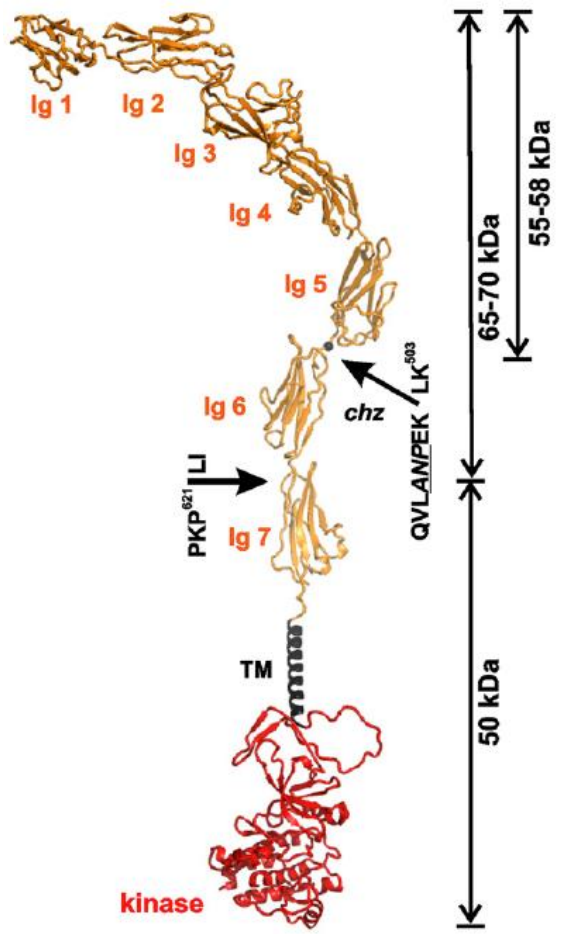

Figure 1.18. Structure model of PTK7 shows the MT1MMP cleavage sites. The IG domains 17 are depicted in orange, the transmembrane domain in black and the intracellular kinase homology domain in red. The wildtype MMP cleavage site is indicated to the left between IG 6 and IG 7 (PKP $621 \mathrm{LI}$ ). The additional cleavage site in chuzoi mutant is indicated to the right (QVLANPEK LK 503); the inserted amino acids are underlined. The fragment sizes of the resulting cleavage products are given. Taken from Golubkov et al. The Journal of Biological chemistry Vol 286, NO 23 20970-20976 June 10, 2011 (Golubkov et al., 2011). 


\subsection{Ror2 signaling}

\subsubsection{Ror2 is a Wnt co-receptor}

For non-canonical Wnt signaling pathways different Wnt co-receptors are known. One of them is the Receptor tyrosine kinase-like orphan receptor 2 (Ror2). Ror2 belongs to the Receptor tyrosine kinase family (RTK), which is a large superfamily. The members of the RTK superfamily are transmembrane glycoproteins, which function as cell surface receptors mainly in processes like proliferation, differentiation and migration (Schlessinger, 2000). The Ror proteins are highly conserved in invertebrates and vertebrates including Caenorhabditis elegans, Aplysia, Drosophila melanogaster, Xenopus, mice and humans. Structural characteristics of Ror proteins are their extracellular Frizzled-like cysteine-rich domains (CRDs) and kringle domains (KD) (Figure 1.19.). The extracellular region of Ror family RTKs contain an immunoglobuline-like domain (IG) and the already mentioned $\mathrm{CRD}$ and KD regions; it has a single-pass transmembrane domain and the cytoplasmic region of Ror contains a conserved tyrosine kinase domain, as well as proline rich (PRD) and serine/threonine rich (S/TRD) domains (Robinson et al., 2000). These specific domains also implicate specific functions. The IG domain may be involved in protein-protein or protein-ligand interactions. The CRD domain with its 10 conserved cysteine residues exhibits similarities to the Wnt receptor frizzled and has been shown to be required for Ror-Wnt protein interactions (Billiard et al., 2005; Forrester et al., 2004; Green et al., 2007; Green et al., 2008; Hikasa et al., 2002; Kani et al., 2004; Mikels and Nusse, 2006; Oishi et al., 2003). The characteristic kringle domain with its three loops of three disulfide bridges might be involved in peptide or protein binding. For the conserved tyrosine kinase domain autophosphorylation activity as well as tyrosine phosphorylation of the 14-3-3 $\beta$ scaffold protein have been reported (Akbarzadeh et al., 2008; Billiard et al., 2005; Kani et al., 2004; Liu et al., 2007; Liu et al., 2008). The c-terminal S/TRD and PRD domains most likely provide interaction sites for signaling mediators. For example, the Ror2-filaminA interaction to mediate Wnt-induced cell migration has been demonstrated to be PRD dependent (Nishita et al., 2006). Moreover, there are sites for potential phosphorylation as well as consensus motifs for protein interactions like $\mathrm{SH} 3$ and $\mathrm{SH} 2$ recognition motifs present in the cytoplasmic region of Ror2, which could contribute to the Ror2 mediated signal transduction (Minami et al., 2010). 


\subsubsection{Ror2 regulates convergent extension during development}

The function of the Receptor tyrosine kinase Ror2 has been extensively studied in developmental processes during C.elegans, Drosophila, Xenopus and mouse embryology. Studies in Xenopus identified Ror2 as a gene transcriptionally regulated by the organizer specific LIM homeobox gene Xlim-1. Gain of function through ectopic expression of Xror2 resulted in malfunctioned CE movements during gastrulation and insufficient neural tube closure but failed to induce second axes while Lim-1 can do this (Hikasa et al., 2002; Taira et al., 1994). Hikasa et al. also showed an interaction of the Xror2 extracellular domain with Xwnt5a, Xwnt8 and Xwnt11 (Hikasa et al., 2002). Furthermore, mammalian Wnt5a was reported to bind Ror2 through the CRD domain and the simultaneous overexpression of Wnt5a and Ror2 showed their functional interaction to regulate convergent extension (Oishi et al., 2003). In Xenopus it was shown that Wnt5a and Ror2 regulate the transcription of paraxial protocadherin (XPAPC) required for the regulation of CE movements (Schambony and Wedlich, 2007). Taken together, these findings describe a distinct signaling mechanism downstream of Ror2 as receptor for Wnt in the regulation of cell movements during gastrulation.

\subsubsection{Wnt5a Ror2 signaling in cell migration}

The knowledge of Wnt5/Ror2 signaling regulating CE movements during embryogenesis suggests a role of this pathway in the regulation of polarized cell migration. Indeed, transwell migration assays revealed that Ror2 was required for Wnt5a induced cell migration of mouse embryonic fibroblasts (MEFs), whereas Wnt3a induced cell migration happened independently of Ror2 (Nishita et al., 2006). The report of Nishita et al. showing an increase of cell protrusions in MCF7 cells due to Ror2 overexpression and the interaction of Ror2 with filamin A (FLNa) had a crucial influence on the present study (Nishita et al., 2006). Using wound healing assays similar results have been obtained from NIH3T3 cells. Nomachi et al. showed that Ror2 drives the formation of Wnt5a induced lamellipodia and MTOC reorientation at the wound margins in a JNK dependent manner (Nomachi et al., 2008). The following model for the Wnt5a/Ror2 induced polarized cell migration was proposed: Ror2 binds Wnt5a via its CRD domain downstream of Ror2 filamin $A$ is recruited by the PRD domain, and JNK signaling activates polarized cell migration. Further evidence indicates that Dishevelled is required for this process. (Figure 1.19.) (Minami et al., 2010; Nishita et al., 2006). 


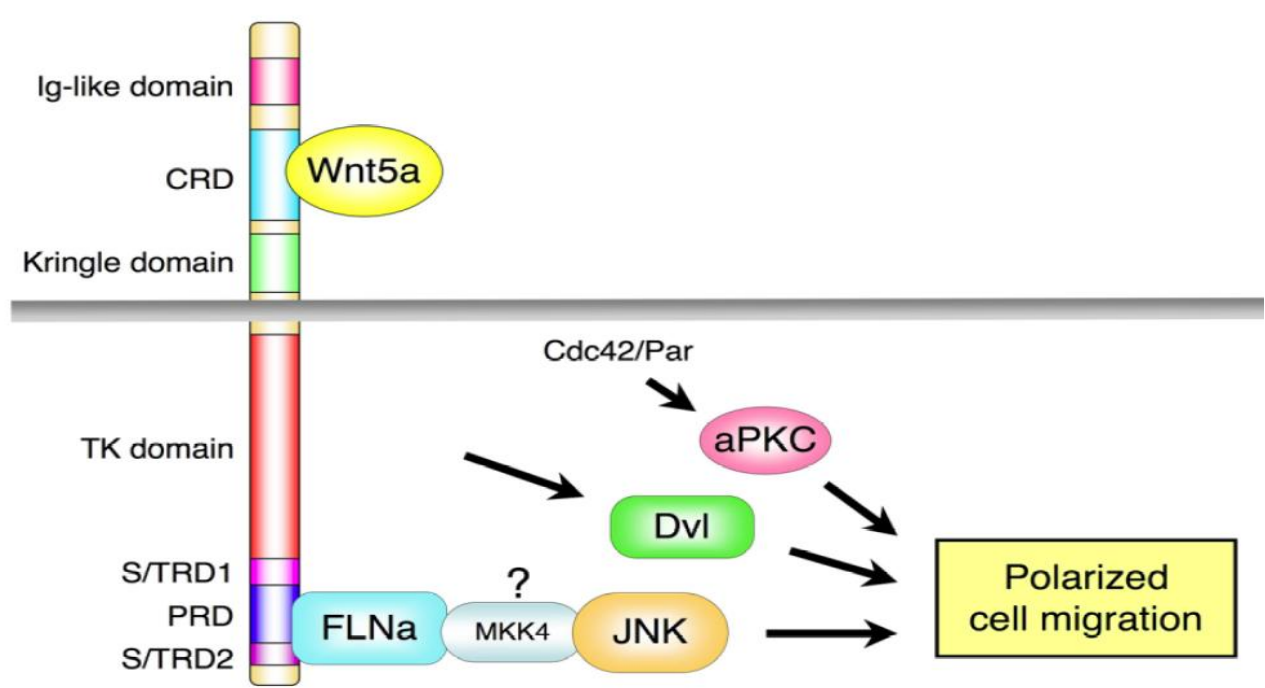

Figure 1.19. Wnt5a/Ror signaling in polarized cell migration. The model shows the Ror2 structure with its extracellular immunoglobuline like domain, the cysteine rich domain (CRD) and kringle domain. Intracellularly it has a tyrosine kinase domain (TK) and the serine/threonine-rich domains (S/TRD) and proline-rich domain (PRD) needed for interactions with other proteins. The signaling can be activated by Wnt5a binding to the CRD domain. Following Wnt binding filaminA ( FLNa) can be recruited via the PRD. This leads in turn to an activation of JNK and, subsequently, polarized cell migration. For this process the PCP regulator Dishevelled (Dsh/Dvl) and the atypical

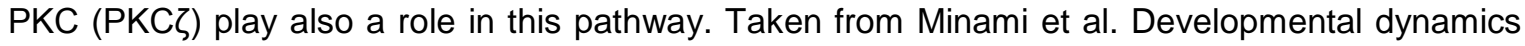
239: 1-15 2010 (Minami et al., 2010).

\subsubsection{Wnt5a Ror2 signaling in tumor invasion}

Some studies have investigated Wnt5a/Ror2 signaling in tumor progression and invasion in different tumor entities such as metastatic melanoma, osteosarcoma and colon cancer. In metastatic melanoma Ror2 was shown to be predominantly expressed in those melanomas, where elevated levels of Wnt5a caused increased Ror2 expression. For Wnt5a mediated melanoma metastasis, Ror2 was required (O'Connell et al., 2009). In osteosarcoma cells the suppression of Ror2 or Wnt5a expression results in a reduction of invasiveness and formation of invadopodia (Enomoto et al., 2009). In contrast to what is seen in melanoma and osteosarcoma, where an elevated expression of Ror2 promotes the tumor, data from colon carcinoma demonstrates an epigenetic Ror2 down regulation by promoter hypermethylation. The data shows that this epigenetic dependent loss of Ror2 promotes the tumor growth in colon cancer. This phenomenon could be explained by the fact that restoration of Ror2 expression in the cells results in less $\beta$-catenin 
dependent transcription (Lara et al., 2010). Indeed an inhibiting effect of Ror2 signaling on canonical signaling has previously been demonstrated (Mikels et al., 2009; Mikels and Nusse, 2006). 


\subsection{Aim of the study}

PTK7 is a regulator of different cell migration processes during development of Xenopus and mice. Some indications also exist for an involvement of PTK7 in promotion of cancer and cancer metastasis. The aim of this study is to analyze whether PTK7 is sufficient to induce an invasive phenotype in a non-invasive cancer model. To address this, the non invasive breast cancer cell line MCF7 was used to establish an inducible PTK7 overexpression model to study the impact of PTK7 expression on cell migration and invasion. The cell culture model was also employed to verify recent findings in the Xenopus model for conservation in mammalian cells. The interaction of PTK7 and its extracellular Wnt ligands was analyzed as to whether it is a direct interaction. Various approaches like cell morphology, scratch assays and transwell invasion assays were utilized. To shed light on the downstream events of PTK7 signaling, TOPflash luciferase reporter assays or pulldown of active small GTPases were conducted. As we know that Ror2 is also involved in regulation of polarized cell migration during development and cancer progression, we further analyzed whether PTK7 and Ror2 can act together to promote cell migration. 


\section{Materials and Methods}

\subsection{Materials}

\subsubsection{Bacteria}

For all bacteria work during this study the E.coli strain XL1 blue (Stratagene) was used. This strain is characterized by the following qualities: endA1 gyrA96(nal $\left.{ }^{R}\right)$ thi-1 $\operatorname{rec} A 1$ relA1 lac glnV44 $\mathrm{F}^{\prime}\left[: \mathrm{Tn}_{10}\right.$ proAB $^{+}$lacl $\left.^{\mathrm{q}} \Delta(\mathrm{lacZ}) \mathrm{M} 15\right]$ hsdR17( $\left.\mathrm{r}_{\mathrm{K}}^{-} \mathrm{m}_{\mathrm{K}}{ }^{+}\right)$.

\subsubsection{Cell lines}

The following human cell lines were used during this study:

HEK293, human embryonic kidney cells immortalized by adenovirus transfection. ATCC No (CRL-1573) (Graham et al., 1977)

MCF7, Breast adenocarcinoma ATCC No (HTB-22)

MDA MB 231, Breast adenocarcinoma ATCC No (HTB-26)

\subsubsection{Model Organism}

During this study the African clawed frog Xenopus laevis was used as a model organism. Adult frogs were purchased from NASCO (USA) and kept according to the rules of the animal welfare law (Tierschutz Gesetz). 


\subsubsection{Chemicals, Buffer and Media}

\subsubsection{Chemicals}

Chemicals and reagents used in this study were mainly purchased from: Biochrom (Berlin), Calbiochem (Darmstadt), Invitrogen (Darmstadt), Roth (Karlsruhe), Sigma (Munich) and Roche (Mannheim).

\subsubsection{Buffers and Media}

Alkaline phosphatase buffer (APB)

$100 \mathrm{mM}$ Tris- $\mathrm{HCl}(\mathrm{pH} 9.5)$

$50 \mathrm{mM} \mathrm{MgCl} 2$

$100 \mathrm{mM} \mathrm{NaCl}$

$0.1 \%$ Tween20

Ammonium persulfate $\quad 10 \%(\mathrm{w} / \mathrm{v})$

Blocking Buffer $\quad 5 \%(w / v)$ dry, non-fat milk powder in TBST

Cell culture Medium Dulbecco's modified Eagle Medium (Biochrom)

$10 \%$ (v/v) FCS (Biochrom, Berlin, Germany)

$100 \mathrm{U} / \mathrm{ml}$ penicillin (Gibco Invitrogen)

$100 \mu \mathrm{g} / \mathrm{ml}$ streptomycin (Gibco Invitrogen)

RPMI 1640 (Biochrom)

10\% (v/v) FCS (Biochrom, Berlin, Germany)

$100 \mathrm{U} / \mathrm{ml}$ penicillin (Biochrom)

$100 \mu \mathrm{g} / \mathrm{ml}$ streptomycin (Biochrom)

Co-IP buffer

$50 \mathrm{mM}$ Tris- $\mathrm{HCl} \mathrm{pH} 7.5$

$150 \mathrm{mM} \mathrm{NaCl}$

$0.5 \%(v / v) N P-40$ 


$\begin{array}{ll}\text { Co-IP lysis-buffer } & 50 \mathrm{ml} \text { of Co-IP buffer } \\ & 1 \mathrm{mM} \mathrm{NaF} \\ & 1 \mathrm{mM} \beta \text {-glycerolphosphate } \\ & 1 \mathrm{mM} \text { Sodium orthovanadate } \\ & 1 \text { tablet of Complete Protease inhibitor mix EDTA free } \\ & \text { (Roche) }\end{array}$

Cystein solution

2\% L-Cystein hydrochloride, $\mathrm{pH} 8.0$

\section{Hybridization mix (Hyb-mix)}

$50 \%(v / v)$ Formamid

$5 \times$ SSC

$1 \mathrm{mg} / \mathrm{ml}$ Torula RNA (Sigma)

$100 \mu \mathrm{g} / \mathrm{ml}$ Heparin

1x Denhards

$0.1 \%(v / v)$ Tween20

$0.1 \%(w / v)$ CHAPS (Sigma)

Injection buffer: $\quad 1 \times$ MBS

2\% (w/v) Ficoll 400 (Sigma)

Laemmli loding buffer (4x)

$200 \mathrm{mM}$ Tris $\mathrm{HCl}$ pH 6.8

$400 \mathrm{mM} \beta$-mercaptoethanol

$40 \%$ (v/v) Glycerol

$4 \%(\mathrm{w} / \mathrm{v})$ SDS

$0.02 \%$ (w/v) Bromphenolblue

Laemmli loading buffer (6x)

$0.35 \mathrm{M}$ Tris $\mathrm{pH} 6.8$

$30 \%(v / v)$ Glycerine

$10 \%(w / v)$ SDS

9.3\% (w/v) Dithiothreitol

$0.02 \%(w / v)$ Bromphenol blue 
Laemmli running buffer

$25 \mathrm{mM}$ Tris $\mathrm{pH} 8.8$

192 mM Glycine

$0.1 \%(w / v)$ SDS

Luria-Bertani (LB)-Medium

$1 \%(\mathrm{w} / \mathrm{v})$ Bacto-Trypton (DIFCO)

$0.5 \%(\mathrm{w} / \mathrm{v})$ yeast extract (DIFCO)

$1 \%(\mathrm{w} / \mathrm{v}) \mathrm{NaCl}, \mathrm{pH} 7.5$

LB-Agar

$1.5 \%(\mathrm{w} / \mathrm{v})$ agar (DIFCO)

in liquid LB-medium

Maleic acid Buffer (MAB)

$100 \mathrm{mM}$ Maleic acid

$150 \mathrm{mM} \mathrm{NaCl}, \mathrm{pH} 7.5$

MBS Buffer (1x)

10 mM Hepes pH 7.4

$88 \mathrm{mM} \mathrm{NaCl}$

$1 \mathrm{mM} \mathrm{KCl}$

$2.4 \mathrm{mM} \mathrm{NaHCO}_{3}$

$0.2 \mathrm{mM} \mathrm{MgSO}_{4}$

$0.41 \mathrm{mM} \mathrm{CaCl}_{2}$

$0.66 \mathrm{mM} \mathrm{KNO}_{3}$

MEM

$100 \mathrm{mM}$ MOPS

2 mM EGTA

$1 \mathrm{mM} \mathrm{MgSO}_{4}$

MEMFA

1x MEM

$3.7 \%(v / v)$ Formaldehyde

10x PBS

$8 \%(\mathrm{w} / \mathrm{v}) \mathrm{NaCl}$

$2 \%(\mathrm{w} / \mathrm{v}) \mathrm{KCl}$,

$65 \mathrm{mM} \mathrm{KH}_{2} \mathrm{PO}_{4} \times 12 \mathrm{H}_{2} \mathrm{O}$

$18 \mathrm{mM} \mathrm{Na}_{2} \mathrm{HPO}_{4}$

per $1000 \mathrm{ml}$ bidest $\mathrm{H}_{2} \mathrm{O} \mathrm{pH}$ adjusted to 7.4 
PBST

Ptw buffer

SDS $10 \%$

SSC

TBS

TBST

TE-Buffer

Transfer buffer

Tris $\mathrm{HCl} \mathrm{pH} 6.8$

Tris $\mathrm{HCl} \mathrm{pH} 8.8$

X-gal staining solution 1x PBS

0.05\% (v/v) Tween 20

$1 \times$ PBS

$0.1 \%(v / v)$ Tween 20

$10 \%(w / v)$ Sodium dodecyl sulfate

$150 \mathrm{mM} \mathrm{NaCl}$

15 mM Sodium citrate, $\mathrm{pH} 7.4$

40 mM Tris-Acetate (pH 8.5)

2 mM EDTA

$50 \mathrm{mM}$ Tris- $\mathrm{HCl} \mathrm{pH} 7.5$,

$150 \mathrm{mM} \mathrm{NaCl}$

TBS

0.5\% (v/v) Tween 20

10 mM Tris- $\mathrm{HCl}$ pH 8.0

1 mM EDTA

$25 \mathrm{mM}$ Tris

192 mM Glycine

$20 \%(v / v)$ Methanol

$1 \mathrm{M}$ Tris $(121.1 \mathrm{~g} / \mathrm{l})$

$1.5 \mathrm{M}$ Tris $(181.65 \mathrm{~g} / \mathrm{l})$

$1 \mathrm{mg} / \mathrm{ml} \mathrm{X-gal}$

$5 \mathrm{mM} \mathrm{K}_{3} \mathrm{Fe}(\mathrm{CN})_{6}$

$5 \mathrm{mM} \mathrm{K}_{4} \mathrm{Fe}(\mathrm{CN})_{6}$ 


\subsubsection{Constructs}

\subsubsection{Vectors}

pCS2+ is an expression vector that was originally designed for in vitro transcription of mRNA to microinject into Xenopus embryos. The expression is controlled under the strong simian Cytomeglovirus immediate early promoter (CMV IE94) followed by a multiple cloning site and the viral SV40 late polyadenylation site. A viral SP6 promoter allows in vitro transcription of sense polyadenylated mRNA and the viral T7 promoter can be used for in vitro transcription of antisense RNA for in situ hybridization. The vector's backbone originates from pBluescript; it includes the ampicilin resistance gene as well as the f1 DNA origin (Turner and Weintraub, 1994).

pCS2+/MT has been modified from pCS2+ by insertion of six copies of the Myc epitope (Rupp et al., 1994).

pCS2+/HA for HA-tagged protein expression pCS2+ was modified by the introduction of the hemagglutinin (HA) epitope (Damianitsch et al., 2009).

pEGFP N1 was designed for the expression of EGFP fusion proteins in mammalian cells. For selection of stable transformants the neomycin resistance gene is included (Clonetech).

pcDNA3 is a mammalian expression vector that uses the CMV promoter (Invitrogen).

pcDNA4 ${ }^{\mathrm{TM}}$ T/O luc Luciferase reporter plasmid. Luciferase is expressed under the control of the CMV promoter and the tetracycline operator, after tetracycline induction (Invitrogen).

pcDNA5 ${ }^{\mathrm{TM}} \mathrm{T} / \mathrm{O}$ is an expression plasmid that can be used for tetracycline inducible gene expression in mammalian cell lines. The gene of interest can be expressed under the control of CMV IE promoter and the tetracycline operator (Hillen and Berens, 1994; Hillen et al., 1983) (Invitrogen).

pcDNA6 ${ }^{T M} T / R$ is a regulatory vector for tetracycline inducible gene expression in mammalian cells. It expresses the tetracycline resistance gene (Hillen and Berens, 1994; Hillen et al., 1983; Yao et al., 1998)(Invitrogen). 
2.1.5.2. Expression constructs and luciferase reporters

Table 2.1. Summarizes the expression plasmids that were used during this study.

\begin{tabular}{|c|c|c|c|}
\hline NAME & VECTOR & DESCRIPTION & CLONING STRATEGY \\
\hline PTK7-HA & $\mathrm{pCS} 2+/ \mathrm{HA}$ & $\begin{array}{l}\text { HA-tagged full-length } \\
\text { human PTK7 }\end{array}$ & (Peradziryi et al., 2011) \\
\hline PTK7-MT & pCS2+/MT & $\begin{array}{l}\text { Myc-tagged full-length } \\
\text { human PTK7 }\end{array}$ & $\begin{array}{l}\text { The coding sequence of human } \\
\text { PTK7 was amplified using the } \\
\text { primers } \text { HPTK7_Clal_sense and and } \\
\text { hPTK7_Clal_reverse. The PCR } \\
\text { product was introduced into Clal } \\
\text { restriction site of pCS2+/MT }\end{array}$ \\
\hline$\Delta \mathrm{k}$ PTK7-HA & $\mathrm{pCS} 2+/ \mathrm{HA}$ & $\begin{array}{l}\text { HA-tagged human } \\
\text { PTK7 without the } \\
\text { intracellular kinase } \\
\text { domain. }\end{array}$ & (Peradziryi et al., 2011) \\
\hline$\Delta \mathrm{k}$ PTK7-MT & pCS2+/MT & $\begin{array}{l}\text { Myc-tagged human } \\
\text { PTK7 without the } \\
\text { intracellular kinase } \\
\text { domain }\end{array}$ & $\begin{array}{l}\text { The coding sequence of the } \\
\text { extracellular domain and the } \\
\text { transmembrane domain were } \\
\text { amplified using primers } \\
\text { hPTK7_Clal_sense and } \\
\text { as_Clal_deltakinase. The PCR } \\
\text { product was introduced into the Clal } \\
\text { restriction site of pCS2+/MT. }\end{array}$ \\
\hline$\Delta \mathrm{E}$ PTK7-MT & pCS2+/MT & $\begin{array}{l}\text { Myc-tagged } \\
\text { transmembrane } \\
\text { domain and } \\
\text { intracellular part of } \\
\text { human PTK7 }\end{array}$ & $\begin{array}{l}\text { Amplified from PTK7-MT excluding } \\
\text { the extracellular domain using } \\
\text { primers: } \\
\text { circle_PCR_sense_Nhel and } \\
\text { circle_PCR_as_Nhel. The primers } \\
\text { introduced a new Nhel restriction site } \\
\text { between the signaling sequence and } \\
\text { the transmembrane domain. } \\
\text { Following the PCR reaction the DNA } \\
\text { template was destroyed by Dpnl } \\
\text { treatment and the Nhel sites of the } \\
\text { product were ligated. }\end{array}$ \\
\hline $\begin{array}{l}\Delta \mathrm{E} \Delta \mathrm{TM} \text { PTK7- } \\
\text { MT }\end{array}$ & pCS2+/MT & $\begin{array}{l}\text { Myc-tagged } \\
\text { intracellular part of } \\
\text { human PTK7 lacking } \\
\text { the extracellular part } \\
\text { and the trans- } \\
\text { membrane domain }\end{array}$ & $\begin{array}{l}\text { Amplified with the primers: } \\
\text { sense_Clal_intra_not_membrane_bo } \\
\text { und and } h P T K 7 \text { Clal_reverse. The } \\
\text { PCR product was introduced into the } \\
\text { Clal restriction site of pCS2+/MT. }\end{array}$ \\
\hline $\begin{array}{l}\text { secreted PTK7- } \\
\text { HA }\end{array}$ & $\mathrm{pCS} 2+/ \mathrm{HA}$ & $\begin{array}{ll}\text { HA-tagged secreted } \\
\text { extracellular part of } \\
\text { human PTK7 }\end{array}$ & (Peradziryi et al., 2011) \\
\hline secreted PTK7- & pCS2+/MT & $\begin{array}{l}\text { Myc-tagged secreted } \\
\text { extracellular part of } \\
\text { human PTK7 }\end{array}$ & $\begin{array}{l}\text { The extracellular part was amplified } \\
\text { using primers: hPTK7_Clal_sense } \\
\text { and secreted_as_Clal. The PCR }\end{array}$ \\
\hline
\end{tabular}




\begin{tabular}{|c|c|c|c|}
\hline NAME & VECTOR & DESCRIPTION & CLONING STRATEGY \\
\hline MT & & & $\begin{array}{l}\text { product was introduced into the Clal } \\
\text { restriction site of } \mathrm{pCS} 2+\mathrm{MT} \text {. }\end{array}$ \\
\hline PTK7-EGFP & pEGFP N1 & $\begin{array}{l}\text { EGFP-tagged full- } \\
\text { length PTK7 }\end{array}$ & $\begin{array}{l}\text { The coding sequence of PTK7 was } \\
\text { amplified using primers: sense } \\
\text { hPTK7_Nhel and as_PTK7_EcoRI } \\
\text { The PCR product was introduced into } \\
\text { pEGFP N1 to the Nhel and EcoRI } \\
\text { restriction sites. }\end{array}$ \\
\hline PTK7-EGFP & pcDNA5 T/O & $\begin{array}{l}\text { EGFP-tagged full- } \\
\text { length PTK7 }\end{array}$ & $\begin{array}{l}\text { The coding sequence for PTK7 fused } \\
\text { to EGFP was amplified from the } \\
\text { pEGFPN1 PTK7 plasmid using } \\
\text { primers: sense_EcoRV_ATG (176- } \\
196 \text { of hPTK7) and as_NotIEGFP } \\
\text { (very end of EGFP). The PCR } \\
\text { product was introduced into the } \\
\text { EcoRV and Notl restriction sites of } \\
\text { the pcDNA5 T/O vector. }\end{array}$ \\
\hline Ror2-HA & $\mathrm{pCS} 2+/ \mathrm{HA}$ & $\begin{array}{l}\text { HA tagged full-length } \\
\text { mouse Ror2 }\end{array}$ & $\begin{array}{l}\text { The coding sequence of mouse Ror2 } \\
\text { was amplified using primers: } \\
m R \text { : and_sense_Xhol and } \\
\text { as_mRor2_Xhol. The PCR product } \\
\text { was introduced into the Xhol } \\
\text { restriction site of the pCS2+/HA } \\
\text { vector. }\end{array}$ \\
\hline $\begin{array}{l}\text { Ror2 } \Delta \mathrm{CRD} / \mathrm{KR}- \\
\text { Flag }\end{array}$ & $\begin{array}{l}\text { pcDNA3/ } \\
\text { Flag }\end{array}$ & $\begin{array}{l}\text { Flag tagged mouse } \\
\text { Ror2 lacking the CRD } \\
\text { and kringle domain }\end{array}$ & (Sammar et al., 2004) \\
\hline Ror2 $\Delta 745$-Flag & $\begin{array}{l}\text { pcDNA3/ } \\
\text { Flag }\end{array}$ & $\begin{array}{l}\text { Flag tagged mouse } \\
\text { Ror2 lacking the c- } \\
\text { terminal } \\
\text { Threonine and Proline } \\
\text { rich domains }\end{array}$ & (Sammar et al., 2004) \\
\hline Ror2 $\Delta 469$-Flag & $\begin{array}{l}\text { pcDNA3/ } \\
\text { Flag }\end{array}$ & $\begin{array}{l}\text { Flag tagged mouse } \\
\text { Ror2 lacking the } \\
\text { complete intracellular } \\
\text { part }\end{array}$ & (Sammar et al., 2004) \\
\hline Ror2-GFP & pCS2+/ GFP & $\begin{array}{l}\text { GFP tagged full-length } \\
\text { Xenopus laevis Ror2 }\end{array}$ & Kind gift from A. Schambony \\
\hline Frizzled7-MT & pCS2+/MT & $\begin{array}{lr}\text { Myc tagged full-length } \\
\text { Xenopus } \\
\text { Frizzled7 }\end{array}$ & (Winklbauer et al., 2001) \\
\hline Frizzled7-HA & $\mathrm{pCS} 2+/ \mathrm{HA}$ & $\begin{array}{lr}\text { HA tagged } & \text { full-length } \\
\text { Xenopus } & \text { laevis } \\
\text { Frizzled7 } & \\
\end{array}$ & (Peradziryi et al., 2011) \\
\hline exFz7-MT & pCS2+/MT & $\begin{array}{lr}\text { Myc } & \text { tagged } \\
\text { extracellular } & \text { domain of } \\
\text { Xenopus } & \text { laevis } \\
\end{array}$ & (Winklbauer et al., 2001) \\
\hline
\end{tabular}




\begin{tabular}{|l|l|l|l|}
\hline \multicolumn{1}{|c|}{ NAME } & VECTOR & \multicolumn{1}{|c|}{ DESCRIPTION } & CLONING STRATEGY \\
\hline JNK1-HA & PCDNA3 & $\begin{array}{l}\text { HA tagged human } \\
\text { protein kinase } \\
\text { (JNK1) }\end{array}$ & Kind gift from K. Giehl \\
\hline mGFP & pCS2+ & $\begin{array}{l}\text { GFP with GAP43 } \\
\text { myristoylation signal } \\
\text { for membrane } \\
\text { association }\end{array}$ & Kind gift from D. Wedlich \\
\hline xTwist & pGEMT-T & $\begin{array}{l}\text { Full-length Xenopus } \\
\text { laevis twist }\end{array}$ & (Hopwood et al., 1989) \\
\hline lacZ & pCS2+ & $\begin{array}{l}\text { Bacterial } \\
\text { galactosidase }\end{array}$ & (Smith and Harland, 1991) \\
\hline Renilla & pRL-TK & $\begin{array}{l}\text { Contains the Renilla } \\
\text { luciferase gene, } \\
\text { downstream of the } \\
\text { herpes simplex virus } \\
\text { thymidine kinase } \\
\text { (HSV-TK) promoter }\end{array}$ & Promega \\
\hline TOPflash & $\begin{array}{l}\text { Contains 7CF/LEF } \\
\text { binding sites and the } \\
\text { firefly luciferase gene } \\
\text { to monitor B-catenin } \\
\text { signaling }\end{array}$ & (Korinek et al., 1997) \\
\hline
\end{tabular}


2.1.5.3. Linearization of expression constructs for in vitro transcription and stable transfection

Table 2.2. Summarizing the restriction enzymes used for linearization of plasmids and polymerases used for in vitro transcription.

\begin{tabular}{|c|c|c|c|c|c|}
\hline \multirow{2}{*}{$\begin{array}{l}\text { Name of } \\
\text { the } \\
\text { construct }\end{array}$} & \multicolumn{2}{|l|}{ sense RNA } & \multicolumn{2}{|c|}{ antisense RNA } & \multirow{2}{*}{$\begin{array}{l}\text { Stable } \\
\text { transfection } \\
\text { Restriction }\end{array}$} \\
\hline & Restriction & Polymerase & Restriction & Polymerase & \\
\hline $\begin{array}{l}\text { pGEMT-T } \\
\text { xTwist }\end{array}$ & & & EcoRI & T7 & \\
\hline pCS2+lacZ & Not I & SP6 & & & \\
\hline $\begin{array}{l}\text { Pcs2+ } \\
\text { mGFP }\end{array}$ & Not I & SP6 & & & \\
\hline $\begin{array}{l}\text { pcDNA5 } \\
\text { T/O PTK7- } \\
\text { EGFP }\end{array}$ & & & & & Nrul \\
\hline $\begin{array}{l}\text { pcDNA6 } \\
\text { T/R }\end{array}$ & & & & & Sapl \\
\hline
\end{tabular}

\subsubsection{Oligonucleotides}

\subsubsection{Sequencing primers}

For sequencing of expression constructs the following DNA oligonucleotide primers were used sequences are given in the 5 '-3`direction:

pCS2+

$\begin{array}{ll}\text { SP6 } & \text { TTAGGTGACACTATAGAATAC } \\ \text { T7 } & \text { TCTACGTAATACGACTCACTATAG } \\ \text { T3 } & \text { AATTAACCCTCACTAAAGGG }\end{array}$

PcDNA

CMV CGCAATGGGCGGTGGCGTG 


\subsubsection{Cloning primers}

For cloning of expression constructs the following primers were used. Sequences are given in the 5'-3' direction. Restriction enzyme sites are underlined:

\begin{tabular}{ll}
\multicolumn{2}{c}{ Cloning of human PTK7 constructs } \\
hPTK7 Clal sense & CACGTGATCGATGCCCTCAGCTCCTTTTCCTGA \\
hPTK7 Clal reverse & GACGTGATCGATGCGGCTTGCTGTCCACGGT \\
as Clal for dk PTK7 & CCGTATCGATCGGGCTCCTTCTGCAGC \\
Circle PCR sense Nhel & CGACTGCTAGCTACAAGATGATCCAGACCATTG \\
Circle PCR as Nhel & CGACTGCTAGCTGTCTGGGTACCGCCCAGC \\
sense Clal intra PTK7 & AGCAATCGATGCCAAGCGGCTGCAGAAG \\
secr PTK7 as Clal & GACTGATCGATACCCAATGGTCTGGATCATCTTG \\
sense hPTK7 Nhel & CACGTGGCTAGCGCCCTCAGCTCCTTTTCCTGA \\
hPTK7 as EcoRI & GACGAATTCGCGGCTTGCTGTCCACGGT \\
sense EcoRV hPTK7 & GTCGATATCATGGGAGCTGCGCGGGGATCC \\
as Notl EGFP & ACGGCGGCCGCCTTGTACAGCTCGTCCATGC
\end{tabular}

Cloning of the mouse Ror2 construct

mRor2 sense Xhol ACGCTCGAGGTGCATCGGGGCAGGAAAGGGGAC as mouse Ror2 Xhol ACGCTCGAGGGCTTCAAGCTGGACATGAGCCG

2.1.6.3. Morpholino oligonucleotides

Morpholino oligonucleotides were purchased from GeneTools, LLC

PTK7MO2 Xenopus laevis PTK7

TGCATCGCGGCCTCTCCCCTCAC 10 ng/embryo

PTK7MO3 Xenopus laevis PTK7

TTCCTGCCCCGGATCCTCTCACTGC

$10 \mathrm{ng} / \mathrm{embryo}$

control MO no target

CCTCTTACCTCAGTTACAATTTATA

20 ng/embryo 


\subsubsection{4. $\quad$ siRNAs}

For protein knockdown in mammalian cells the siRNA technique was used (Elbashir et al., 2001). siRNAs used for this study were purchased from Thermo Scientifc as ONTARGETplus Smart pool

Human PTK7 NM_152881

siRNA J-003167-13 PTK7

Target sequence GAGCAUAGUGGGCUGUAUU

siRNA J-003167-14 PTK7

Target sequence CGCCACAGCACAAGUGAUA

siRNA J-003167-15 PTK7

Target sequence UUGAAGACAUGCCGCUAUU

siRNA J-003167-16 PTK7

Target sequence GCAAGGAUGUGUAACAG

Non targeting siRNA\#1 D-001810-01 


\subsubsection{Antibodies}

Table 2.3. Summarizes antibodies and working concentrations used in this study.

\begin{tabular}{|c|c|c|c|c|c|c|}
\hline \multirow[b]{2}{*}{ Name } & \multirow{2}{*}{$\begin{array}{l}\text { Company, } \\
\text { catalogue } \\
\text { number }\end{array}$} & \multirow[b]{2}{*}{ Description } & \multicolumn{4}{|c|}{ Dilution } \\
\hline & & & WB & IP & IF & FACS \\
\hline GFP & Abcam, ab290 & $\begin{array}{l}\text { Primary rabbit polyclonal, } \\
\text { against GFP }\end{array}$ & & & $1: 1000$ & \\
\hline GFP & $\begin{array}{l}\text { Roche, } \\
11814460001\end{array}$ & $\begin{array}{l}\text { Primary mouse monoclonal, } \\
\text { against GFP }\end{array}$ & $1: 1000$ & & & \\
\hline HA.11 & $\begin{array}{l}\text { Covance, } \\
\text { MMS-101P }\end{array}$ & $\begin{array}{l}\text { Primary mouse monoclonal } \\
\text { recognizes HA tag (peptide } \\
\text { CYPYDVPDYASL) }\end{array}$ & $1: 1000$ & $1: 150$ & $1: 100$ & \\
\hline $\begin{array}{l}\text { HA.11- } \\
\text { FITC }\end{array}$ & $\begin{array}{l}\text { Covance, FITC- } \\
101 \mathrm{~L}\end{array}$ & $\begin{array}{l}\text { HA.11 antibody directly coupled } \\
\text { with FITC fluorescent dye }\end{array}$ & & & $1: 200$ & \\
\hline IgG2a-PE & $\begin{array}{l}\text { Miltenyi Biotec, } \\
130-091-837\end{array}$ & $\begin{array}{l}\text { Mouse IgG2a isotype control } \\
\text { antibody conjugated to PE } \\
\text { fluorescent dye to be used as a } \\
\text { negative control antibody to } \\
\text { distinguish specific from non- } \\
\text { specific binding of mouse lgG2a } \\
\text { in flow cytometry }\end{array}$ & & & & 1:10 \\
\hline JNK-1 & $\begin{array}{l}\text { Santa Cruz, sc- } \\
571\end{array}$ & $\begin{array}{l}\text { Primary rabbit polyclonal, } \\
\text { recognizes JNK-1,2,3 }\end{array}$ & $1: 10000$ & & & \\
\hline$p-J N K$ & $\begin{array}{l}\text { Santa Cruz, } \\
\text { sc6254 }\end{array}$ & $\begin{array}{l}\text { Primary mouse monoclonal } \\
\text { antibody, recognizes a short aa } \\
\text { sequence containing Thr-183 } \\
\text { and Tyr-185 phosphorylation of } \\
\text { JNK-1 }\end{array}$ & $1: 1000$ & & & \\
\hline 9E10 MT & Sigma, M4439 & $\begin{array}{l}\text { Primary mouse monoclonal } \\
\text { antibodies, recognizes myc tag } \\
\text { peptide corresponding to } \\
\text { residues } 408-439 \text { of the human } \\
\text { cMyc protein }\end{array}$ & $1: 2000$ & $1: 500$ & & \\
\hline $\begin{array}{l}\text { 9E10 } \\
\text { MT- } \\
\text { Cy3 }\end{array}$ & Sigma, C6594 & $\begin{array}{l}\text { 9E10 MT antibody directly } \\
\text { coupled with Cy3 fluorescent } \\
\text { dye }\end{array}$ & & & $1: 200$ & \\
\hline MT & $\begin{array}{l}\text { Abcam } \\
\text { ab19234 }\end{array}$ & $\begin{array}{l}\text { Primary goat polyclonal against } \\
\text { myc tag (recognizes peptide } \\
\text { EQKLISEEDL) }\end{array}$ & $1: 10000$ & & & \\
\hline MT-HRP & $\begin{array}{l}\text { Miltenyi Biotech } \\
130-092- \\
113\end{array}$ & $\begin{array}{l}\text { Primary antibody against the } \\
\text { Myc epitope, directly coupled } \\
\text { with HRP, can be used in WB } \\
\text { without secondary antibody }\end{array}$ & & & & \\
\hline
\end{tabular}




\begin{tabular}{|c|c|c|c|c|c|c|}
\hline \multirow[b]{2}{*}{ Name } & \multirow{2}{*}{$\begin{array}{l}\text { Company, } \\
\text { catalogue } \\
\text { number }\end{array}$} & \multirow[b]{2}{*}{ Description } & \multicolumn{4}{|c|}{ Dilution } \\
\hline & & & WB & IP & IF & FACS \\
\hline $\begin{array}{l}\text { Phalloidin } \\
\text { TRITC }\end{array}$ & Sigma, P1951 & $\begin{array}{l}\text { Fungal toxin of Amanita } \\
\text { phalloides, binds specifically to } \\
\text { f-actin coupled with TRITC } \\
\text { fluorescent dye }\end{array}$ & & & $1: 500$ & \\
\hline $\begin{array}{l}\text { PTK7-PE } \\
\text { (CCK-4) }\end{array}$ & $\begin{array}{l}\text { Miltenyi Biotec, } \\
130-091-346\end{array}$ & $\begin{array}{l}\text { Mouse, monoclonal clone 188B } \\
\text { IgG2a, recognizes human } \\
\text { Protein tyrosine kinase } 7, \\
\text { coupled with PE fluorescent dye }\end{array}$ & & & & 1:10 \\
\hline $\begin{array}{l}\text { PTK7 } \\
\text { (CCK-4) }\end{array}$ & $\begin{array}{l}\text { R\&D Systems, } \\
\text { AF449 }\end{array}$ & $\begin{array}{l}\text { Primary, affinity purified goat, } \\
\text { recognizes CCK-4 } 4 \text { Colon } \\
\text { carcinoma kinase } 4 \text { also known } \\
\text { as PTK7 }\end{array}$ & 1:1000 & & $1: 200$ & \\
\hline Ror2 & $\begin{array}{l}\text { R\&D Systems, } \\
\text { AF2064 }\end{array}$ & $\begin{array}{|lrr|}\text { Primary } & \text { goat } & \text { polyclonal, } \\
\text { recognizes } & \text { Ror2 } & \text { extracellular } \\
\text { domain } & & \end{array}$ & 1:1000 & & & \\
\hline Wnt3a & $\begin{array}{l}\text { Cell Signaling, } \\
2721\end{array}$ & $\begin{array}{l}\text { Primary rabbit against mouse } \\
\text { Wnt3a }\end{array}$ & 1:1000 & & & \\
\hline Wnt5a & $\begin{array}{l}\text { Cell Signaling, } \\
2392\end{array}$ & $\begin{array}{l}\text { Primary rabbit against mouse } \\
\text { Wnt5a }\end{array}$ & 1:1000 & & & \\
\hline $\begin{array}{l}\text { a-mouse- } \\
\text { Alexa } 488\end{array}$ & $\begin{array}{l}\text { Invtrogen, } \\
\text { A11029 }\end{array}$ & $\begin{array}{l}\text { Secondary goat anti mouse IgG } \\
\text { coupled with Alexa } 488 \\
\text { fluorescent dye (green) }\end{array}$ & & & $1: 400$ & \\
\hline $\begin{array}{l}\text { a-mouse- } \\
\text { Alexa } 596\end{array}$ & $\begin{array}{l}\text { Invitrogen, } \\
\text { A11005 }\end{array}$ & $\begin{array}{l}\text { Secondary goat anti mouse IgG } \\
\text { coupled with Alexa } 596 \\
\text { fluorescent dye (red) }\end{array}$ & & & $1: 400$ & \\
\hline $\begin{array}{l}\text { a-rabbit- } \\
\text { FITC }\end{array}$ & Sigma, F7367 & $\begin{array}{l}\text { Secondary goat anti rabbit IgG } \\
\text { coupled with FITC dye }\end{array}$ & & & $1: 400$ & \\
\hline $\begin{array}{l}\text { a-rabbit- } \\
\text { HRP }\end{array}$ & $\begin{array}{l}\text { Cell Signaling, } \\
7074\end{array}$ & $\begin{array}{l}\text { Secondary anti rabbit } \lg G \\
\text { coupled with HRP }\end{array}$ & & 1:1000 & & \\
\hline $\begin{array}{l}\text { a-mouse- } \\
\text { HRP }\end{array}$ & $\begin{array}{l}\text { Santa Cruz, sc- } \\
2005\end{array}$ & $\begin{array}{l}\text { Secondary goat anti mouse } \lg G \\
\text { coupled with HRP }\end{array}$ & & $1: 5000$ & & \\
\hline $\begin{array}{l}\text { a-goat- } \\
\text { HRP }\end{array}$ & $\begin{array}{l}\text { Santa Cruz } \\
\text { SC-2020 }\end{array}$ & $\begin{array}{l}\text { Secondary donkey anti goat } \operatorname{lgG} \\
\text { coupled with HRP }\end{array}$ & & $1: 10000$ & & \\
\hline
\end{tabular}




\subsection{Methods}

\subsubsection{Techniques using DNA}

\subsubsection{Plasmid DNA preparations}

Isolation of plasmid DNA from bacteria cultures was performed in analytical scale using

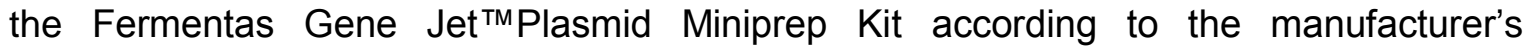
instructions. For the isolation of preparative amounts, the NucleoBond Xtra Midi Kit (Macherey and Nagel) was used according to the manufacturer's instructions. Quantification of DNA was carried out using the NanoDrop 2000c spectrophotometer (Thermo scientific) according to the manufacturer's instructions.

\subsubsection{DNA restriction digestion}

Restriction digest of DNA during this study was carried out using Fermentas Life Sciences (St. Leon-Rot) Restriction Enzymes according to the manufacturer's instructions.

\subsubsection{Agarose gel electrophoresis}

For the electrophoretic separation of DNA fragments after restriction digest or PCR amplification, the standard agarose electrophoresis method was applied (Fisher and Dingman, 1971; Helling et al., 1974). 1x Tris- acetate buffer (TAE) was used as running buffer. DNA was visualized using Ethidium bromide $0.5 \mu \mathrm{g} / \mathrm{ml}$ (Sharp et al., 1973).

\subsubsection{Purification of DNA fragments from agarose gels}

For purification of DNA fragments out of agarose gels or after enzymatic reactions the Invisorb "Spin DNA extraction/Fragment cleanup" kit (Invitek, Berlin) was used according to the manufacturer's instructions.

\subsubsection{Polymerase chain reaction (PCR)}

To amplify DNA fragments, a standard PCR reaction was carried out (Sharp et al., 1973). For the analytical DNA amplification Fermentas Life Sciences "DreamTaq TMDNA polymerase" was used. If PCR fragments should be used in a process of molecular cloning Fermentas "High Fidelity PCR Enzyme Mix" was used. All conditions were chosen according to the manufacturer's manuals. 


\subsubsection{DNA ligation}

During the process of molecular cloning all DNA ligation steps were performed using T4 Ligase (Fermentas Life Sciences) according to the manufacturer's instructions. During ligation the ratio of vector DNA and insert DNA was 1:3.50 ng of vector DNA were used.

\subsubsection{Transformation of bacteria}

For chemical transformation of E. coli cells, the chemical competent XL1 blue cells were thawed on ice. $100 \mathrm{ng}$ of plasmid DNA or 1-2 $\mu$ of a ligation mix were added and incubated on ice for 30 minutes. Following this incubation step a heat shock was performed for 90 seconds at $42{ }^{\circ} \mathrm{C}$. Immediately after the heat shock the cells were incubated on ice again for 2 minutes before LB medium was added and the cells were cultivated for $30 \mathrm{~min}$ at $37^{\circ} \mathrm{C}$ shaking (Mandel and Higa, 1970). For transformation by electroporation electro-competent cells were thawed on ice, $1 \mu \mathrm{l}$ of the cold ligation mix was added. The cells together with the DNA were transferred to a cold electroporation cuvette (2mm). Using the BioRad E coli pulser a pulse of $1.8 \mathrm{kV}$ and $25 \mu \mathrm{F}$ was given. Immediately after the pulse $1 \mathrm{ml}$ of cold LB medium was added to the cells and shaking incubated at $37^{\circ} \mathrm{C}$ for $30 \mathrm{~min}$ (Dower et al., 1988). Independent of the transformation methods the pelleted E.coli cells were platted on LB-agar plates which contained an appropriate antibiotic ampicillin $0.1 \mathrm{mg} / \mathrm{ml}$ or kanamycin $0.05 \mathrm{mg} / \mathrm{ml}$, and incubated for 18 h at $37^{\circ} \mathrm{C}$.

\subsubsection{DNA sequencing}

For sequencing of plasmid DNA the Dye-termination method, which was modified from (Sanger et al., 1977), was used. The sequencing was performed using the Big Dye ${ }^{\mathrm{TM}}$ Terminator Kit (Applied Biosystems) according to the manufacturer's instructions. The sequencing analysis was carried out on the ABI 3100 Automated Capillary DNA Sequencer (Applied Biosystems).

\subsubsection{Techniques using RNA}

\subsubsection{In vitro synthesis of capped sense RNA}

To produce capped mRNAs for microinjection into Xenopus laevis embryos, in vitro synthesis of capped mRNA was carried out using the SP6 mMessage mMachine kit тм (Ambion) according to the manufacturer's manual. The synthesized mRNA was cleaned up using the Illustra ${ }^{\mathrm{TM}}$ RNAspin Mini RNA Isolation Kit (GE Healthcare). The mRNA was quantified using the NanoDrop 2000c spectrophotometer (Thermo scientific). 


\subsubsection{In vitro synthesis of labeled antisense RNA}

Digoxigenin labeled antisense RNA to use as a probe in whole mount in situ hybridization was prepared using the following reaction mix:

\begin{tabular}{|c|c|}
\hline $5 \mu l$ & of a $5 x$ transcription buffer (Fermentas) \\
\hline $1 \mu l$ & each 10 mM rATP, rCTP, rGTP (Roche) \\
\hline $0.64 \mu \mathrm{l}$ & 10 mM rUTP (Roche) \\
\hline $0.36 \mu \mathrm{l}$ & digoxigenin-rUTP (Roche) \\
\hline $1 \mu l$ & 0.75 M DTT \\
\hline $0.5 \mu l$ & RNAseOut (Invitrogen), \\
\hline $200-1000$ ng & linearized DNA template \\
\hline$\mu l$ & T7 polymerase $(20 \mathrm{U} / \mu \mathrm{l}$, Fermentas $)$ \\
\hline
\end{tabular}

RNAse-free water to the final volume of $25 \mu \mathrm{l}$

The reaction mix was incubated at $37^{\circ} \mathrm{C}$ for $2-3$ hours. The DNA template was destroyed using Turbo DNAsel (Ambion) before the mixture was cleaned up using the RNeasy ${ }^{\mathrm{TM}}$ mini Kit (Qiagen).

\subsubsection{Cell culture techniques}

\subsubsection{Propagation of cell lines}

All cell culture media components were purchased from Biochrome (Berlin, Germany). The human cell lines used during this study were cultivated at standard cell culture conditions, $37^{\circ} \mathrm{C}, 5 \%(\mathrm{v} / \mathrm{v}) \mathrm{CO}_{2}$ and $95 \%$ humidity. HEK293 cells were kept in Dulbecco`s Modified Eagle`s Medium (DMEM). MCF7 and MDA MB231 cells were kept in RPMI 1640 medium. Both media were supplemented with $10 \%$ (v/v) fetal calf serum (FCS), 100 $\mathrm{U} / \mathrm{ml}$ penicillin and $100 \mu \mathrm{g} / \mathrm{ml}$ streptomycin. For propagation of the cell lines, cells were split 1-2 times per week using Trypsin-EDTA for detachment $(0.025 \%$ (w/v) Trypsin, 0.53 mM EDTA). A subcultivation ratio of 1:3 was used. For cryopreservation of cell lines cells were frozen in FCS supplemented with 10\% (v/v) DMSO and stored long-term in liquid nitrogen. 


\subsubsection{Transfection of cell lines}

To transfect mammalian cells with DNA of expression plasmids a lipid mediated DNA transfection method was used (Felgner et al., 1987). Lipofectamin ${ }^{\mathrm{TM}} 2000$ (Invitrogen) was used according to the manufacturer's manual. Prior to transfection the cells were plated into an appropriate culture vessel. For transfection the cells were cultivated within an antibiotic-free culture medium, which was supplemented with $10 \%(\mathrm{v} / \mathrm{v})$ FCS. The transfection complexes were prepared by dilution of DNA and Lipofectamin in Opti-MEM medium (Invitrogen). To perform co-immunoprecipitation, transfections were carried out in 6-well plates. For each transfection condition two wells of a 6-well plate were transfected with the identical mixture. For morphology analysis cells were seeded on glass coverslips in 24-well plates prior to transfection. For collection of cell culture supernatants containing secreted proteins, cells were transfected in $10 \mathrm{~cm}$ diameter Petri dishes.

Table 2.4 Volumes of culture medium, amount of DNA/RNA and Lipofectamin. (all volumes are indicated per well)

\begin{tabular}{|l|l|l|l|l|l|l|}
\hline $\begin{array}{l}\text { Culture } \\
\text { vessel }\end{array}$ & $\begin{array}{l}\text { Volume of } \\
\text { plating } \\
\text { medium }\end{array}$ & $\begin{array}{l}\text { Volume of } \\
\text { dilution } \\
\text { medium } \\
\text { OptiMEM }\end{array}$ & DNA & $\begin{array}{l}\text { Lipofectam } \\
\text { in }\end{array}$ & RNA & $\begin{array}{l}\text { Lipofectam } \\
\text { in }\end{array}$ \\
\hline 96-well & $100 \mu \mathrm{l}$ & $2 \times 25 \mu \mathrm{l}$ & $0.2 \mu \mathrm{g}$ & $0.5 \mu \mathrm{l}$ & $5 \mathrm{pmol}$ & $0.25 \mu \mathrm{l}$ \\
\hline 24-well & $500 \mu \mathrm{l}$ & $2 \times 50 \mu \mathrm{l}$ & $0.8 \mu \mathrm{g}$ & $0.5 \mu \mathrm{l}$ & $5 \mathrm{pmol}$ & $0.25 \mu \mathrm{l}$ \\
\hline 6 -well & $2 \mathrm{ml}$ & $2 \times 250 \mu \mathrm{l}$ & $4 \mu \mathrm{g}$ & $10 \mu \mathrm{l}$ & $100 \mathrm{pmol}$ & $5 \mu \mathrm{l}$ \\
\hline $10 \mathrm{~cm}$ & $7.5 \mathrm{ml}$ & $2 \times 750 \mu \mathrm{l}$ & $12 \mu \mathrm{g}$ & $30 \mu \mathrm{l}$ & $300 \mathrm{pmol}$ & $15 \mu \mathrm{l}$ \\
\hline
\end{tabular}

\subsubsection{Generation of stable transfection}

For generation of stable transfected MCF7 cells, the appropriate antibiotics for selection were added 24 hours after transfection to the culture medium. All antibiotics used were purchased from Invitrogen.

$\begin{array}{lll}\text { pEGFP N1 } & \text { G418 } & 1.5 \mu \mathrm{g} / \mathrm{ml} \\ \text { pcDNA 6 T/R } & \text { Blasticidine } & 6 \mu \mathrm{g} / \mathrm{ml} \\ \text { pcDNA 5 T/O } & \text { Hygromycin } & 1 \mu \mathrm{g} / \mathrm{ml}\end{array}$

Ten to 15 days after the selection pressure by the antibiotics started, colonies of stable transfectants could be observed. Single colonies were transferred into single culture wells 
and cultivation was continued. After the acquisition of enough culture material, clones were tested for expression of the protein of interest. Samples of the clones were frozen in liquid nitrogen for later availability.

\subsubsection{Flow cytometry analysis}

For analysis of PTK7 expression in MCF7 cells, flow cytometry analysis was performed. Cells were harvested using mechanical detachment from the culture vessel, washed in PBS and transferred to MACS buffer (PBS, 0.5\% (w/v) BSA 2 mM EDTA). 5x $10{ }^{6}$ cells per tube were aliquoted and resuspended in $100 \mu \mathrm{l}$ of MACS buffer. For staining either 10 $\mu \mathrm{l}$ of PBS (unstained control), mouse IgG2a-PE isotype control antibody (isotype control) or anti-PTK7 (CCK-4)-PE antibody were added to the different tubes. The cells were incubated for 10 minutes in the dark at $4-8^{\circ} \mathrm{C}$. Cells were washed with $2 \mathrm{ml}$ of MACS buffer and centrifugated at $300 \mathrm{xg}$ for 10 minutes. The supernatants were removed and the cells were resuspended in PBS containing 4\% (w/v) PFA for fixation. Stained and fixed cells were stored at $4^{\circ} \mathrm{C}$ in the dark until measurement by flow cytometry. For flow cytometry analysis the FACScan system (Becton Dickinson) was used. Data analysis was performed using the FlowJo software (Becton Dickinson).

\subsubsection{MTT assay}

MTT assay was used to analyze cellular growth and survival (Mosmann, 1983). $1 \times 10^{5}$ cells were plated per well in a 24 well plate and grown for 24 hours. The medium was removed and the cells were washed using sterile PBS. A stock solution of 3(4,5Dimethylthiazol-2-yl)-2,5-di-phenyltetrazolium bromide (MTT) $(5 \mathrm{mg} / \mathrm{ml})$ was diluted $1: 10$ in a cell culture medium and added to the cells for 4 hours. After 4 hours the MTT solution was removed and the cells were lysed by adding $500 \mu \mathrm{l}$ of MTT lysis buffer to each well (two parts of $5 \%$ formic acid in 2-propanol and one part of DMSO). After 5 minutes of incubation $100 \mu \mathrm{l}$ of each lysate were transferred to flat bottom 96-well plates and measured at $545 \mathrm{~nm}$ using an ELISA reader (BioRad). Each condition was analyzed in triplicates. 
2.2.3.6. Analyzing the generation time of cells using the Celigo ${ }^{\mathrm{TM}}$ instrument The generation time of uninduced MCF7 cells versus doxycycline inuduced PTK7-EGFP expression in MCF7 cells was characterized using the Celigo ${ }^{\mathrm{TM}}$ Cyntellect system (Cyntellect Europe). To obtain cell numbers within the cell culture wells this system uses label free bright field detection of cells and enables the generation of growth curves over time to calculate the doubling time of cell lines. For this purpose the cells were plated at three different concentrations in duplicates. The plates were imaged every 24 hours over a period of 72 hours. Using the cell count option of the Celigo ${ }^{\mathrm{TM}}$ instrument the growth curves and generation times were achieved (Nabzdyk et al., 2011).

\subsubsection{Scratch assay}

For the analysis of differences in migration speed between MCF7 wildtype cells and MCF7 cells after doxycycline-induced overexpression of PTK7EGFP, so-called "wound scratch assays" were carried out (Nobes and Hall, 1999; Vaughan and Trinkaus, 1966). For this purpose the cells in uninduced and doxycycline-induced conditions were plated to 12 well plates and grown to a density of $95 \%$. The cell layers were wounded by scratching the layer with a sterile yellow pipette tip. Directly after wounding images of the complete area of every well were taken by the Celigo ${ }^{\mathrm{TM}}$ instrument (Cyntellect Europe). After imaging, the cells were grown for 24 hours under standard cell culture conditions and imaged again. To measure the decrease of wound size over time, the images were analyzed using ImageJ (National Institutes of Health). On the image for the scratch at time point 0 hours the distances between the borders of the wound were measured at six different positions. The distances were also measured from the image of the same scratch 24 hours later at the identical positions. Finding of the positions was done assisted by ImageJ (National Institutes of Health). The decrease in wound size was calculated by normalizing the distances to the distance measured at time point 0 hours (Fig. 3.7. A).

\subsubsection{Boyden chamber assay}

The invasive potential of MCF7 cells was analyzed using the modified Boyden chamber assay (Albini et al., 1987; Hagemann et al., 2004). $1 \times 10^{5}$ of MCF7 cells, uninduced or doxycycline-induced, were seeded per well to the upper part of the Boyden chamber. The upper and lower compartments of the Boyden chamber were separated by a polycarbonate membrane with a pore size of $10 \mu \mathrm{m}$ that was covered with extracellular matrix proteins (ECM) (Roche). The Boyden chambers were incubated for 96 hours. Cells that reached the lower compartment during this time were counted and the 
percentages of invasion rates were calculated (Fig. 3.8. A).All Boyden chamber experiments were carried out by our collaborators in the laboratory of Claudia Binder and Tobias Pukrop at the Department for Hematology and Oncology, University Medical Center in Goettingen.

\subsubsection{Protein techniques}

\subsubsection{Preparation of protein cell lysates}

For protein analysis, cell lysates were prepared. Cells that were transfected or treated before were washed with cold TBS buffer within the culture vessel. In $0.5 \mathrm{ml}$ of cold TBS buffer the cells were mechanically detached from the surface of the culture vessel by scraping with a sterile cell scraper and transferred to a $1.5 \mathrm{ml}$ reaction tube. Cells were centrifuged for 10 minutes at low speed (3000 rpm). The supernatant was removed and the pellet was resuspended in lysis buffer. The volume was $800 \mu \mathrm{l}$ for coimmunoprecipitation samples and $100 \mu$ for analytical protein samples. The cells were lysed by homogenizing them through a $30 \mathrm{G}$ syringe. After centrifugation at high speed (13000 rpm) for 10 minutes the supernatant was transferred to a fresh reaction tube. The samples were either directly used in the co-immunoprecipitation protocol or one third of the sample volume $4 x$ Laemmli denaturation buffer was added. The samples were boiled at $95^{\circ} \mathrm{C}$ for $3 \mathrm{~min}$ for denturation and either frozen or loaded on poly acrylamide gels.

\subsubsection{Protein electrophoresis (SDS-PAGE)}

To separate denaturated proteins according to their size in an electric field the SDSpolyacrylamide-gel-electrophoresis (SDS-PAGE) was used (Laemmli, 1970). Standard protocols were used to prepare polyacrylamide gels in a concentration range from 8-12 percent. (Russel, 2001). Maximum $20 \mu$ of lysates or immuno pellets were loaded on SDS poly acrylamide gels. The BioRad Mini Protean Tetra Cell was used according to the manufacturer's instructions.

\subsubsection{Western blotting}

For the transfer of size-separated proteins from polyacrylamide (PAA) gels to nitrocellulose membranes the Western-blot method was used (Towbin and Gordon, 1984; Towbin et al., 1979; Towbin et al., 1992). The transfer process was carried out using the BioRad wet blot cell for $70 \mathrm{~min}$ at $110 \mathrm{~V}$ on ice according to the manufacturer's instructions. To saturate unspecific binding sites the nitrocellulose membranes were blocked using $5 \%(\mathrm{w} / \mathrm{v})$ milk powder in TBST buffer. Later the appropriate antibody diluted in milk buffer as indicated in (Table 2.4) was applied and incubated overnight at 4 
${ }^{\circ} \mathrm{C}$. The following day the antibody solution was removed and the membrane washed for 30 min with TBST buffer. Further the horseradish peroxidase coupled secondary antibody was given to the membrane and incubated for 1 hour at room temperature. A second washing step of 30 minutes was performed before the membrane was incubated with the chemiluminescent substrate Super Signal West Dura (Thermo Scientific) according to the protocol (Kricka and Thorpe, 1985; Thorpe and Kricka, 1986; Thorpe et al., 1985; Whitehead et al., 1979). The resulting chemiluminescent signal was detected by exposure to $\mathrm{x}$-ray films.

\subsubsection{Co-immunoprecipitation (co-IP)}

In order to identify potential interaction partners on the protein level co-immunoprecipitations were performed from either cell lysates or cell supernatants as described in Peradziryi et al. (Peradziryi et al., 2011). A total amount of $4 \mu \mathrm{g}$ DNA was transfected per well. In case of single plasmid transfection the total amount of DNA was adjusted by control plasmid. In general two wells of a 6 -well plate were identically transfected and the cells of these two wells were combined prior to cell lysis.

\subsubsection{GTPase activity assays}

The detection of activated RhoA and Rac1 in cell lysates was carried out by our collaboration partner Klaudia Giehl as previously described (Stahle et al., 2003). For this purpose we transfected MCF7 cells with PTK7-MT, PTK7 $\triangle \mathrm{k}-\mathrm{MT}$ or a control plasmid that did not result in protein expression. Forty-eight hours after transfection the samples were prepared and immediately frozen in liquid nitrogen. After shipment with dry ice the samples were analyzed at Klaudia Giehl's laboratory in Giessen.

\subsubsection{Topflash luciferase assays}

The inhibitory influence of PTK7 on canonical Wnt signaling was measured in HEK293 cells using TOPflash luciferase reporter (Korinek et al., 1997) assays as described in Peradziryi et al. (Peradziryi et al., 2011).

\subsubsection{Immunofluorescense staining and confocal microscopy}

To study the effect of protein overexpression on the morphology of MCF7 cells immunoflourescene staining was carried out. For this purpose the cells were platted on glass coverslips ( $5 \times 10^{4}$ per well) in 24 -well plates. The cells were transfected or induced and 48 hours later fixed with $4 \%$ PFA. The fixed cells were permeabilized with $0.05 \%$ $(\mathrm{w} / \mathrm{v})$ Triton X. Unspecific protein binding sites were blocked by incubation with $1 \%(\mathrm{w} / \mathrm{v})$ BSA in PBS. The appropriate primary antibodies were diluted as indicated in table 2.3. 
and applied overnight at $4^{\circ} \mathrm{C}$. After thorough washing, a secondary antibody was used, for one hour with subsequent washing. Coverslips were fixed to microscopy glass slides using Fluorescent Mounting Medium (Dako) supplemented with DAPI. Microscopy was carried out using the Laser scanning microscope LSM 510 Meta (Zeiss).

\subsubsection{Xenopus techniques}

\subsubsection{Obtaining and cultivation of embryos}

To obtain Xenopus embryos HCG (human chorion gonadotropin) stimulation of the female frog, egg collection and in vitro fertilization using testes homogenates of male frogs as well as microinjection and embryo cultivation were performed as described in the laboratory manual "Early Development of Xenopus laevis" by Sive, Grainger and Harland 2000 (Hazel L. Sive, 2000). The staging of embryo development was done according to the Nieuwkoop and Faber table (Nieuwkoop, 1991).

\subsubsection{Whole mount in situ hybridization in Xenopus laevis embryos}

To visualize the expression pattern of the twist expressing neural crest cells in microinjected Xenopus laevis tadpole embryos, whole mount in situ hybridization with a Digoxigenin labeled twist antisense RNA probe was performed according to the method description in (Harland, 1991). A detailed protocol is included in the supplement section.

\subsubsection{3. $\quad \beta$-gal staining for lineage tracing}

For lineage tracing of the injected side of Xenopus embryos, mRNA of the $\beta$ galactosidase gene was co-injected together with mRNA or morpholinos. The Bgalactosidase activity was visualized by staining using $X$-gal as substrate. The staining was carried out as described in chapter 9 of the laboratory manual "Early Development" of Xenopus laevis" by Sive, Grainger and Harland 2000 (Hazel L. Sive, 2000). It resulted in a blue stain covering the half of the embryo, which was injected at two-cell stage. 


\section{Results}

\subsection{PTK7 phenotypes in human cell lines}

\subsubsection{PTK7 overexpression increases cell protrusions}

In order to examine the function of PTK7 in cancer cells we used transient transfections to overexpress PTK7 in the non-invasive breast cancer cell line MCF7. Upon overexpression of the tagged full-length PTK7 protein the MCF7 cells showed a remarkable change in morphology. Immunostaining against the myc-tag and f-actin followed by laser scanning microscopy revealed that cells, which overexpress PTK7 displayed a highly increased number of cell protrusions compared to mock transfected cells. (Fig. 3.1. A-C). Quantification of the percentages of cells showing the indicated amounts of filopodia illustrates the significant increase in cell protrusions (Fig. 3.1. D). While $95 \%$ of the mock transfected cells showed $0-5$ filopodia per cell, $45 \%$ of cells expressing PTK7 showed more than 10 protrusions per cell and $25 \%$ showed $6-10$ filopodia per cell. The same phenotype was detected after PTK7 overexpression in HEK 293 cells as well as in the highly invasive breast cancer cell line MDA MB 231 (data not shown). These data indicate that PTK7 might be involved in processes, which drive actin cytoskeleton remodeling and migration. 


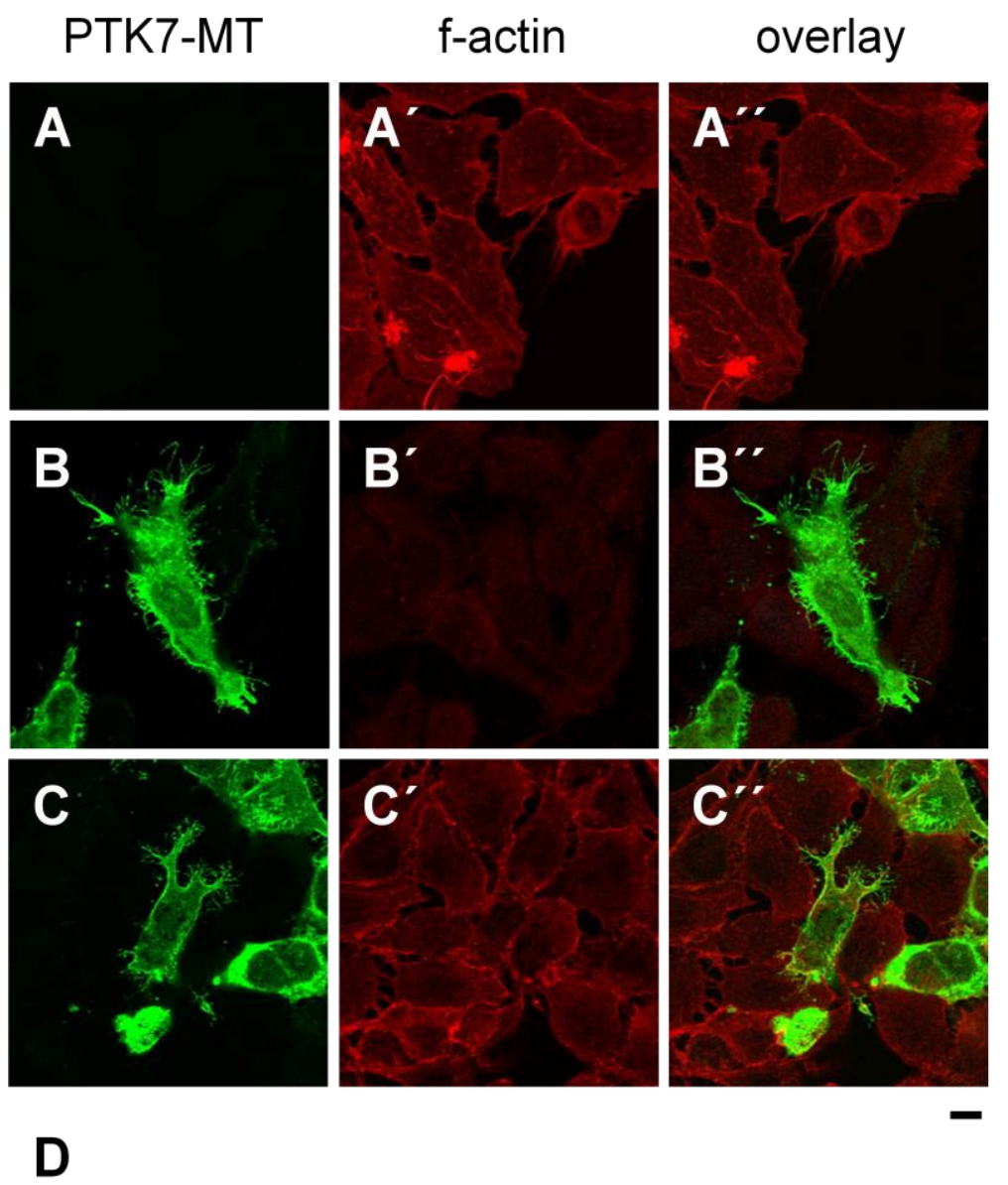

$\%$ filopodia formation

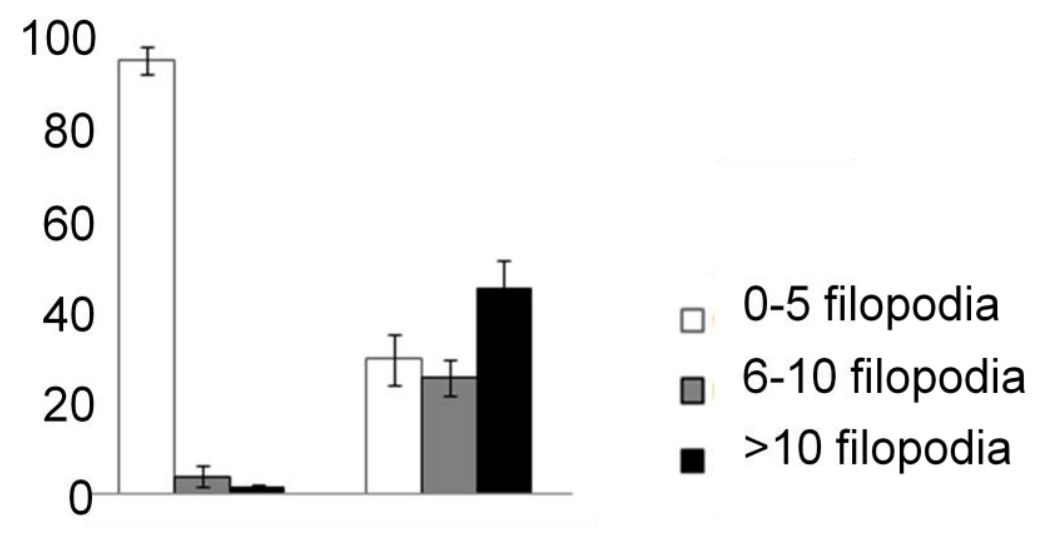

Figure 3.1. PTK7 overexpression increases number of cell protrusions (A-C). Images from laser scanning microscopy after (A) mock transfection, or (B, C) PTK7-MT transfection. Immunostaining was performed using (A-C) anti-myc antibodies and ( $\left.\mathbf{A}^{\prime} \mathbf{-} \mathbf{C}^{\prime}\right)$ f-actin staining using Cy3phalloidin. (A'-C') Overlay of PTK7-MT and actin. Scale bar $10 \mu \mathrm{m}$. (D) Quantification of filopodia formation. Percentages of cells showing the indicated number of filopodia per cell were calculated. Graph summarizes the results of three independent experiments $(n>150)$, standard errors of the mean are given. 


\subsubsection{Stable overexpression of PTK7}

To study the contribution of PTK7 to cell migration in the context of cancer cells, functional studies, such as migration assays, are required. Using transiently transfected cells, the numbers of efficiently transfected cells are too low to perform functional assays. Therefore, a stable transfection of MCF7 cells was performed. First, an expression construct for the stable expression of a PTK7-EGFP fusion protein was created using the pEGFP N1 plasmid (Clonetech) and introducing the coding sequence of human PTK7 in frame with the coding sequence of GFP into the restriction sites Clal and EcoRI of the plasmid (Fig. 3.2. A). This plasmid drives the expression of the GFP fusion protein under the immediate early promoter of CMV. A second promoter, the SV40 early promoter, regulates the Neomycin resistance. Clones of MCF7 cells, with stable integration of the expression plasmid into their DNA, could be selected with the help of the Neomycin resistance. Protein lysates of GFP positive clones were prepared and Western blotting was performed to detect the PTK7-EGFP fusion protein using anti-GFP antibodies (Fig. 3.2. B). Morphological analysis revealed a filopodia phenotype as previously seen (Fig.3. 2. $C-E)$.

In order to determine the expression level of PTK7-EGFP in these cells, flow cytometry analysis was performed (Fig. 3). To set up the system and the conditions for measurement, MCF7 wild type cells were used (Fig 3.3. A). MCF7 cells that stably express EGFP (Fig. 3.3. B) were compared to the PTK7-EGFP expressing cells (Fig. 3.3C). PTK7 expression was verified by the detection of EGFP fluorescence from the PTK7-EGFP fusion protein as well as of anti-PTK7 staining (anti CCK4 PE, Miltenyi). Wildtype MCF7 cells showed a positive staining for the endogenous PTK7 with the antiCCK4 antibody (Fig. 3.3. A). MCF7 EGFP cells showed staining of GFP and the endogenous PTK7 (Fig. 3.3. B). Staining of MCF7 PTK7-EGFP cells showed a strong correlation between the signals for EGFP and PTK7 (Fig. 3.3. C), indicating that every cell, which is positive for GFP is also positive for PTK7. For the comparison of expression levels between wild type MCF7 and stable transfected MCF7 PTK7-EGFP cells a histogram was used (Fig. 3.3. D), showing that the difference in expression levels between wild type and overexpression conditions is unexpectedly low. These findings allow reasonable doubt as to whether these cells are the right tool to study overexpression phenotypes in functional assays. 

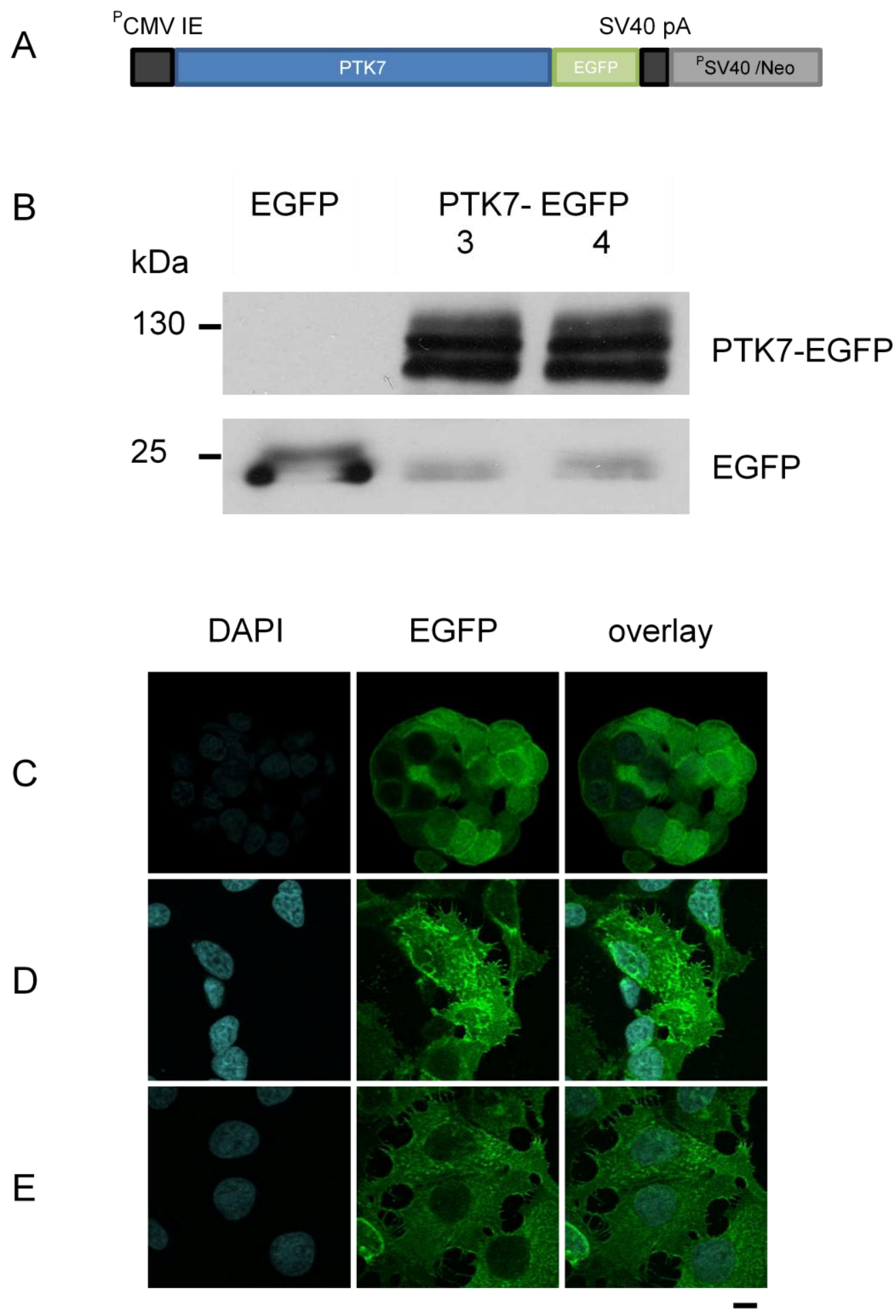

Figure 3.2. Stable overexpression of PTK7-EGFP in MCF7 cells. (A) Schematic view of the pEGFPN1 expression plasmid used for stable expression of PTK7-EGFP. A PCR fragment of the full-length PTK7 was inserted into the multiple cloning site of the vector using the Clal and EcoRI sites. The expression of the EGFP fusion protein is under the control of the CMV immediate early promoter while the expression of the Neomycin resistance is regulated by a second promoter SV40. (B) Cell lysates of MCF7 cells, stably expressing EGFP alone and two different clones expressing PTK7-EGFP, analyzed for the expression of PTK7-EGFP (upper panel) and EGFP (lower panel) using Western blot. (C)The cytoplasm of MCF7 cells is stained for GFP when cells 
express EGFP (D, E), whereas membrane staining is present in the case that cells express PTK7EGFP. Additionally these cells show filopodia-like cell protrusions. Scale bar: $10 \mu \mathrm{m}$.

A

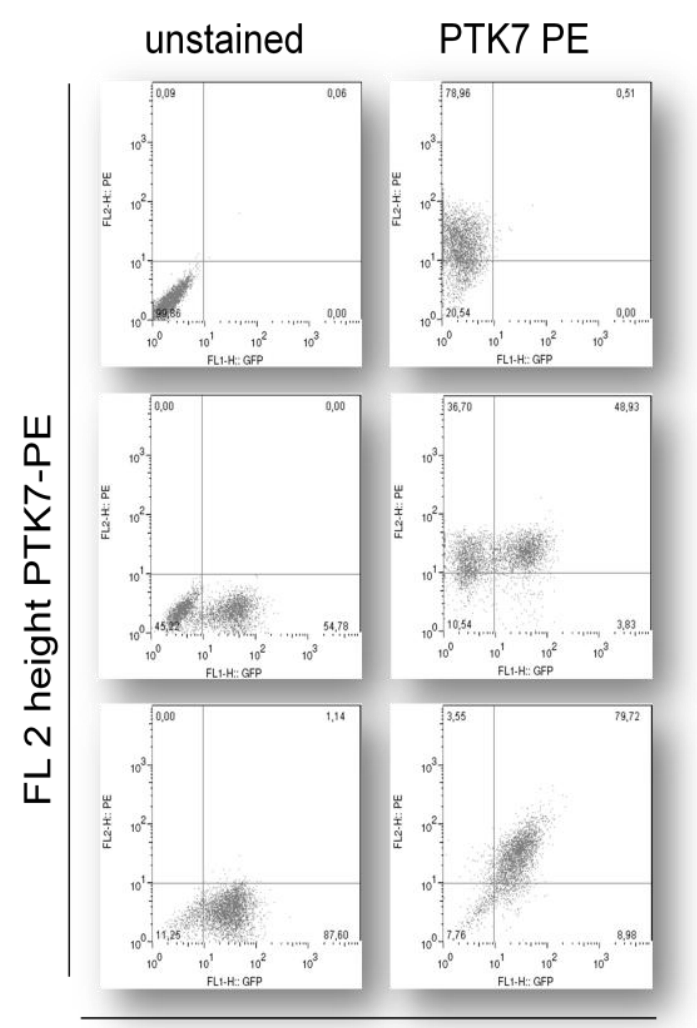

FL 1 height GFP
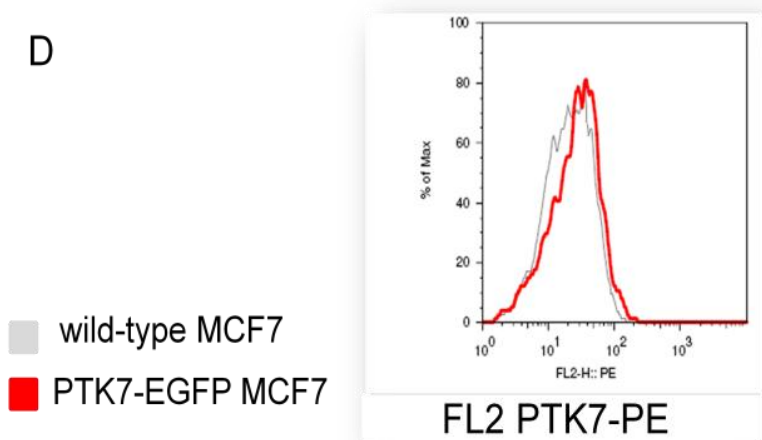

Figure 3.3. Flow cytometry analysis of PTK7-EGFP expressing MCF7 cells. MCF7 cells were analyzed for their expression of GFP and PTK7. (A) Wildtype MCF7 cells were measured without staining (left panel). Cells are completely unstained. All signals appear in the lower left compartment of the plot. After PTK7 staining using an anti-CCK4 PE antibody (right panel), cells are partially negative for the expression of PTK7 (lower left compartment) and partially express PTK7 (upper left compartment). (B) MCF7 EGFP expressing cells were measured without staining (left panel). Cells are partially negative for GFP (lower left compartment) and partially positive for GFP fluorescence (lower right compartment). After PTK7 staining (right panel). Most of the cells express PTK7 (upper left and right compartment) and a distinct amount of cells express PTK7 also express GFP (upper right compartment). (C) MCF7 cells, which stably express PTK7-EGFP appear in their unstained condition (left panel) to $87 \%$ in the lower right compartment, which 
means that they express GFP. Stained for PTK7 (right panel), $80 \%$ of the cells are positive for both PTK7 and GFP (upper right compartment). (D) A histogram plot compares the intensity of the PTK7 signal for MCF7 wildtype cells versus MCF7 cells overexpressing PTK7-EGFP.

\subsubsection{Inducible overexpression of PTK7}

To optimize the conditions to gain high overexpression levels of PTK7 in MCF7 cells, a tetracycline-inducible expression system was used. For the inducible expression of a protein, two plasmids need to be stably integrated into the cells (Fig. 3.4. A). The first plasmid is the regulatory plasmid pcDNA ${ }^{\mathrm{TM}} 6 / \mathrm{TR}$ (Invitrogen), which expresses high levels of the tetracycline repressor under the control of the human cytomegalovirus immediate early promoter (CMV). The stable expression of the tetracycline repressor is selected using blasticidin. (Hillen and Berens, 1994; Hillen et al., 1983). The second plasmid, an expression plasmid pcDNA ${ }^{\mathrm{TM}} 5 / \mathrm{TO}$ (Invitrogen) to express the gene of interest under the control of the CMV promoter (CMV IE) and two copies of the tetracycline operator 2 site $\left(\mathrm{TetO}_{2}\right)$. Tetracycline regulated expression is based on the binding of tetracycline to the tetracycline repressor and thereby derepression of the promoter, controlling the expression of the gene of interest (Yao et al., 1998). First, MCF7 cells were transfected with the pcDNA ${ }^{\mathrm{TM}} 6 / \mathrm{TR}$ plasmid and clones with stable expression of the plasmid were selected using blasticidin. Clones of cells expressing the tetracycline repressor were tested for their inducibility using co-transfection of the reporter plasmid pcDNA ${ }^{\mathrm{TM}}$ 4/TO firefly luciferase. Clones with no luciferase activation in the absence of tetracycline and a medium to high luciferase activation under tetracycline treatment were selected. For the tetracycline-inducible overexpression of PTK7 the open reading frame of human PTK7 was fused with EGFP and integrated in frame into the multiple cloning site of the pcDNA $^{\mathrm{TM}} 5 / \mathrm{TO}$ plasmid using the EcoRV and Not I restriction sites. After transfection of the pcDNA ${ }^{\mathrm{TM}}$ 5/TO PTK7-EGFP into MCF7 cells already containing the pcDNA ${ }^{\mathrm{TM}} 6 / \mathrm{TR}$ plasmid, the cells were selected using blasticidin and hygromycin. Clones of cells that were able to grow in medium containing both antibiotics (blasticin and hygromycin) are supposed to have stably integrated both plasmids and were tested for the expression of EGFP and PTK7 with and without tetracycline induction.

Time courses were performed to test the expression of PTK7-EGFP in culture conditions with and without tetracycline. During this study doxycycline was used to induce PTK7EGFP expression because of its higher stability and easier application. Cells were cultivated for 24,48 and 72 hours under non-inducing or inducing conditions $(+/-1 \mu \mathrm{g} / \mathrm{ml}$ doxycycline). After the indicated time periods protein lysates were prepared and analyzed 
by Western blotting using antibodies against PTK7, GFP or actin (Fig. 3.4. B). Without doxycycline induction cells show no PTK7-EGFP expression, but do show low levels of endogenous PTK7 expression. After doxycycline induction the cells show increasing amounts of PTK7 EGFP expression with time.

Immunofluorescence staining for GFP, visualized by laser scanning microscopy, exhibited the expression of PTK7-EGFP at the membrane and a similar filopodia phenotype as seen before after transient overexpression of PTK7 (Fig.3.4. C). Quantification of the phenotype after PTK7-EGFP induction represents the same tendency but with less strength (Fig.3.5.). 
A

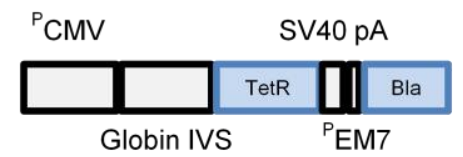

${ }^{\mathrm{P}} \mathrm{CMV} 2 \mathrm{x} \mathrm{TetO}_{2}$

BGH pA

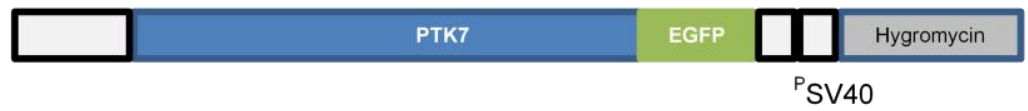

B

$\begin{array}{lllllll}\text { Doxycycline } & - & - & - & + & + & + \\ \text { time }(\mathrm{h}) & 24 & 48 & 72 & 24 & 48 & 72\end{array}$

C
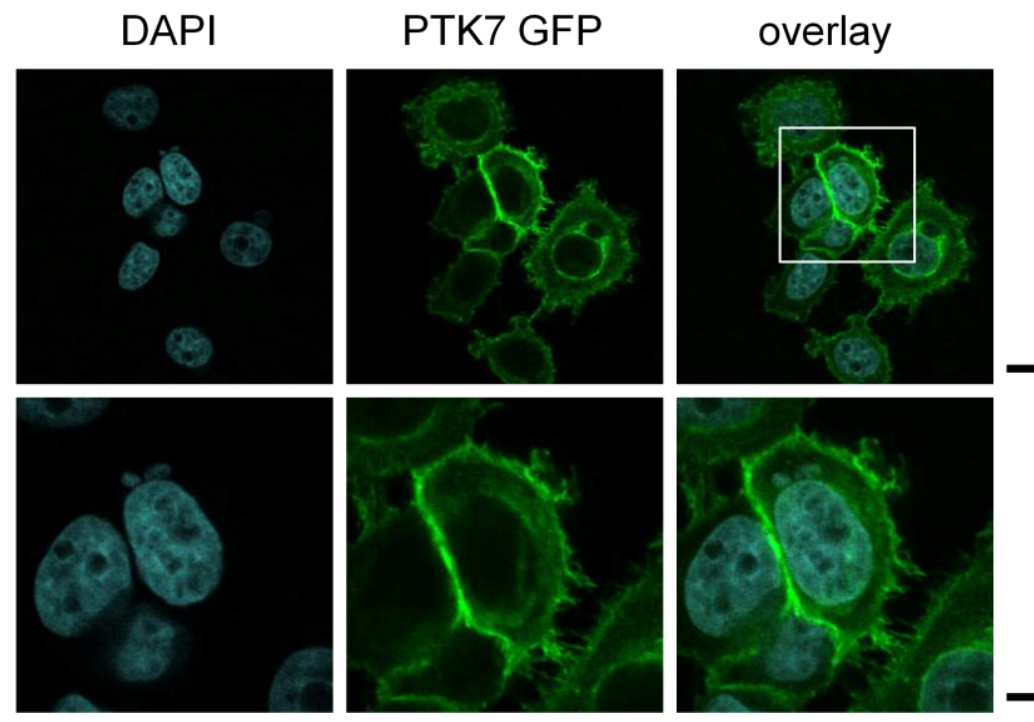

Figure 3.4. Inducible expression of PTK7. (A) Schematic view of the constructs used for tetracycline/doxycycline inducible gene expression in mammalian cell lines. Upper: pcDNA ${ }^{\mathrm{TM}} 6 \mathrm{~T} / \mathrm{R}$, regulatory plasmid to express the tetracycline repressor under the control of the CMV promoter, whereas blasticidin resistance is expressed from the same plasmid under control of the EM-7 promoter. PCMV: CMV promoter, Globin IVS: Rabbit $\beta$-globin intron II, TetR: tetracycline repressor gene, SV40 pA: SV40 early polyadenylation sequence, pEM7: EM-7 promoter, Bla: Blasticidin resistance gene. Lower: pcDNA ${ }^{\mathrm{TM}} 5 \mathrm{~T} / \mathrm{O}$ expression plasmid. The coding sequence of PTK7GFP was PCR amplified and introduced into the multiple cloning site of the vector using 
EcoRV and Notl sites. The expression is under control of the CMV immediate early promoter and two copies of the tetracycline operator. $\mathrm{pCMV} 2 \mathrm{xTetO}_{2}$ : Cytomegalovirus immediate early promoter and two tetracycline operator sites, BGH pA: bovine growth hormone polyadenylation signal, pSV40: SV40 promoter, Hygromycin resistance gene. (B) Time course of MCF7 cell culture +/Doxycycline over 72 hours. Every 24 hours, cell lysates were prepared from uninduced and induced cells. The lysates were analyzed for PTK7-EGFP expression by Western blotting using anti-PTK7, anti-GFP and anti-actin antibodies. (C) Doxycycline-induced cells were fixed and stained with DAPI and anti-GFP antibody. The lower panel shows a higher magnification of the cell indicated within the square. Scale bars: $10 \mu \mathrm{m}$.

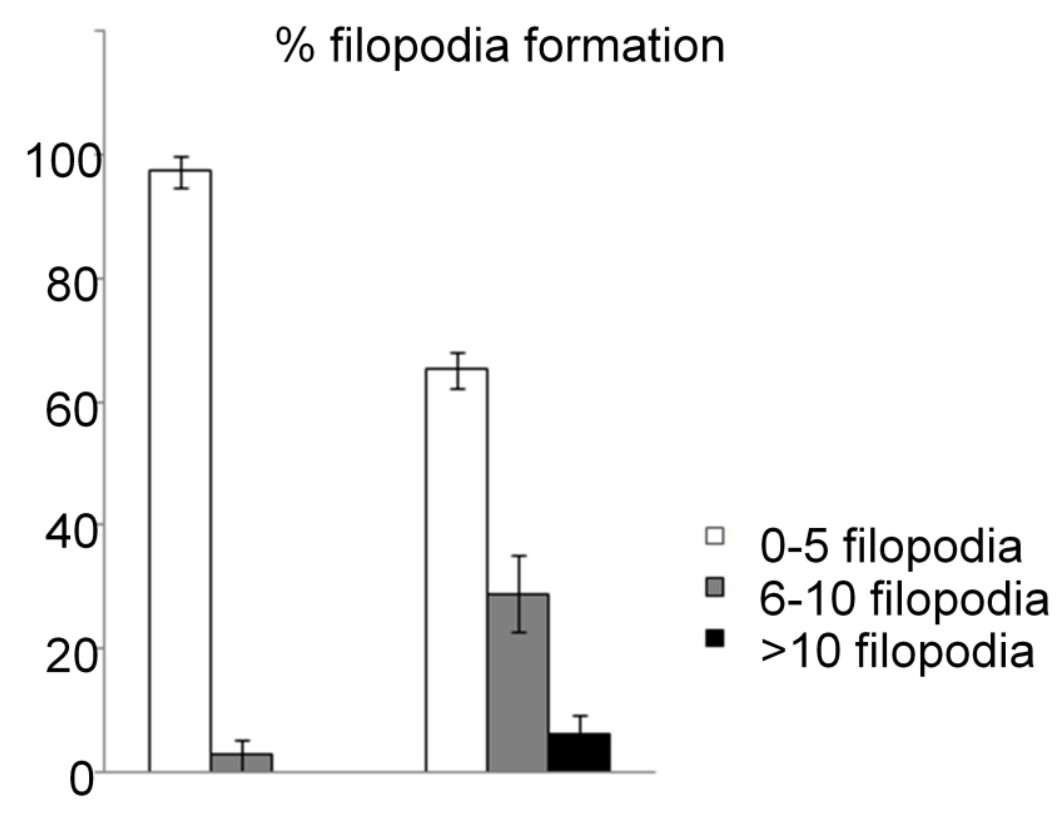

Figure 3.5. Doxycycline induction of PTK7GFP in MCF7 cells results in filopodia formation. Graph summarizes the percentages of cells showing the indicated numbers of filopodia of three independent experiments $(n>250)$. Standard errors of the mean are shown.

\subsubsection{PTK7 overexpression did not increase proliferation}

After obtaining two different cell lines, which stably overexpress PTK7 in a constitutive or inducible way, it was necessary to see whether PTK7 is responsible for increased or reduced cell proliferation. Therefore, two different tests were performed. The constitutive MCF7 PTK-EGFP cells were tested in MTT assays to measure differences in metabolism. In these experiments no difference in metabolism between MCF7 EGFP and MCF7 PTK7-EGFP was detectable (Fig. 3.6. A). The inducible MCF7 PTK7-EGFP cells were analyzed using the Celigo ${ }^{\mathrm{TM}}$ Cyntellect system. This system uses label free bright field detection of cell numbers within cell culture wells and allows the generation of growth curves over time to calculate the doubling time of cell lines. The doubling times of 
uninduced MCF7 cells did not differ from PTK7 induced cells (Fig. 3.6. B). These results allow the conclusion that the overexpression of PTK7 in MCF7 cells does not influence proliferation rates.

A

cell viability $\%$

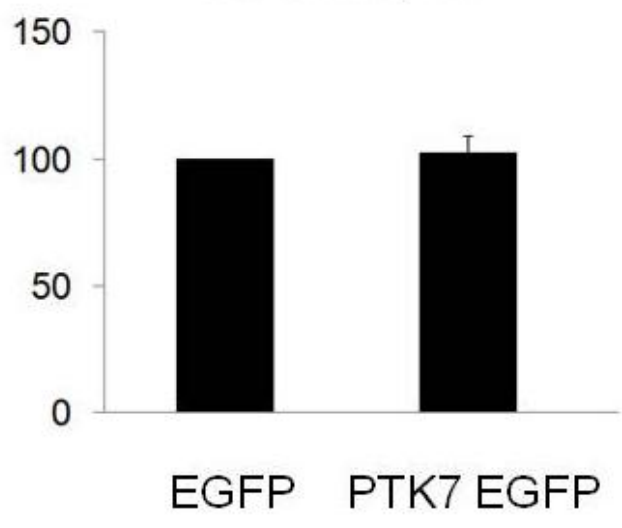

$B$

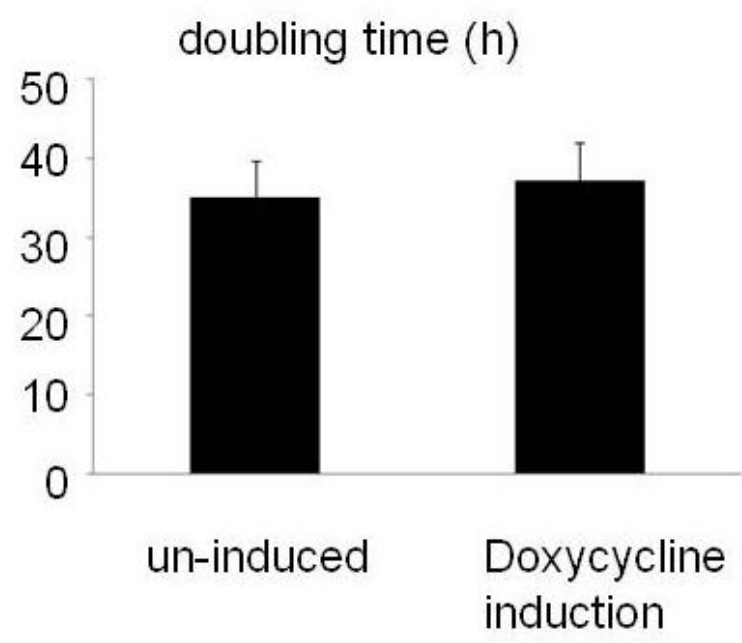

Figure 3.6. PTK7 overexpression does not influence cell proliferation. (A) Graph summarizes percentages of cell viability in MTT assays of three independent experiments. To compare cell viability of EGFP expressing with PTK7-EGFP expressing MCF7 cells, cell viability was normalized to cell viability of EGFP expressing cells, standard errors of the mean are given. (B) Doubling time analysis was carried out using the Celigo ${ }^{\mathrm{TM}}$ system. Graph summarizes the doubling time (h) of tetracycline-inducible PTK7-EGFP expression in MCF7 cells with and without doxycycline induction in three independent experiments. Standard errors of the mean are indicated. 


\subsubsection{PTK7 overexpression does not promote MCF7 migration in scratch assays}

In order to test the hypothesis that high levels of PTK7 expression increase the ability of cells to migrate, scratch assays were conducted. For this purpose the doxycyclineinducible MCF7 cells were grown at a high density and one group was doxycycline induced for 48 hours before a wounding of the cell layer was carried out. Images of the total areas of the well plate were taken at time points 0 hours and 24 hours after wounding using the Celigo ${ }^{\mathrm{TM}}$ system. To analyze the resulting images, measuring of the distances between the wound borders were performed at distinct sites of the wound and compared to the distance of exactly the same position of the sample 24 hours later (Fig. 3.7. A-C). Averages of 6 sites per condition were determined. The decrease of wound size was normalized to the wound size at time point 0 hours. A comparison of PTK7wildtype versus PTK7-overexpression conditions resulted in no difference in respect to wound healing abilities (Fig. 3.7. D). This finding implies that higher levels of PTK7 expression cannot provoke an increase of the migration speed in the breast cancer cell line MCF7. 
A
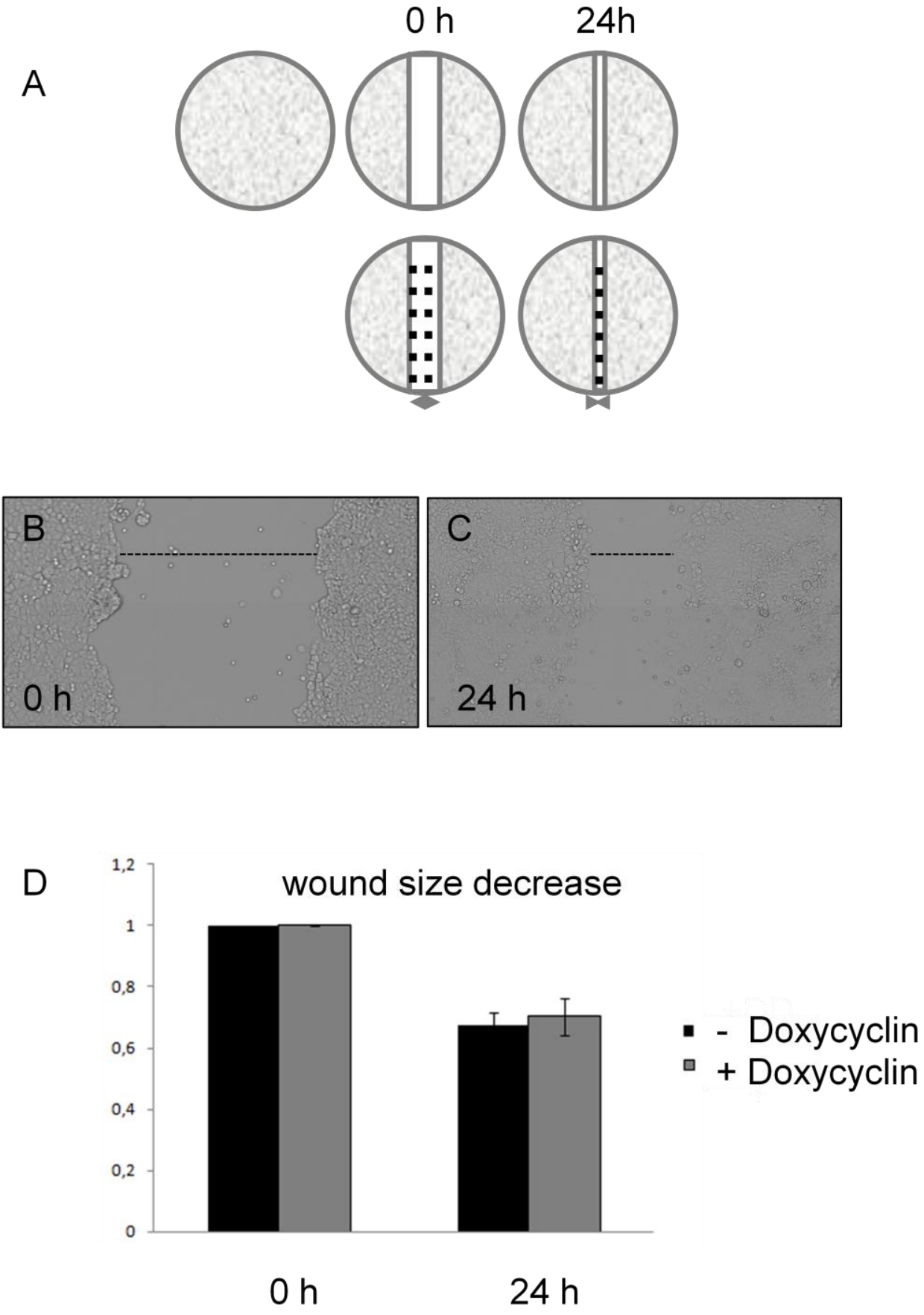

Figure 3.7. PTK7 overexpression in MCF7 cells does not increase the speed of migration in scratch assays. (A) Schematic view of the assay design. MCF7 cells with and without doxycycline induction were grown to a high confluency 48 hours prior to the wounding. At time point 0 hours, the cell layer was scratched and the first images were taken using the Celigo ${ }^{\mathrm{TM}}$ system. Cells were further grown for 24 hours and again images were taken. In the lower part of the scheme the method of analyzing the scratch assay is indicated. The distances between the borders of the wound were measured using Image $J$ at 6 positions distributed over the length of the scratch for time point 0 hours after wounding and at exactly the same positions 24 hours after wounding. (B, C) Show a representative detail of a scratch at 0 hours after wounding (B) and the same position 24 hours later (C). (D) Graph summarizes the decrease of wound size from three independent experiments. The wound size decrease was calculated by normalizing the distances 
for every measuring point to the distances of this point at 0 hours after wounding. Standard errors of the mean are indicated.

\subsubsection{PTK7 overexpression improves invasiveness of MCF7 cells}

PTK7 has been described to be overexpressed in more invasive cell lines (Mossie et al., 1995).The question of whether PTK7 can increase invasiveness of MCF7 cells still remains open. To clarify this aspect of PTK7's role in tumor progression, inducible MCF7 PTK7-EGFP cells were used to measure invasiveness using modified Boyden chambers. MCF7 cells, either induced by doxycycline or uninduced, were seeded to the upper compartment of Boyden chambers. The two compartments of the chambers were separated by an ECM covered polycarbonate membrane with a pore size of $10 \mu \mathrm{m}$ (Fig. 3.8. A). No gradient of chemoattractants was applied. Boyden Chambers were cultivated for 96 hours under cell culture conditions and analyzed for the number of cells that reached the lower compartment. As a positive control, wildtype MCF7 cells were stimulated with recombinant Wnt5a protein to induce invasion ability (Pukrop et al., 2006). The percentages of invasion rates were normalized to the un-stimulated MCF7 cells. Compared to wildtype, stimulation with recombinant Wnt5a protein increased the invasion rates of MCF7 cells by 2.5 fold. The same increase was achieved with induced PTK7 overexpression. When overexpression of PTK7 and Wnt5a stimulation were combined, the invasiveness reached an increase by 3.4 fold (Fig. 3.8. B). This highly significant outcome shows that overexpression of PTK7 is sufficient to enhance the ability of MCF7 cells to invade extracellular matrices in vitro. 
A

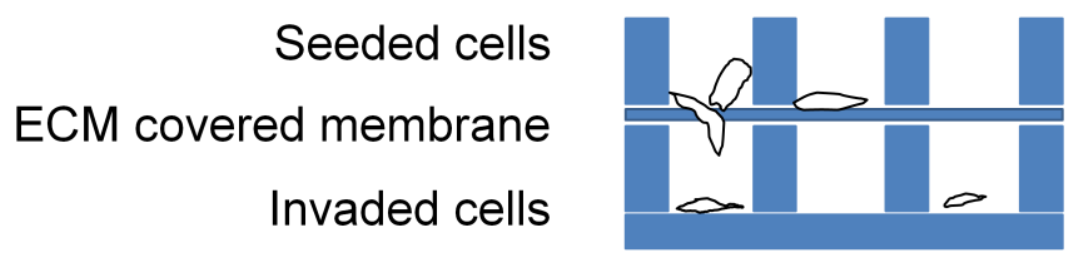

B

$\%$ Invasion rate

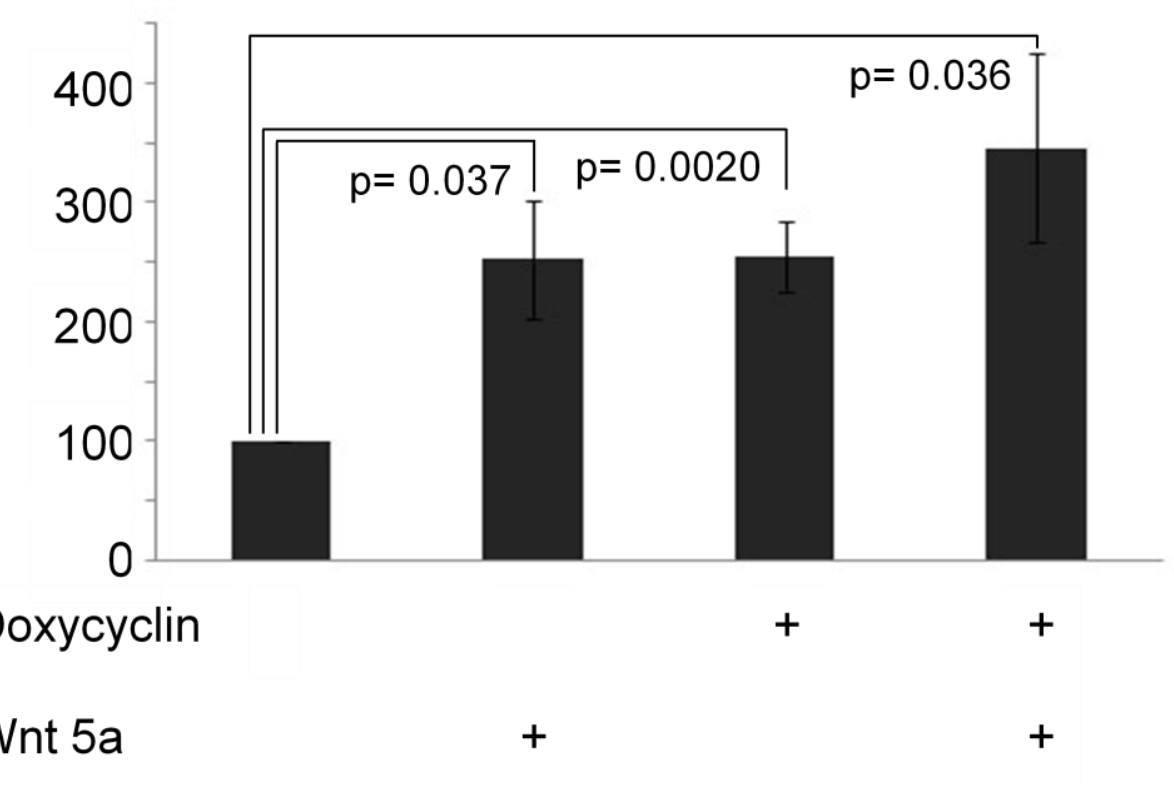

Figure 3.8. PTK7 overexpression in MCF7 cells doubles their invasiveness in Boyden chamber assays. (A) Schematic view of the modified Boyden chamber assay. The modified Boyden chamber is a cell culture system with upper and lower compartments, which are separated from each other by an ECM-covered polycarbonate membrane with a pore size of 10 $\mu \mathrm{m}$. The cells to be tested for their invasive behavior were seeded to the upper wells with a cell number of $10^{5}$ cells per well. During the incubation time of 96 hours the cells have the chance to invade into the lower compartment, which contains the same culture medium as the upper well. After 96 hours of incubation, the numbers of cells that reached the lower well were counted. (B) Graph summarizes the percentages of invasion rates of three independent experiments. Invasion rates are normalized to the invasion rate of uninduced, untreated MCF7 cells. P-values were calculated in a Student's T-test, given are the standard errors of the mean. 


\subsection{Signaling mechanisms}

\subsubsection{PTK7 is a Wnt co-receptor}

PTK7 is a PCP regulator (Lu et al., 2004). It is a member of a Fz-Dsh complex, required to recruit Dsh to the plasma membrane (Shnitsar and Borchers, 2008) and interacts with Wnt proteins (Peradziryi et al., 2011). All of this data was gained in the Xenopus system; therefore it was an important part of the present work to determine if the described properties of PTK7 are conserved in the mammalian system. To address this matter human cell lines were used. First, a possible interaction of the secreted extracellular domain of PTK7 and recombinant Wnt3a was tested in co-immunoprecipitation assays. Direct interaction of extracellular PTK7 with Wnt3a could not be detected. As a positive control, the known interaction partners secreted Frizzled Related Protein 5 (sFRP5) and Wnt3a were used (Fig 3.9.). Based on our knowledge of the presence of a PTK7-Fz-dsh complex we asked whether Fz could also be involved in Wnt3a binding to PTK7. Therefore, HEK293 cells were transfected with full-length as well as a $\Delta$ kinase domain mutant of PTK7 together with Fz7. Co-IPs revealed that, indeed, PTK7 and Fz7 bind to each other. This is also the case for the $\Delta$ kinase mutant of PTK7 and Fz7, indicating that this interaction is independent of Dsh because the kinase domain of PTK7 is required for Dsh recruitment (Fig. 3.10.). To examine the involvement of Fz7 in the PTK7-Wnt3a interaction, a special co-IP setup was designed. HEK293 cells were transfected with constructs that allow the secretion of either the PTK7 extracellular domain or the Fz7 extracellular domain to the cell culture medium. Supernatants of these cells were mixed in the presence or absence of Wnt3a recombinant protein. The fact that PTK7 could coprecipitate Wnt3a only in the presence of Fz7, while Fz7 could co-precipitate Wnt3a on its own, clearly shows that PTK7 requires Fz for Wnt binding (Fig.3.11.). 


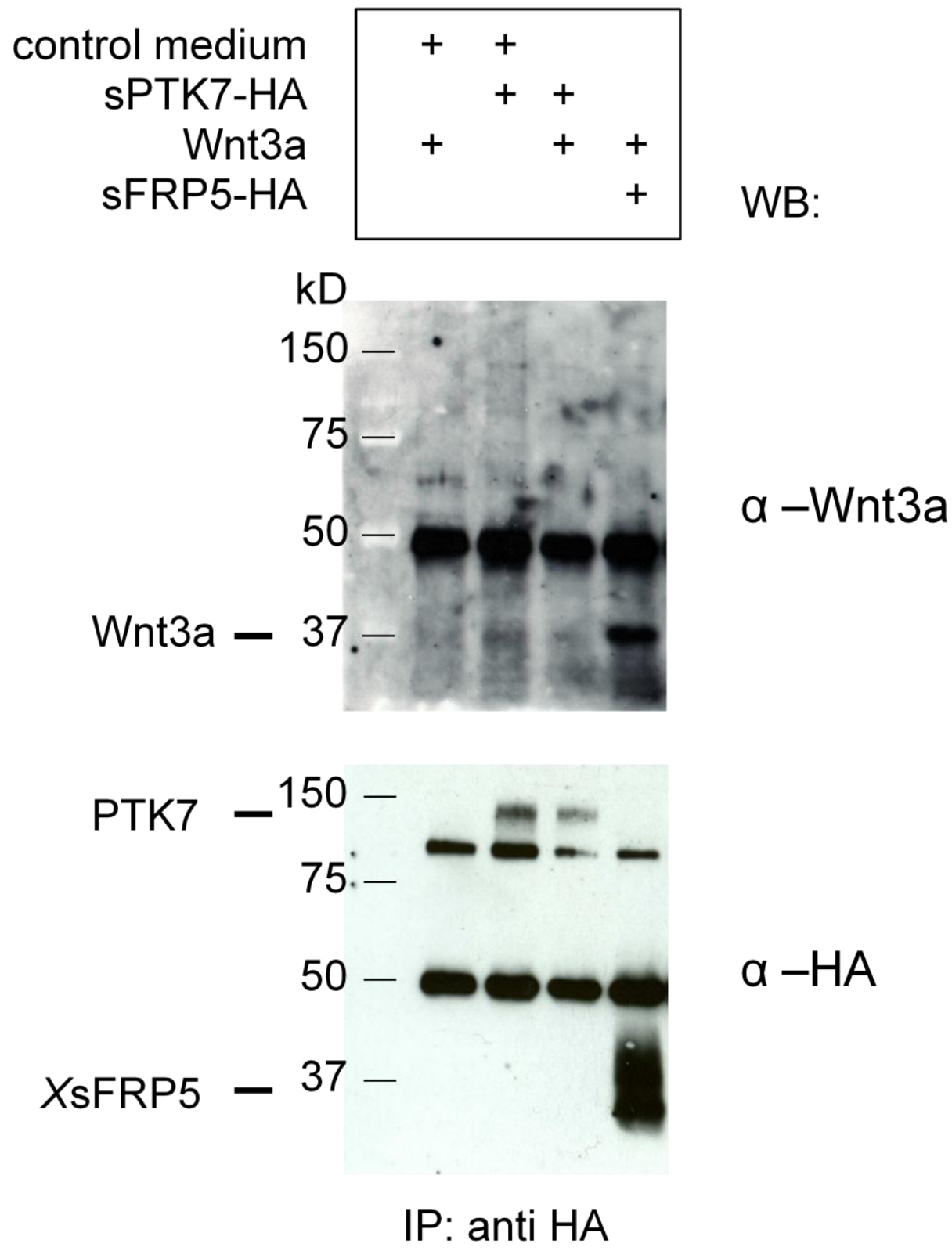

Figure 3.9. PTK7 and Wnt3a do not interact directly. Co-immunoprecipitation assay using supernatants form HEK293 cells that were either transfected with the empty pCS2+ vector (control medium), sPTK7-HA or sFRP5-HA and recombinant Wnt3a protein. The supernatants and Wnt3a were mixed as indicated at the top. Immunoprecipitation was performed using anti-HA antibodies. Precipitates were analyzed using Western blot. Western blot was probed with anti-Wnt3a antibodies (upper panel) or anti-HA antibodies (lower panel). On the left side the protein sizes are indicated and the individual protein bands are marked. 


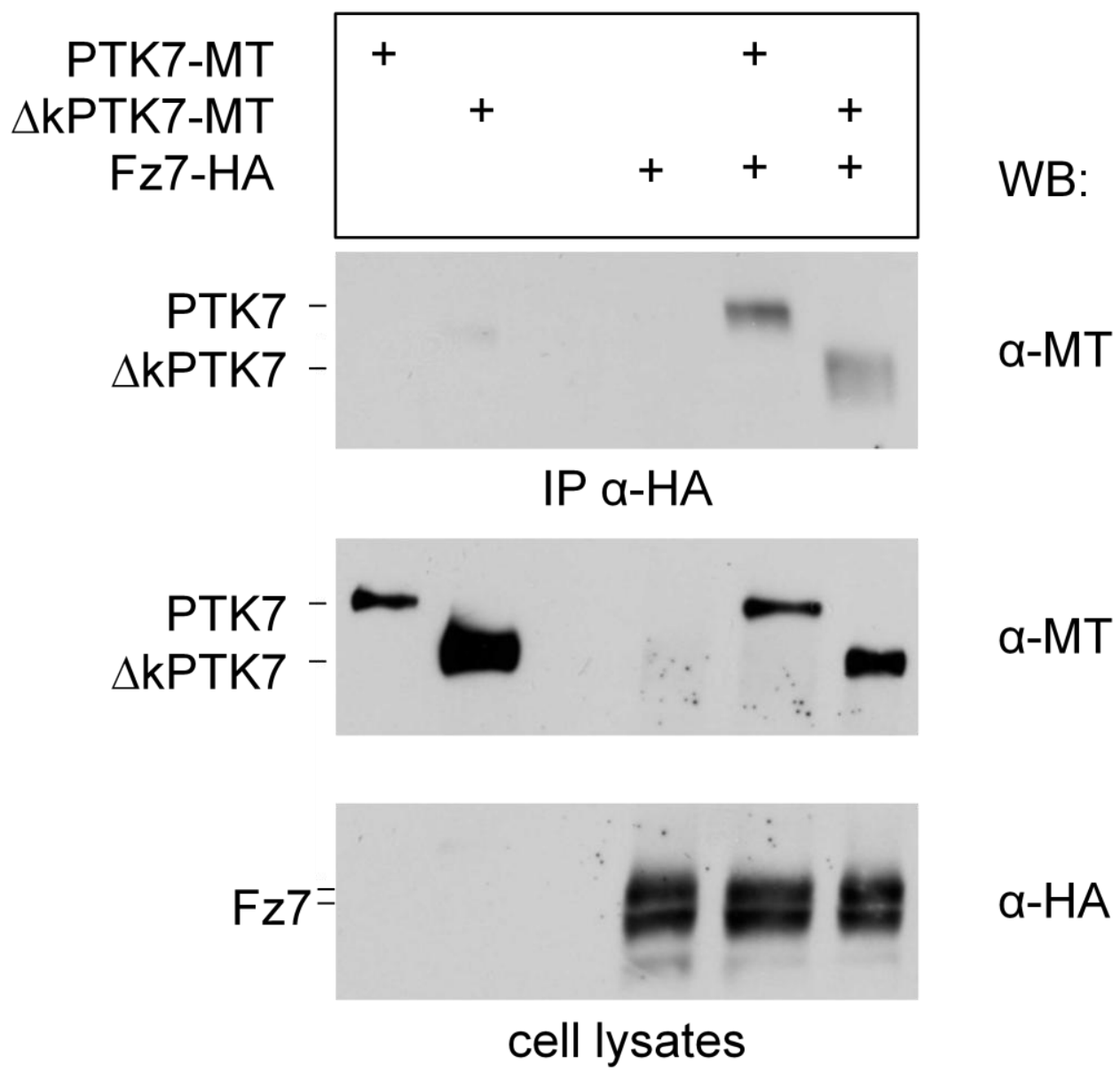

Figure 3.10. PTK7 and Fz7 directly interact. Co-immunoprecipitation assay that shows an interaction of myc-tagged PTK7 or $\triangle \mathrm{k}$ PTK7 by the immunoprecipitation of HA-tagged Fz7. HEK 293 cells were transfected as indicated in the top panel. Immunoprecipitation was performed using anti-HA antibody, antibodies used for detection in Western blotting are indicated on the right. Labels on the left map the different protein sizes. 


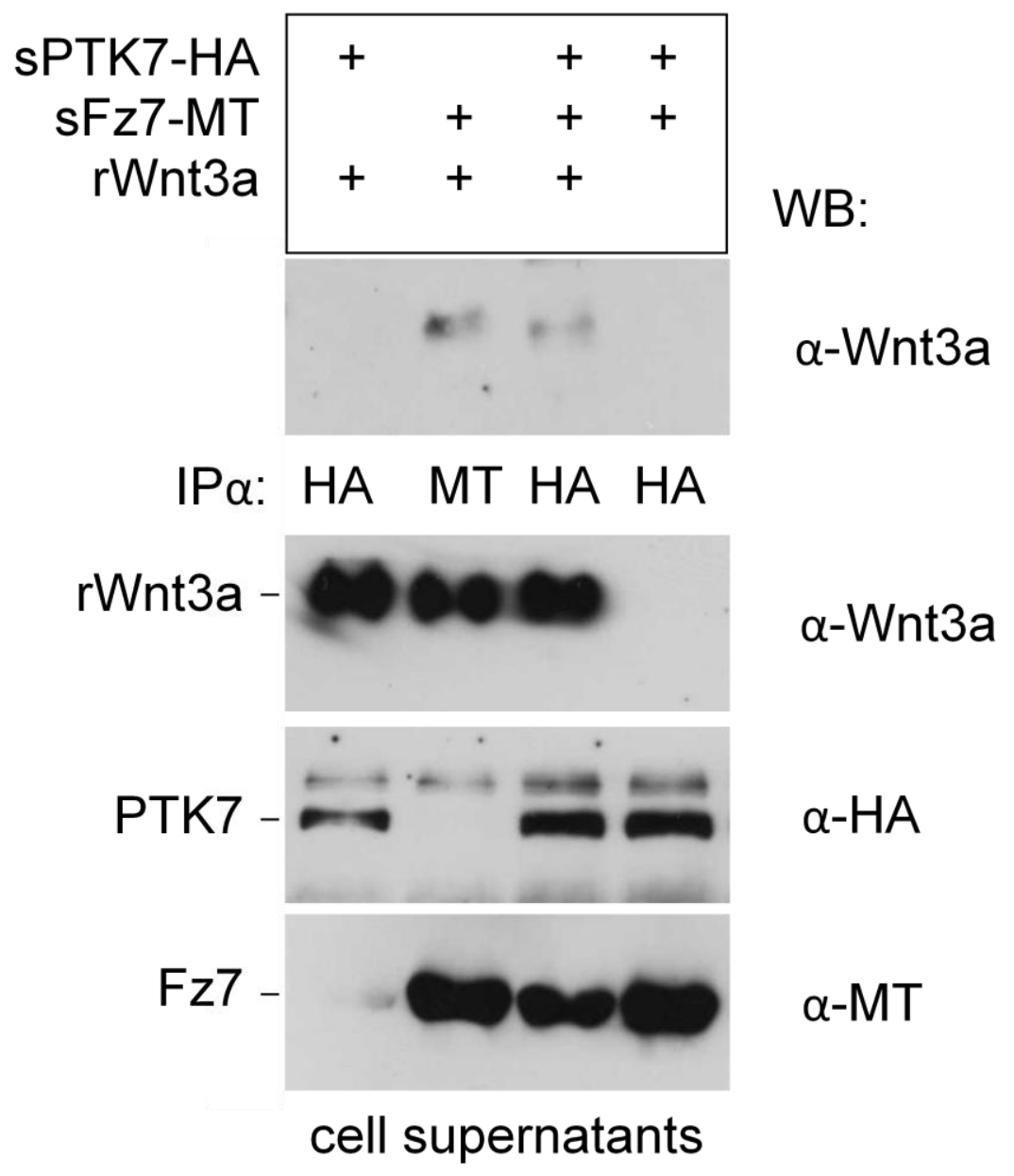

Figure 3.11. PTK7 and Fz7 form a receptor complex that is required for binding Wnt. Coimmunoprecipitation assays shows an interaction of Wnt3a protein with PTK7 only in the presence of Fz7. Immunoprecipitation was performed using cell culture supernatants from cells overexpressing either secreted HA-tagged PTK7 or secreted myc-tagged Fz7 in combination with recombinant human Wnt3a as indicated at the top. For immunoprecipitation of PTK7 anti-HA antibodies were used, and for immunoprecipitation of $\mathrm{Fz} 7$ anti-myc antibodies were used. The antibodies used for Western blotting are indicated at the right and the labels at the left indicate the individual proteins.

\subsubsection{PTK7 inhibits canonical Wnt signaling}

Since we found an interaction of PTK7 with Wnt3a, which is a ligand acting in the $\beta$ catenin dependent Wnt signaling, and PTK7 activity so far was only known to be involved in $\beta$-catenin independent PCP signaling, we asked whether PTK7 can modify $\beta$-catenin dependent Wnt signaling. In Xenopus embryos activation of $\beta$-catenin dependent Wnt signaling can easily be monitored by induction of a secondary body axis. Surprisingly, PTK7 could inhibit Wnt8 induced second axes in embryos. This was confirmed using 
whole embryo lysates in luciferase reporter analysis measuring the activation of $\beta$ catenin-dependent gene transcription (Peradziryi et al., 2011). In the human cell line HEK293 a similar experiment was carried out using externally supplied Wnt3a recombinant protein. Indeed, in this experimental design the expression of PTK7 as well as the $\Delta$ kinase mutant of PTK7 caused the inhibition of Wnt3a induced reporter activation (Fig. 3.12.). This data shows that, firstly, the mechanism of PTK7 to inhibit canonical Wnt signaling is conserved in human cells and, secondly, the effect occurs in the responding cells due to externally supplied Wnt3a protein.

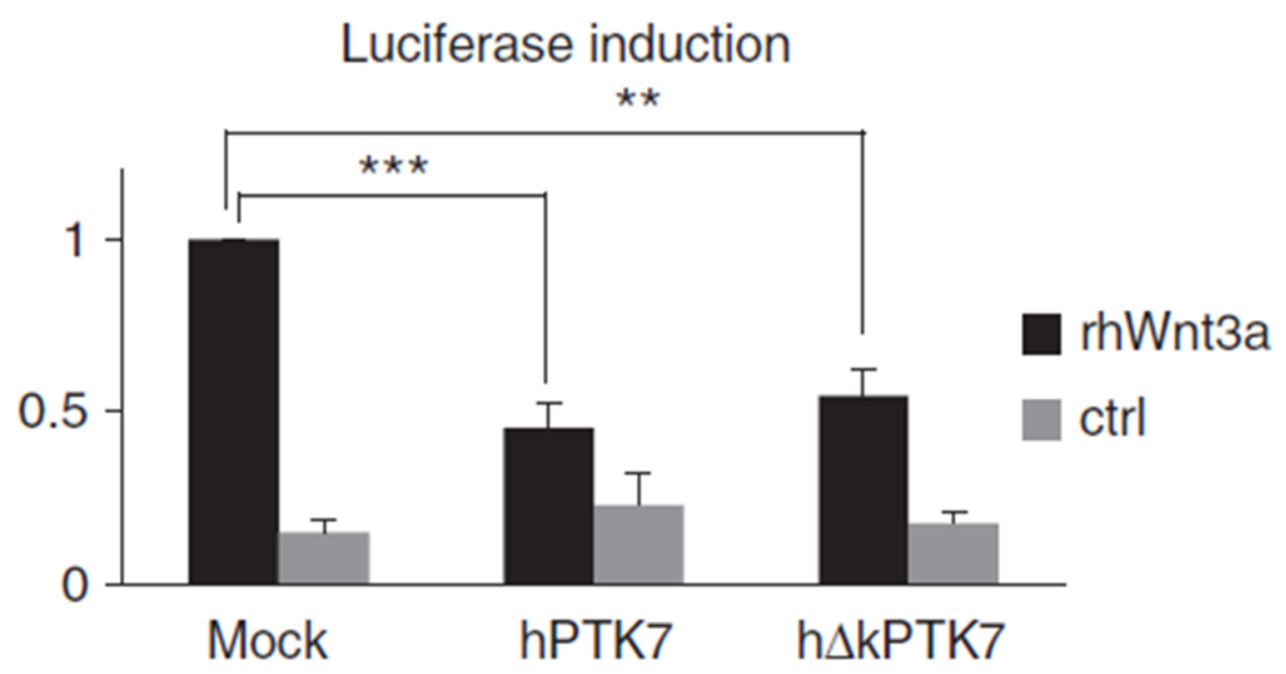

Figure 3.12. PTK7 inhibits canonical Wnt signaling. PTK7 and a mutant version of PTK7 lacking the kinase homology domain ( $\triangle \mathrm{k}$ PTK7) can inhibit Wnt3a induced canonical Wnt signaling. HEK293 cells were transfected with the TOPflash reporter together with the PTK7 constructs or a control plasmid (mock). After stimulation with recombinant Wnt3a protein the mock transfected cells show an increased induction of the luciferase reporter. This is inhibited in the presence of PTK7 or $\triangle k$ PTK7. Graph summarizes the renilla normalized TOPflash reporter induction of three independent experiments. Values for luciferase induction are normalized for the value of mock transfected Wnt3a stimulated cells. Given are standard errors of the mean. P. values were calculated in a Student's T-test: ${ }^{* \star *}<0.001,{ }^{* *}<0.01$ 


\subsection{3.siRNA knockdown of PTK7 in human cell lines}

Since PTK7 overexpression results in an inhibition of Wnt3a induced $\beta$-catenin signaling, one would expect the opposite effect for PTK7 knockdown. In order to achieve a reliable PTK7 knockdown in cell lines PTK7 siRNA knockdown was established. Pools of three different siRNAs were transfected into HEK293, MCF7 and MDA MB231 cells. To monitor the knockdown effect, cell lysates were prepared from HEK293 cells after 48 hours (Fig. 3.13. A). For MCF7 and MDA MB 231 time courses were carried out to lyse the cells 24 , 48 and 72 hours after siRNA transfection. Lysates from cells transfected with a nontargeting siRNA were used as controls. Reduction of PTK7 expression was analyzed using Western blotting. For all tested cell lines an effective knockdown of PTK7 protein due to PTK7 siRNA transfection was detected already after 24 hours (Fig. 3.13.). 
A

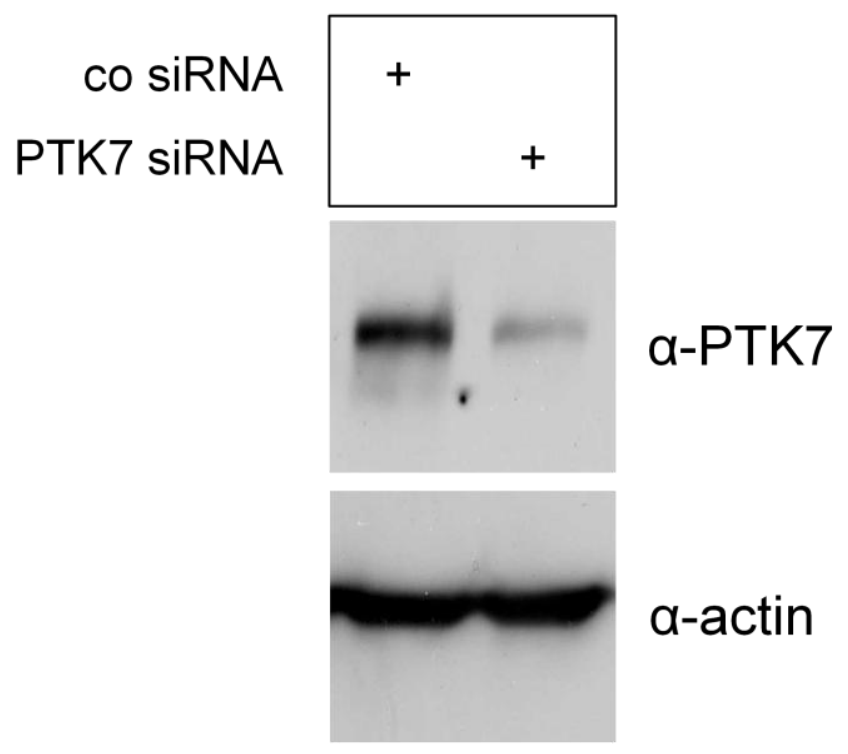

HEK 293

B
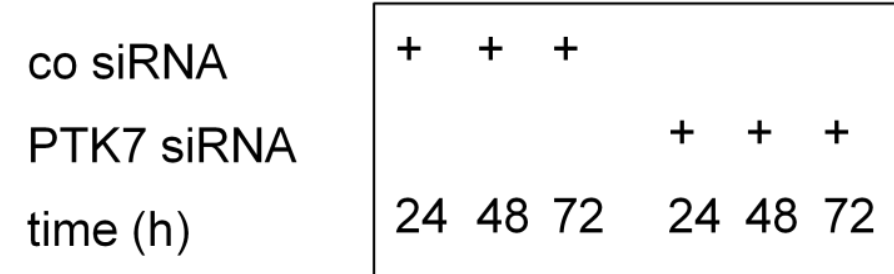

MCF7

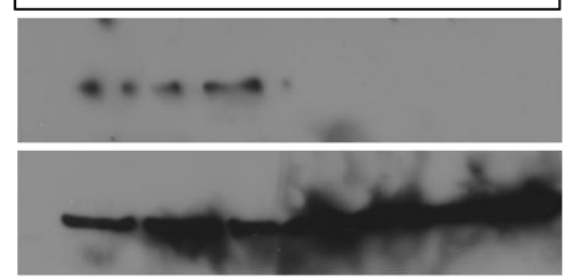

a- PTK7

a- actin

MDA MB 231

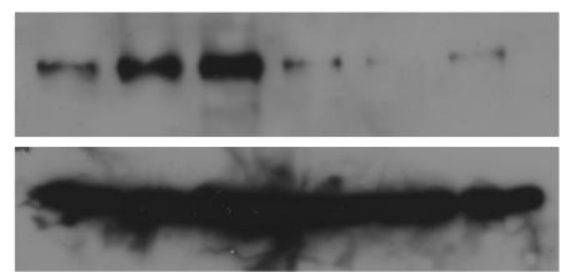

\section{a- PTK7}

a- actin

Figure 3.13. The expression of PTK7 can be effectively downregulated by siRNA transfection. PTK7 knockdown in HEK293 cells. HEK293 cells were transfected with nontargeting control siRNA or PTK7 targeting siRNA. Forty-eight hours after transfection cell lysates were prepared and analyzed for protein expression by Western blotting using anti-PTK7 and antiactin antibodies. (B) siRNA-mediated knockdown of PTK7 in MCF7 and MDA MB 231 breast cancer cell lines. Cells were transfected with either non-targeting siRNA or PTK7 targeting siRNA and time courses were performed over the period of 72 hours. Cell lysates were prepared after 24 hours, 48 hours and 72 hours. Protein expression was analyzed by Western blotting using antiPTK7 and anti-actin antibodies. 


\subsection{4. siRNA knockdown of PTK7 cannot abolish canonical Wnt signaling in TOPflash reporter assays}

After establishing a reliable knockdown of PTK7 protein using siRNA transfection, this approach was used in combination with TOPflash reporter assays. HEK293 cells were transfected with either non-targeting control siRNA or PTK7 siRNA together with the TOPflash reporter. Forty-eight hours after siRNA transfection one group of cells was stimulated with recombinant Wnt3a protein. Lysate preparation and measurement of luciferase activity were performed. The luciferase activity was increased to only a small amount after siRNA knockdown of PTK7 (Fig. 3.14.). However, this result shows that PTK7 is not required for activation of canonical Wnt signaling because it is activated in the absence of PTK7. This finding confirms the role of PTK7 as an inhibitor of canonical Wnt signaling.

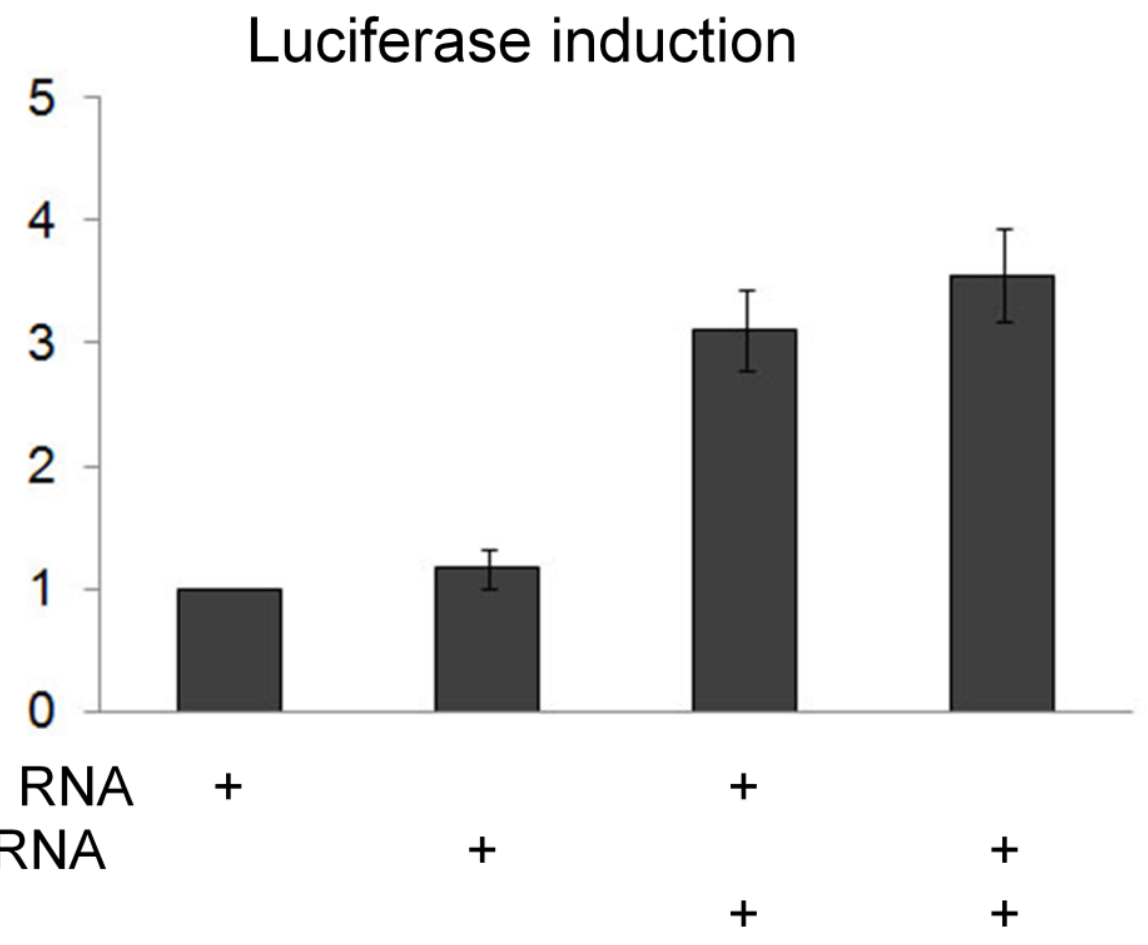

Figure 3.14. Activation of canonical Wnt signaling does not require PTK7. After siRNA knockdown of PTK7 in HEK293 cells canonical Wnt signaling can still be activated using recombinant Wnt3a. The loss of function slightly activates canonical Wnt signaling. HEK293 cells were transfected with either non-targeting control siRNA or PTK7 targeting siRNA together with the TOPflash reporter. After 48 hours cells were stimulated using recombinant Wnt3a protein. Luciferase induction was measured. Graph summarizes the renilla normalized luciferase induction of three independent experiments. The values for luciferase induction are normalized to the value for control siRNA transfected non-stimulated cells. Standard errors of the mean are given. 


\subsubsection{PTK7 activates downstream targets of PCP signaling}

PTK7 is known as a regulator of PCP signaling; however, so far no evidence for direct activation of downstream PCP molecules was achieved. To address this issue a test system to detect active, meaning GTP bound RhoA and Rac1 in cell lysates was employed. This method uses sepharose coupled proteins, which specifically bind to GTP bound GTPases. In this way a precipitation of active GTPases is possible. Analysis of MCF7 cell lysates, PTK7 or mock transfected, showed that the overexpression of PTK7 resulted in an increased amount of active RhoA and Rac1 (Fig. 3.15.). This finding led to the conclusion that, indeed, PTK7 could activate intracellular players of the planar cell polarity signaling cascade. These results were obtained in collaboration with the group of Klaudia Giehl from Giessen. The cell transfections and lysis preparation were carried out in Göttingen whereas the pulldown, Western blotting and figure design were performed by Klaudia Giehl.

A

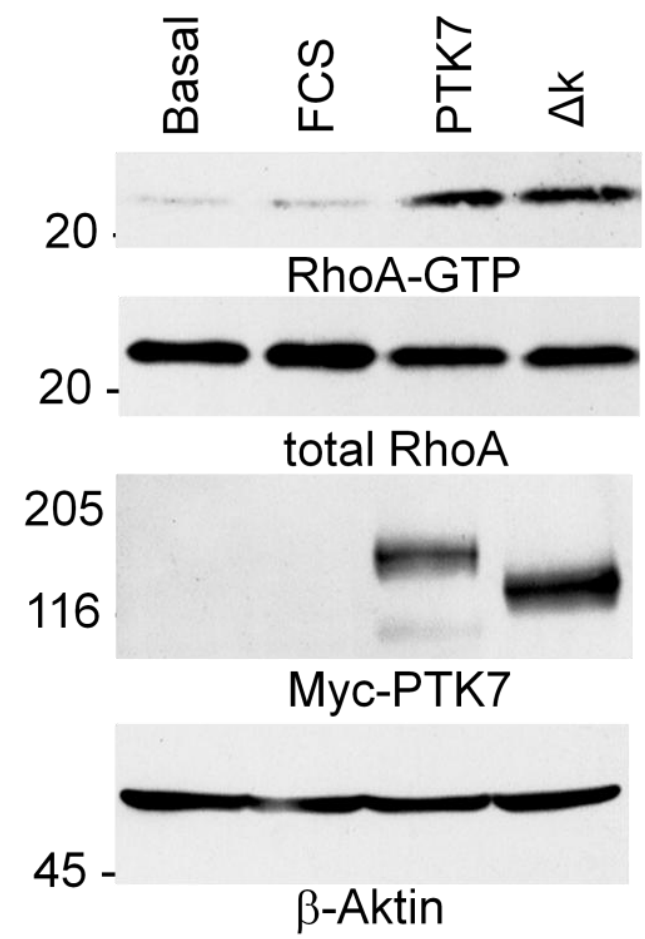

B

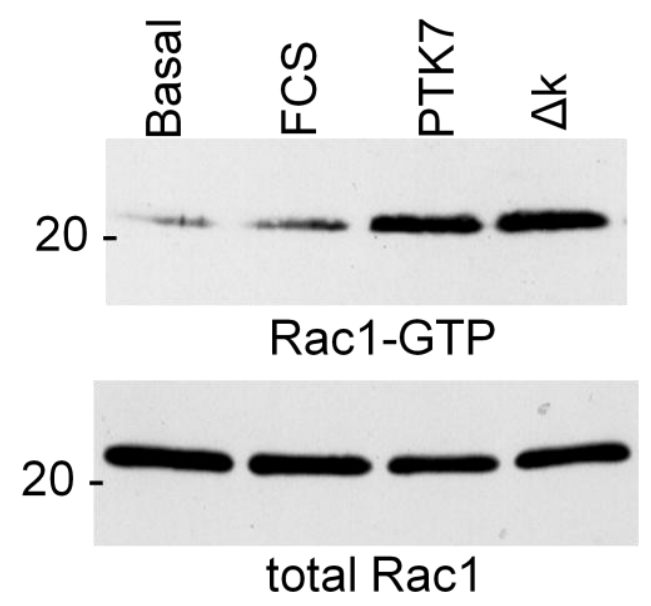

$205-$

$116-$

$97.4-$

Figure 3.15. PTK7 activates the small GTPases RhoA and Rac1. Cell lysates of MCF7 cells overexpressing PTK7 or $\triangle \mathrm{k}$ PTK7 were used to perform assays for specific pull down of activated, GTP bound RhoA (A) and Rac1 (B). Total cell lysates and pulldown samples were analyzed by Western blotting using anti-RhoA, anti-Rac1, anti-myc and anti-actin antibodies. Protein expression and treatment of the cells were carried out as indicated. 


\subsubsection{PTK7 showed no indication for activation of JNK}

The jun amino terminal kinase (JNK) is an additional member of the PCP signaling cascade which can be activated by a Dsh-Rac1 complex. In the active state JNK is phosphorylated and can be visualized using antibodies in Western blots, which specifically detect phosphorylated epitopes. In order to increase the total amount of JNK in HEK293, cells human JNK-HA was overexpressed. To avoid activation of JNK by mitogenic factors included in the medium, cells were kept under serum-free conditions. For the application of different test conditions the cells were either co-transfected with PTK7, other potential activators of JNK, or stimulated with FCS or Wnt5a protein prior to lysate preparation. The analysis by Western blot displayed no indication that PTK7 or any of the other tested components clearly induces the phosporylation of JNK (Fig. 3.16.).

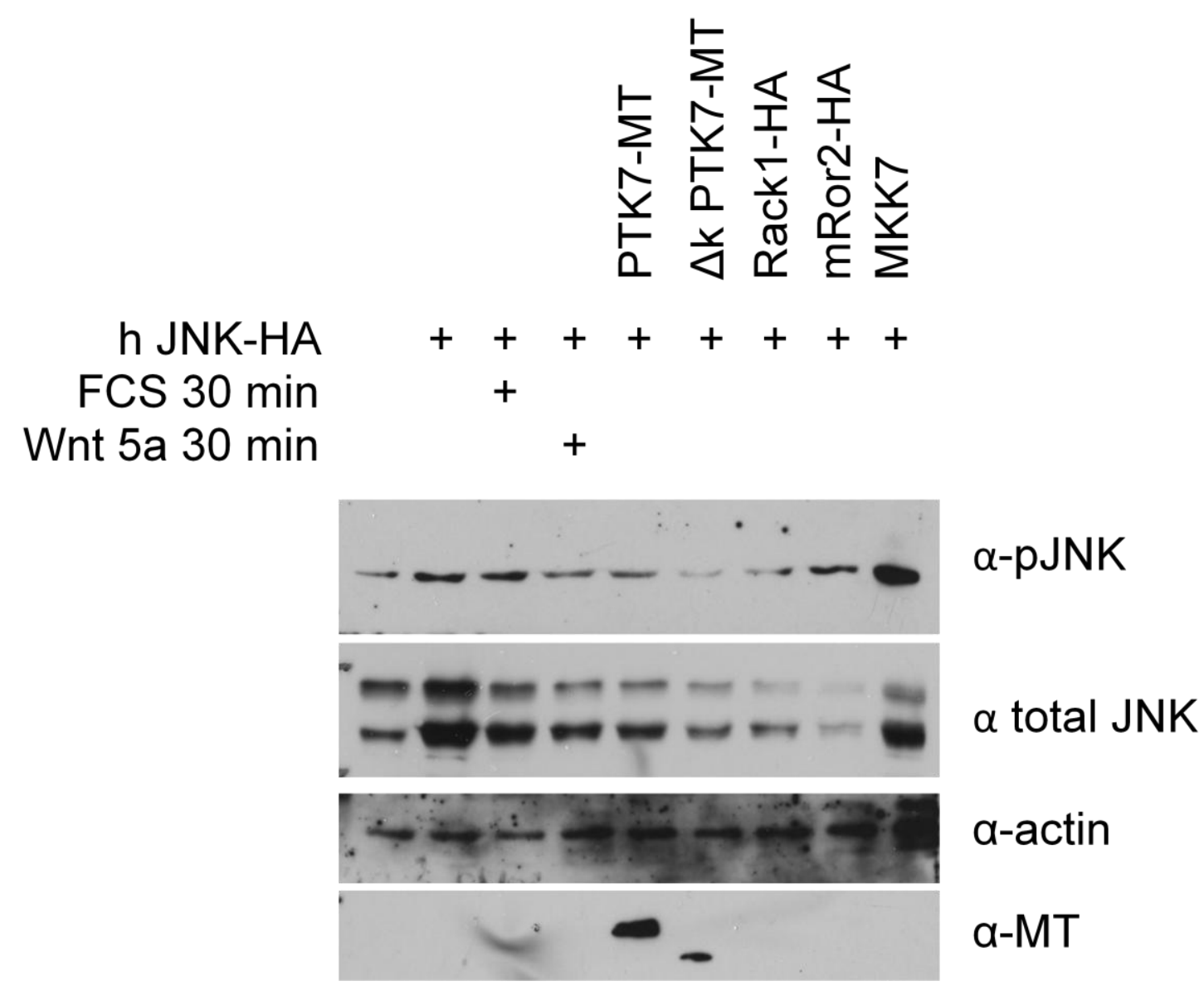

Figure 3.16. PTK7 overexpression does not activate JNK. MCF7 cells transfected with hJNKHA in combination with PTK7, $\triangle \mathrm{k}$ PTK7, Rack1, mRor2 or MKK7 were kept in a serum-free culture. Prior to cell lysis, batches of the cells were stimulated with either FCS or recombinant Wnt5a protein. Cell lysates were prepared and analyzed by Western blotting using anti-pJNK or anti-total JNK antibodies. Control panels show staining with anti-actin and anti-myc antibodies. 


\title{
3.3. PTK7- Ror2 interaction
}

\subsubsection{The PTK7 overexpression phenotype resembles the Ror2 phenotype}

\begin{abstract}
The phenotype seen in MCF7 cells overexpressing PTK7 (Fig. 3.1., 3.2., 3.4.) resembles published data for the overexpression of Ror2 in HEK293 and MCF7 cells (Nishita et al., 2006). Based on this knowledge, the question of whether PTK7 and Ror2, which are both known to be involved in non-canonical Wnt signaling, are functionally connected is obvious. By overexpressing both proteins in a single and combined way, it became clear that, indeed, both phenotypes resemble each other to a high degree (Fig. 3.17.). This could mean that both proteins operate in the same or similar processes and a functional interaction is possible.
\end{abstract}



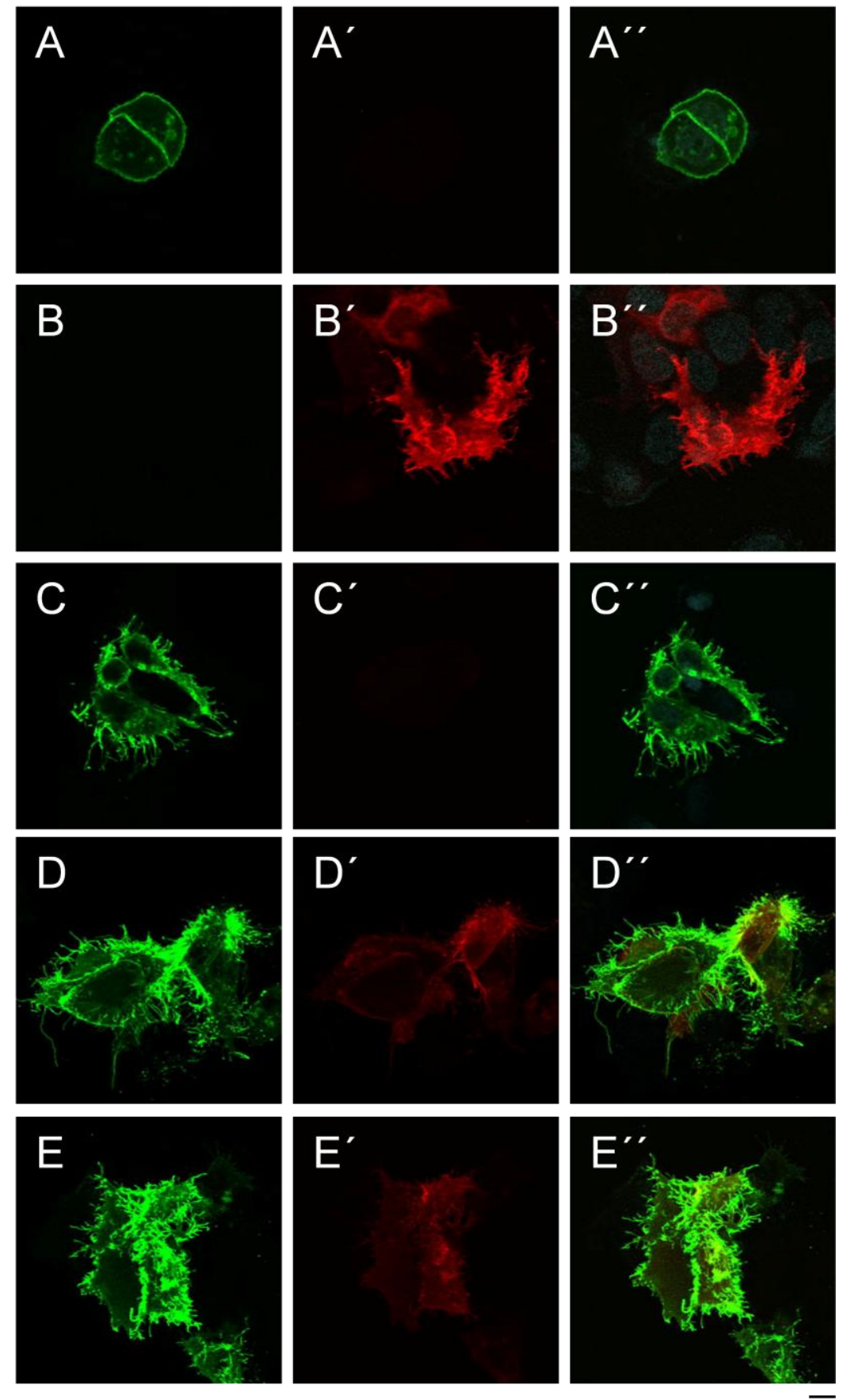

Figure 3.17. Overexpression of Ror2 in MCF7 cells resembles the PTK7 overexpression phenotype. MCF7 cells were grown on glass coverslips and transiently transfected. Morphological phenotypes of MCF7 cells overexpressing: (A) membrane GFP, (B) PTK7-myc, (C) Ror2-HA and (D, E) PTK7-myc together with Ror-HA. The filopodia morphology is seen in both PTK7 and Ror2 overexpression (B-E). Immunostaining was done using anti-GFP antibody (A), anti-HA and antimyc antibodies (B-E). Shown are the GFP expression (A), HA expression (B-E) the myc expression ( $\left.\mathbf{B}^{\prime}-\mathbf{E}^{\prime}\right)$ and the overlayed images $\left(\mathbf{A}^{\prime \prime}-\mathbf{E}^{\prime \prime}\right)$. Scale bar: $10 \mu \mathrm{m}$. 


\subsubsection{PTK7 and Ror2 co-precipitate each other in cell lysates}

In order to analyze the potential relationship between PTK7 and Ror2, biochemical approaches were used. Co-immunoprecipitation assays were conducted using tagged constructs of human PTK7, a $\Delta$ kinase-domain mutant of PTK7, and mouse Ror2 overexpressed in MCF7 cells (Fig. 3.18. C). Immuno-precipitations were carried out in two ways: Anti-HA antibodies were used to precipitate HA-tagged Ror2 protein and coprecipitated the myc-tagged PTK7 proteins (Fig. 3.18. A). Vice versa anti-myc antibodies were used for precipitation of myc-tagged PTK7 proteins to co-precipitate Ror2 (Fig.3.18. B). Co-precipitation of PTK7 and Ror2 as well as of $\Delta$ kinase PTK7 and Ror2 worked in both directions, which is a biochemical indication for protein interaction. As the previous results do not provide information about the domains involved in their interaction it was necessary to further characterize these regions. Constructs for the expression of additional deletion mutants of Ror2 and PTK7 were used for co-immunoprecipitations (Fig. 3.19.). Co-IPs using Flag-tagged deletion constructs of Ror2 in combination with the full-length PTK7 protein revealed that all three different deletion mutants were able to coprecipitate the full-length PTK7 protein (Fig. 3.20.). This result suggests that the immunoglobulin-like domains of both proteins or the transmembrane domains could be responsible for their interaction. For this reason full-length Ror2 in combination with a secreted version of PTK7 lacking large parts of the transmembrane domain as well as mutants of PTK7 lacking the extracellular domain or the extracellular and transmembrane domain were designed (Fig. 3.21.). These experiments showed clear binding of secreted extracellular PTK7 and $\Delta$ extracellular PTK7 to Ror2. For the binding of the smaller, nonmembrane-anchored fragment of PTK7 and full-length Ror2 there is some weaker interaction, which could be due to less effective expression of this construct. Taken together, it is very likely that the interaction between PTK7 and Ror2 is mediated via the transmembrane domains of both proteins (Fig. 3.22.). 


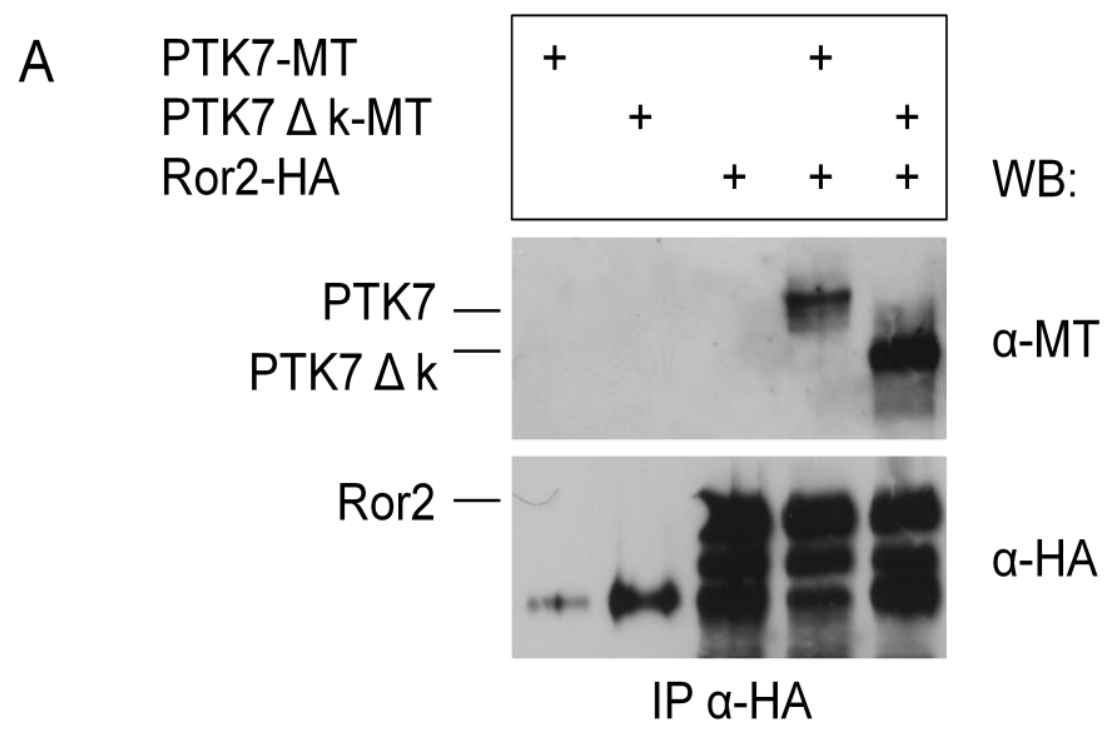

B

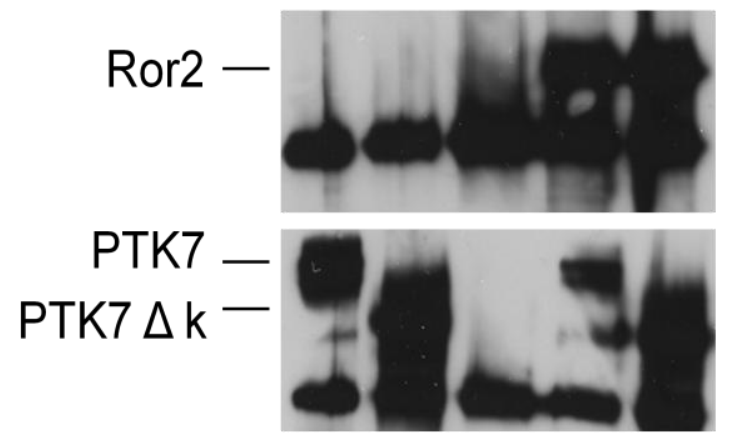

$\alpha-\mathrm{HA}$

IP a-MT

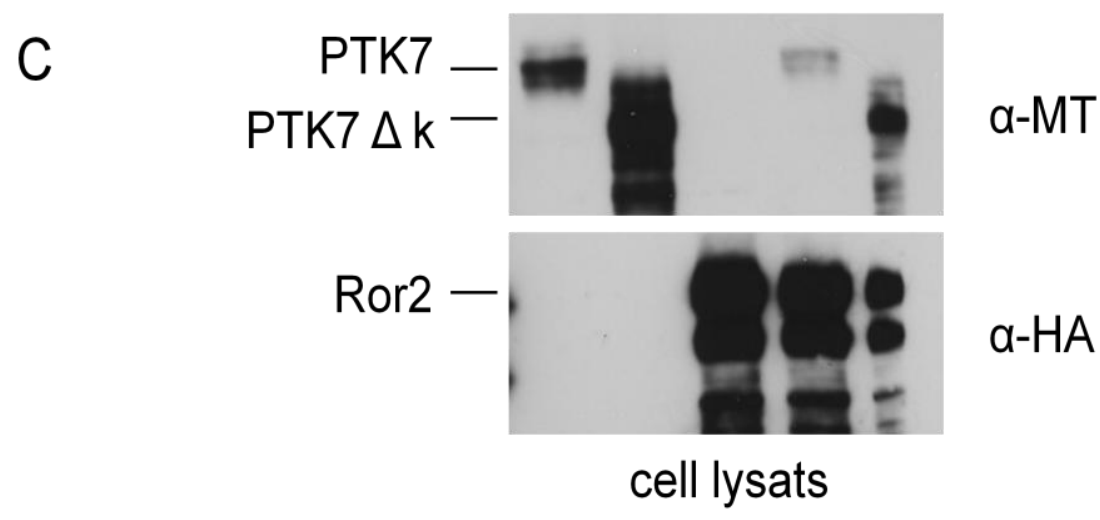

Figure 3.18. PTK7 and Ror2 co-precipitate each other in cell lysates. Ror2 co-precipitates PTK7 and $\triangle \mathrm{k}$ PTK7 (A) and Ror2 is co-precipitated by PTK7 and $\triangle \mathrm{k}$ PTK7 (B). MCF7 cells were transfected as indicated in the top panel. Cell lysates were prepared and co-immunoprecipitation was carried out using anti-HA antibody (A) or anti-myc antibody (B). Cell lysates used for coimmunoprecipitation show the correct expression of the proteins (C). Antibodies used for precipitation are indicated below, the panels and antibodies used for Western blotting are indicated on the right side. Labels on the left side indicate the individual proteins. 
IG CRD KR TM TK $\quad$ S/T P S/T

A

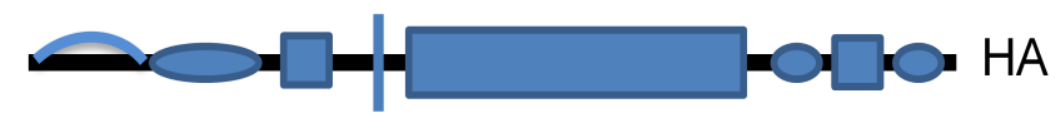

B $\triangle \mathrm{CRD} / \mathrm{KR} \rightleftharpoons$ FLAG

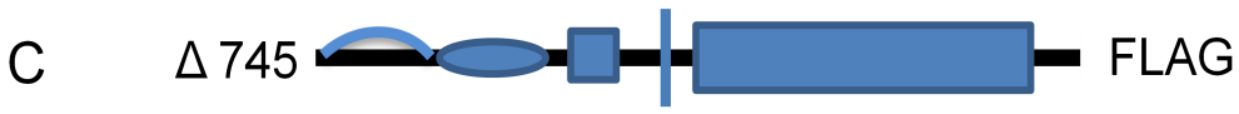

$\mathrm{D} \Delta 469$-Flag $\rightleftharpoons$ FLAG

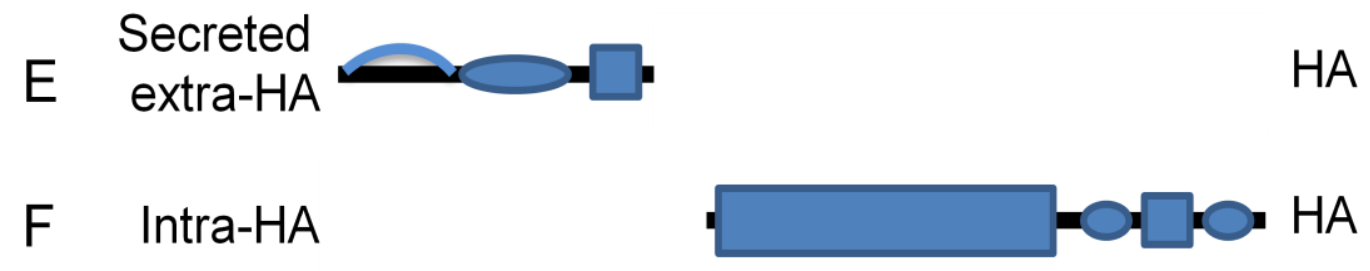

Figure 3.19. Full-length and deletion constructs of Ror2. Schematic view of the constructs used for mapping of binding sites of the PTK7-Ror2 interaction. Full-length HA-tagged Ror2 (A) contains the extracellular domains: immunoglobulin-like domain (IG), Cysteine rich domain (CR) and Kringle domain (KR). It further has a transmembrane domain (TM), an intracellular tyrosine kinase domain $(T K)$ and Serine/Threonine $(\mathrm{S} / \mathrm{T})$ or Proline $(\mathrm{P})$ rich domains. Ror2 $\triangle \mathrm{CRD} / \mathrm{KR}$-Flag lacks the extracellular CRD and KR domains (B). Ror2 $\Delta 745$-Flag lacks the intracellular $S / T$ and $P$ domains (C). Ror2 $\Delta 469$-Flag lacks the complete intracellular part (D). Secreted Ror2-HA contains the extracellular part of Ror2 without the transmembrane domain and is secreted into the medium (E). Intracellular Ror2-HA consists of the intracellular domains without transmembrane domain (F). 


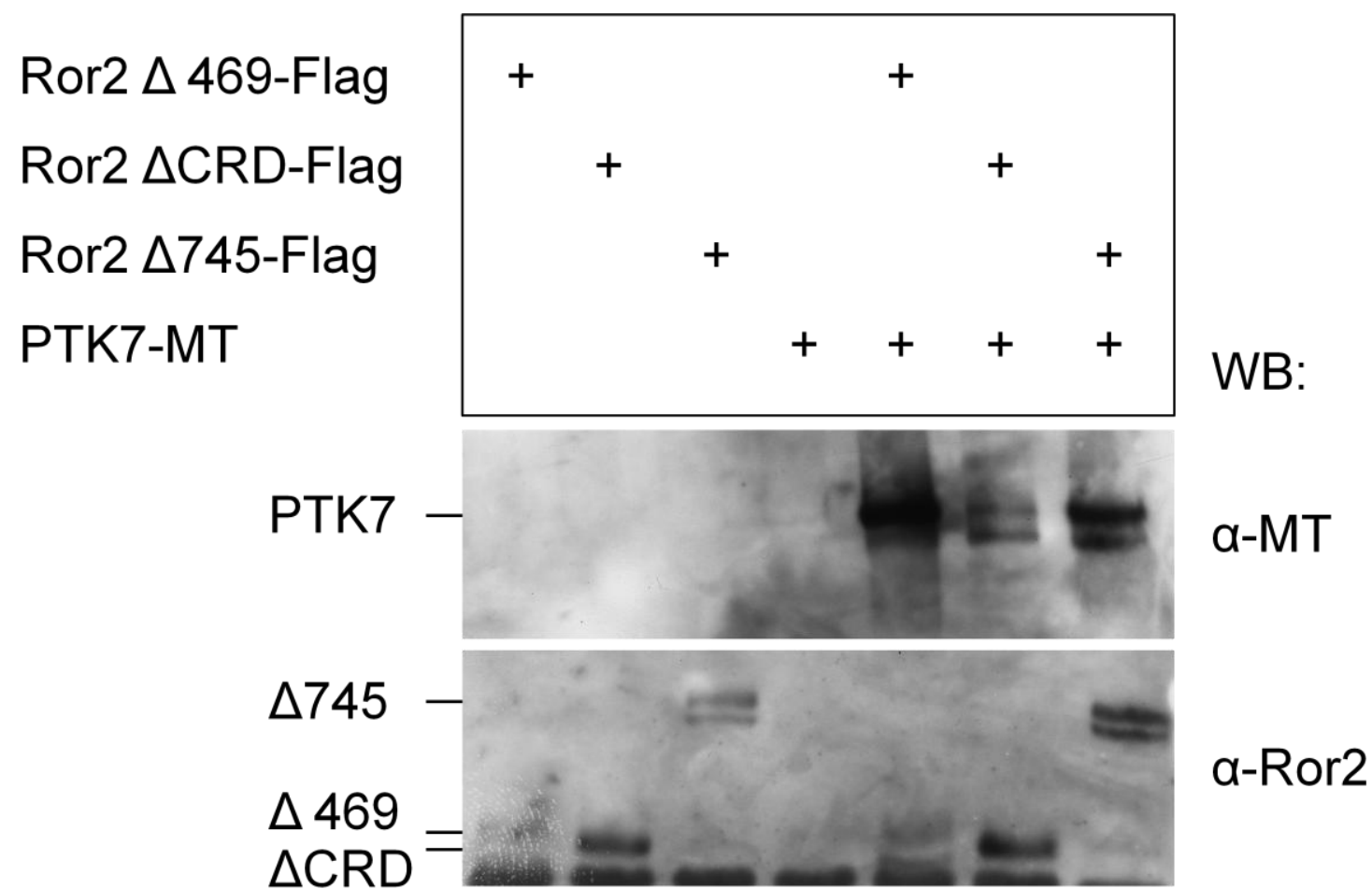

IP a-Flag

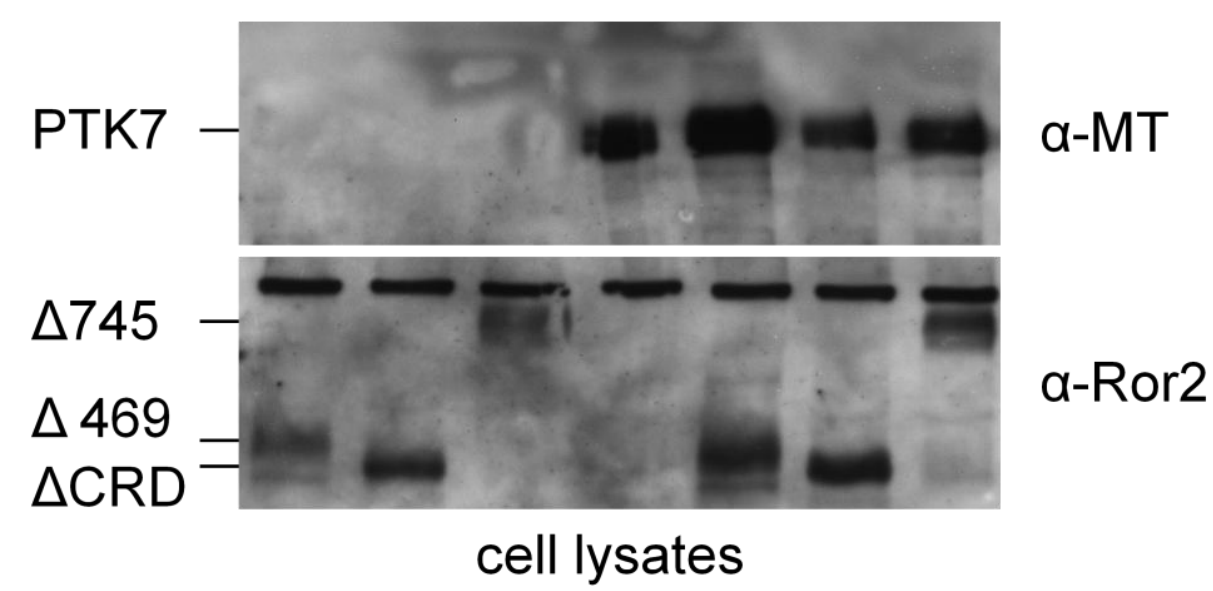

Figure 3.20. Deletion mutants of Ror2 co-precipitate PTK7. The Flag -tagged deletion mutants of Ror2 were expressed in combination with PTK7 in MCF7 cells as indicated in the top panel. Cell lysates were prepared and co-immunoprecipitation was carried out using anti Flag antibodies. Western blotting showed that PTK7 is co-precipitated by all three deletion mutants tested, Ror2 $\Delta 469$, Ror2 $\Delta$ CRD and Ror2 $\Delta 745$ (A). The antibodies used for Western blotting are indicated on the right and the labels on the left map the individual proteins. The cell lysates used for coimmunoprecipitation are analyzed for the correct expression of the different proteins (lower panel). 

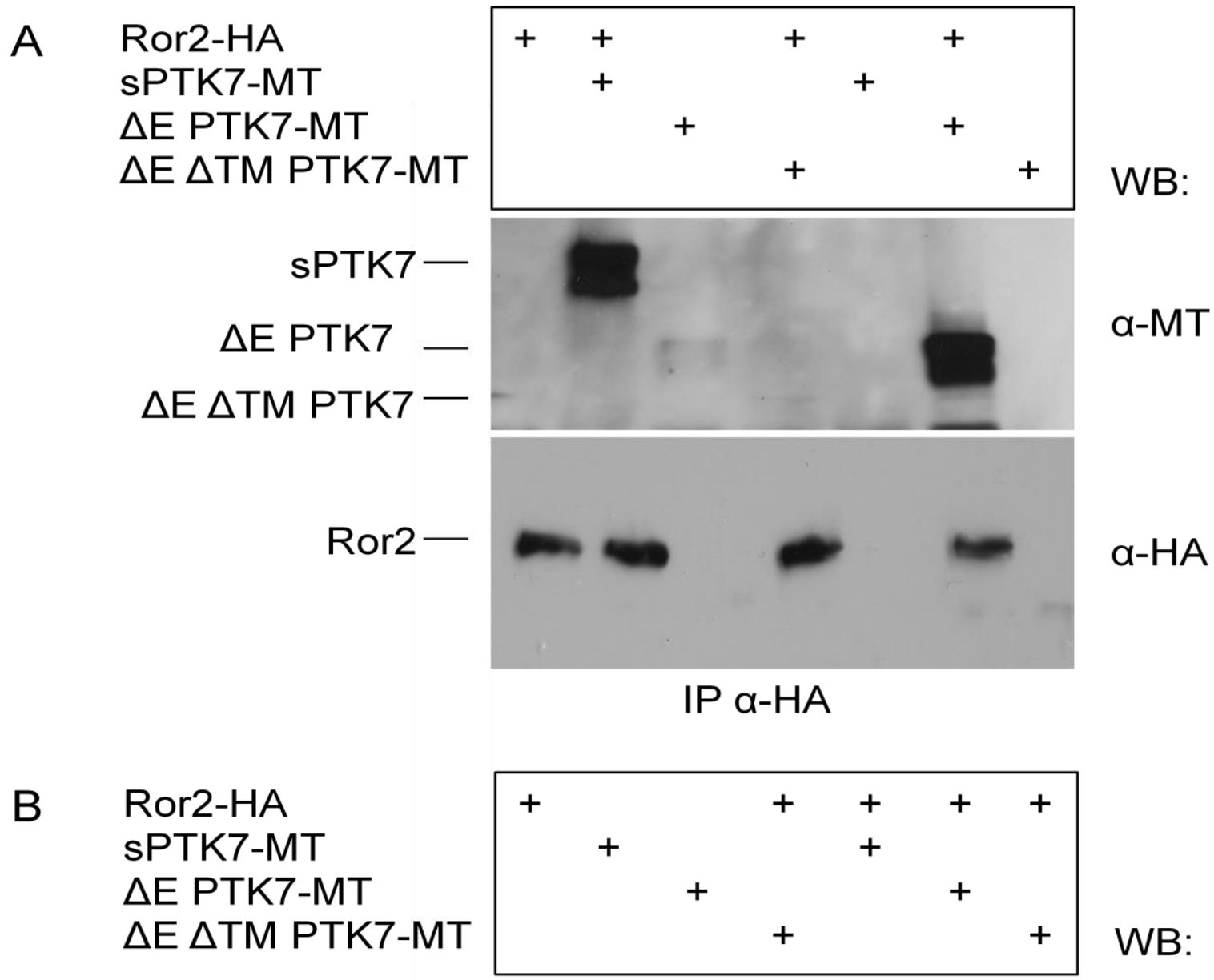

WB:
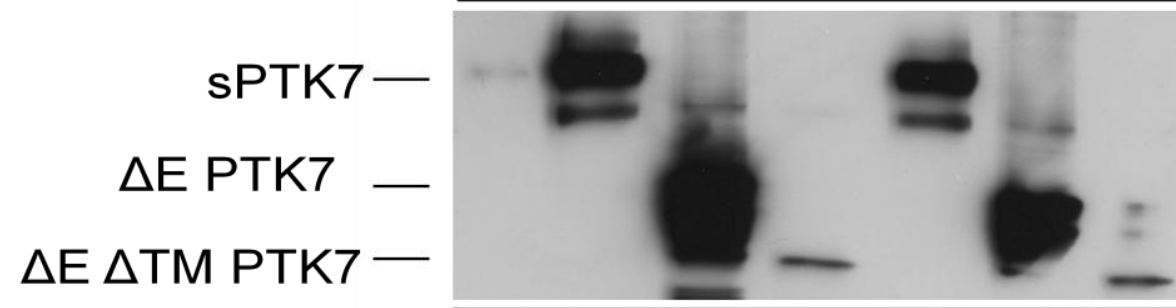

a-MT

Ror2-

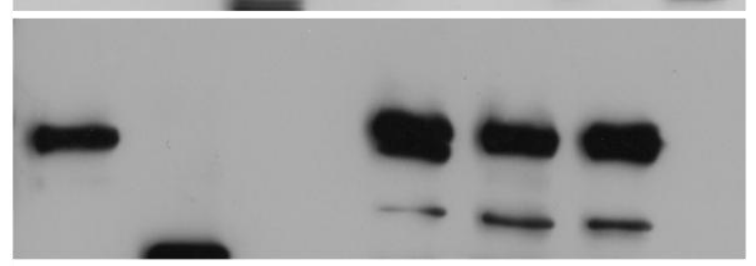

cell lysates

a-HA

Figure 3.21. Ror2 co-precipitates deletion mutants of PTK7. Full-length Ror2 was expressed together with deletion mutants of PTK7 as indicated in the top panels (A, B). Cell lysates were prepared and co-immunoprecipitation was performed using anti-HA antibodies. Western blotting clearly showed the co-precipitation of secreted PTK7 and $\triangle E$ PTK7 together with the full-length Ror2 protein (A). The cell lysates prior to immunoprecipitation were analyzed by Western blotting and showed the correct protein expression (B). Antibodies used for Western blotting are indicated at the right side. Individual protein bands are labeled on the left side. 
A

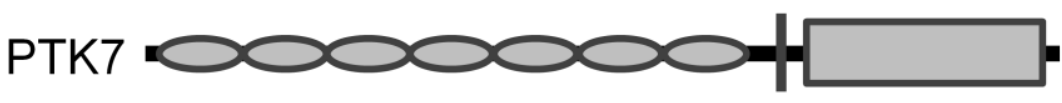

Ror2 yes

$\triangle \mathrm{CRD} / \mathrm{KR}$

$\Delta 745$

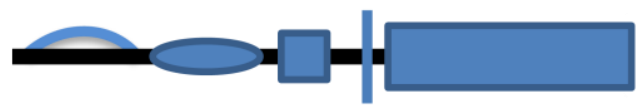

yes

$\Delta 469-$ Flag

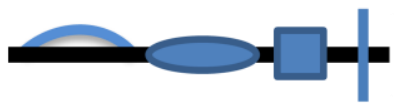

yes

B
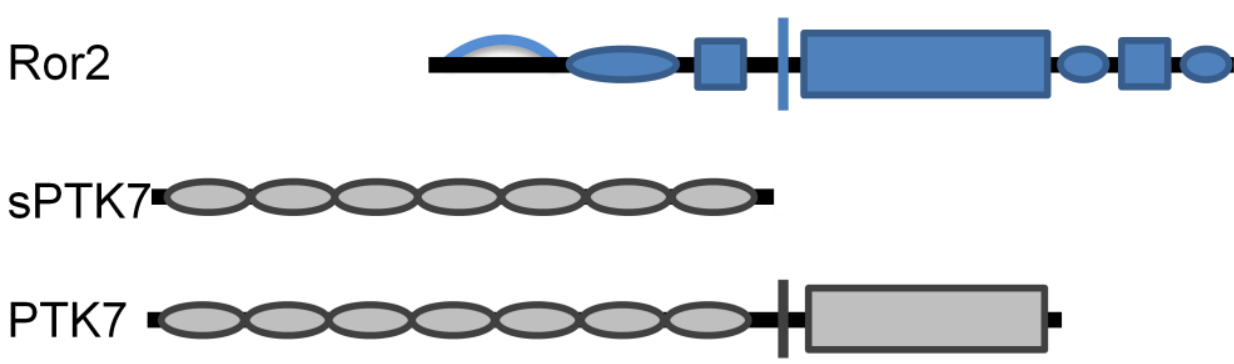

yes

$\Delta \mathrm{k}$

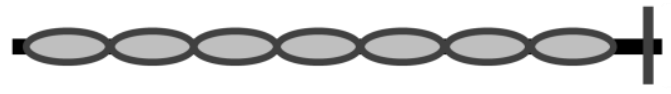

yes

$\Delta \mathrm{E}$

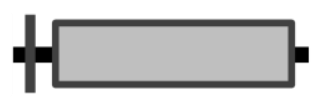

yes

$\Delta \mathrm{E} / \Delta \mathrm{TM}$

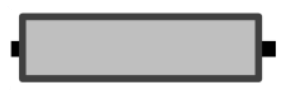

no

Figure 3.22. Summary of the interacting domains of PTK7 and Ror2. Summary of the domains of PTK7 and Ror2 that were experimentally found to co-precipitate in coimmunoprecipitation assays (Fig. 3.18., 3.20., 3.21.). PTK7 co-precipitates the full-length Ror2 as well as the deletion mutants $\Delta \mathrm{CRD} / \mathrm{KR}, \Delta 745$ and $\Delta 469$ (A). Ror2 co-precipitates secreted PTK7 and the deletion mutants $\Delta \mathrm{k}$ and $\Delta \mathrm{E}(\mathrm{B})$. Shown is a schematic view of the protein domains that were present in the individual constructs. 


\subsubsection{Ror2 rescues PTK7 knockdown in Xenopus laevis neural crest cell migration}

We showed an interaction of PTK7 and Ror2 on a biochemical level; therefore one could ask whether there is also a functional relationship between the interaction partners. As PTK7 is required for proper neural crest cell migration (Shnitsar and Borchers, 2008) and Ror2 in developing embryos is also expressed in the cranial neural crest cells (Hikasa et al., 2002) it is very likely that PTK7 and Ror2 act together in some aspects of neural crest cell migration.

To study cell migration in vivo the migrating neural crest cells of Xenopus embryos are a convenient and established model. By microinjection of specific antisense morpholino oligonucleotides the expression of PTK7 could be abolished. Inhibition of protein expression can be targeted to exactly one half of the embryo by injecting into one cell of a two-cell stage embryos. Using this technique, one can induce an impairment of neural crest cell migration in the injected half of the embryo while the unaffected side develops normally (Fig. 3.23. A, B). In the context of this study, PTK7 morpholino injection was used as a positive control to induce an impaired migration of the neural crest cells in about $60 \%$ of the embryos. In order to assess whether Ror2 affects PTK7's function in neural crest cell migration, Ror2 mRNA was injected alone or together with the PTK7 morpholino. Surprisingly, Ror2 did not increase the phenotype but rather rescued it (Fig. 3.23. C, D). Quantification of the embryos with neural crest migration defects demonstrated that overexpression of Ror2 alone contributes to neural crest migration defects in less than $10 \%$ of the embryos, whereas its co-injection together with PTK7 morpholino significantly decreased the percentage of embryos showing a neural crest migration defect (Fig. 3.23. E). The latest results allow the conclusion that, indeed, PTK7 and Ror2 are interacting partners that fulfill a common function in regulating of neural crest migration. 


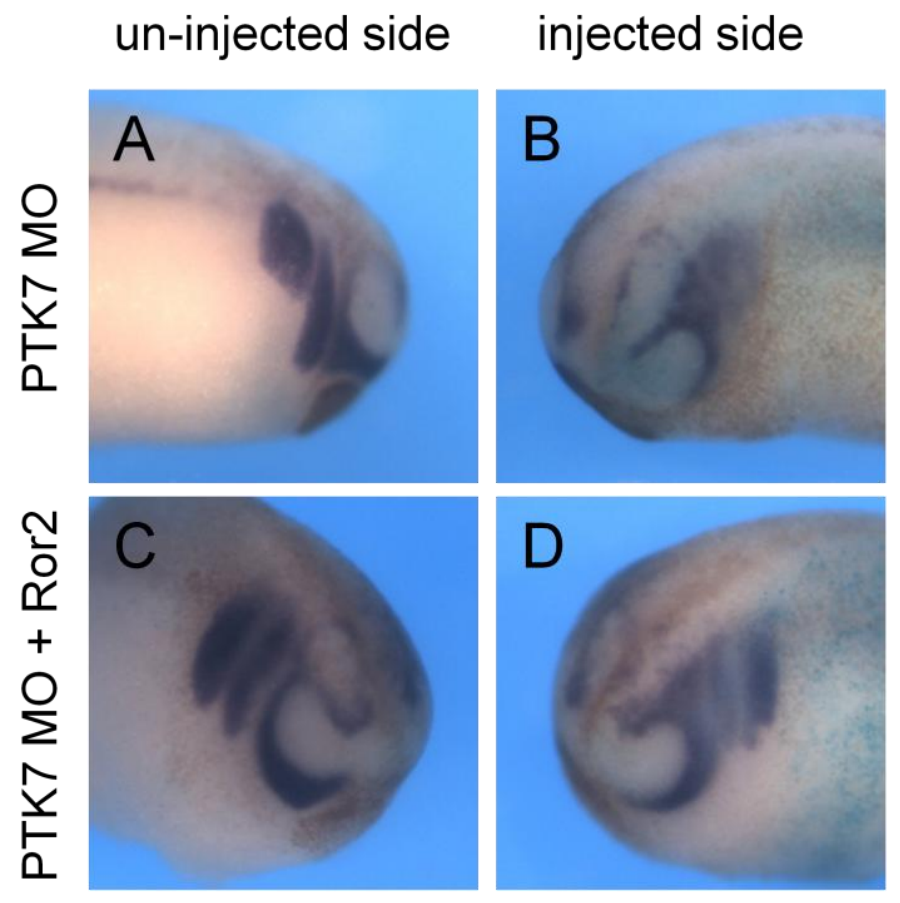

\section{E \% neural crest migration defects}

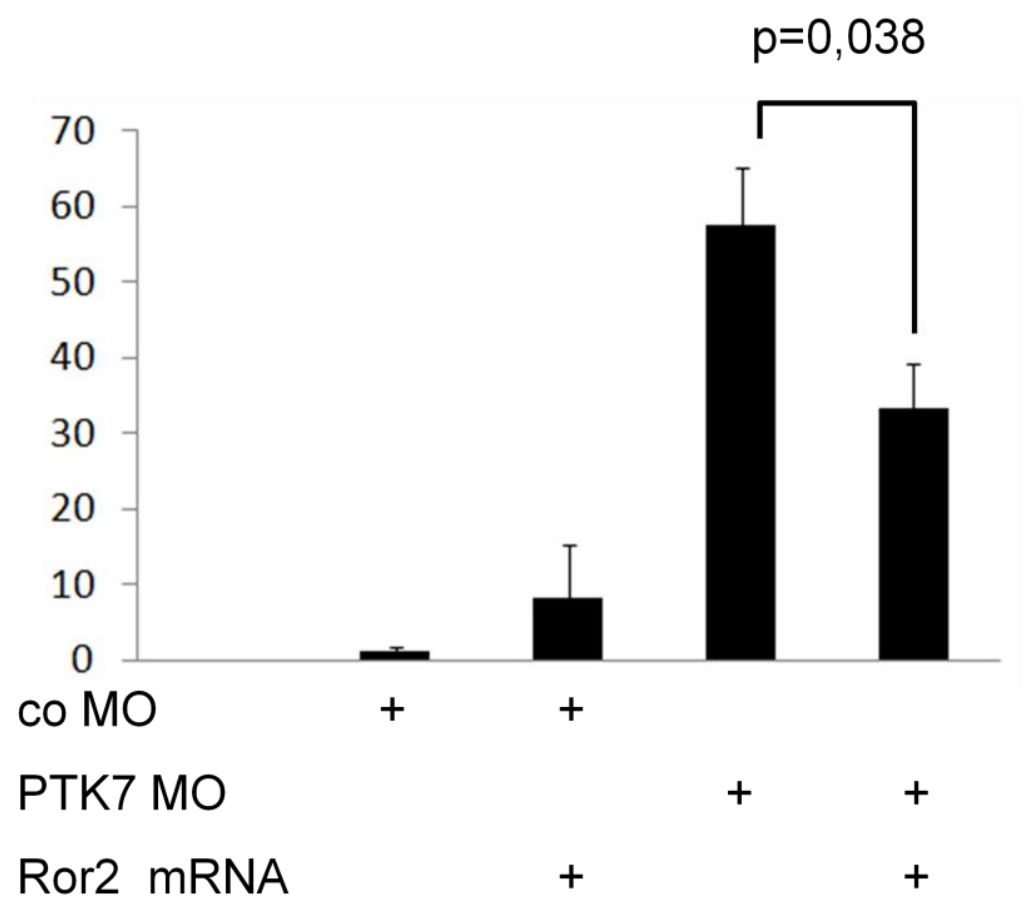

Figure 3.23. Ror2 rescues the PTK7 loss of function phenotype in Xenopus neural crest migration. Xenopus laevis embryos were injected with $20 \mathrm{ng}$ of PTK7 morpholino and $100 \mathrm{pg}$ of GFP mRNA (A, B) or with $20 \mathrm{ng}$ of PTK7 morpholino and $100 \mathrm{pg}$ of Ror2 mRNA (C, D) to one blastomere of the two cell stage embryo. lacZ mRNA was co-injected as a lineage tracer. Embryos 
were fixed at stage 23-24, stained for the expression of B-galactosidase and processed with whole-mount in situ hybridization using an RNA antisense probe for twist. Neural crest cell migration was analyzed by comparison of the un-injected to the injected side of the embryo. Normally migrating neural crest cells are shown in $(\mathbf{A}, \mathbf{C})$. The migration of neural crest cells is highly impaired in (B), whereas it is rescued in (D). (E) Graph summarizes the percentages of neural crest migration defects of five independent experiments. Standard errors of the mean are given and p-value was calculated using Student's T-Test. 


\section{Discussion}

PTK7 was identified as a regulator of PCP (Lu et al., 2004) and is required for cell migration processes during development like gastrulation (Yen et al., 2009), neural tube closure (Lu et al., 2004; Paudyal et al., 2010; Savory et al., 2011), and neural crest migration (Shnitsar and Borchers, 2008). PTK7 was also reported to be upregulated in invasive cancers (Gorringe et al., 2005; Mossie et al., 1995; Muller-Tidow et al., 2004; Saha et al., 2001) and indications emerge that malignant diseases can develop if embryonic skills are re-acquired by mistake during adulthood (Aman and Piotrowski, 2010; Friedl and Gilmour, 2009). Therefore, one can hypothesize that PTK7 gain of function in non-invasive epithelial cells induces cell migration and invasion.

\subsection{PTK7 induces filopodia formation}

The major aim of this study was to investigate the involvement of PTK7 in cell migration and invasion. For gain of function analysis, transient transfection of PTK7 in the breast cancer cell line MCF7 was performed to study cell morphology and it showed that PTK7 gain of function highly influences cell morphology. Cells that overexpressed PTK7 showed a significant increase in filopodia-like structures. PTK7 acts upstream in the PCP signaling pathway, which results in actin rearrangement, it is likely that the appearance of new cell protrusions is regulated by PTK7 activated PCP signaling. The stably inducible PTK7 overexpression was performed using a PTK7-EGFP fusion protein to easier monitor the gene expression and allows the usage in future fluorescence time-lapse imaging experiments. Characterizing the inducible PTK7-EGFP expressing MCF7 cells revealed similar morphological changes as were seen due to transient overexpression of PTK7. However, using a loss of function approach by transfection of PTK7 siRNA in colon cancer cells, morphological changes were not observed. This observation could be caused by the epithelial character of the colon carcinoma cells.

\subsection{PTK7 does not influence cell proliferation}

PTK7 gain of function has no positive or negative influence on cell viability and cell proliferation of MCF7 cells. This data confirms results provided by others for the overexpression of PTK7 in human umbilical vascular endothelial cells (HUVECs) (Shin et al., 2008). Also thymidine incorporation proliferation assays could not reveal any difference in proliferation following PTK7 overexpression or knockdown in AML cells 
(Prebet et al., 2010). Contrary data exists for cell proliferation. BrdU incorporation was significantly decreased due to PTK7 knockdown shown in a study using the colon carcinoma cell line HCT116 (Meng et al., 2010). The divergent findings in AML and colon cancer cells regarding proliferation could be explained by individual differences of the cell types used to obtain these results. Apart from cell proliferation also data on cell survival exists. Recent publications comparing survival rates of mouse pro-B cells (BAF-3) in serum-free conditions indicate that cells overexpressing PTK7 show significantly increased survival rates. Vice versa shRNA knockdown of PTK7 expression reduces the survival rates during growth factor deprivation. They further showed that PTK7 overexpression can reduce the percentage of apoptotic cells and knockdown of PTK7 increases apoptotic cells after doxorubicin chemotherapeutic treatment (Prebet et al., 2010). Results provided by Prebet et. al. suggest a role for PTK7 in cell viability/ proliferation. However, PTK7 gain of function does not increase proliferation; therefore, the survival advantage is driven by inhibition of apoptosis regulation, rather than activating proliferation. This hypothesis is supported by Prebet et al., who described PTK7 overexpression associated with reduced induction of caspase 3 and 7 activity (Prebet et al., 2010). However, in respect of apoptosis, their findings in colon cancer point in the same direction as seen in AML cells, where silencing of PTK7 increases caspasedependent apoptosis rates (Meng et al., 2010; Prebet et al., 2010). Summarizing the available findings concerning PTK7's impact on cell survival it is most likely that PTK7 is involved in inhibition of apoptosis. However, the molecular mechanism remains unknown.

\subsection{PTK7 increases invasiveness of MCF7 cells}

PTK7 can significantly increase invasiveness in transwell assays, but not the ability to migrate in $2 \mathrm{D}$ wound healing assays. These results were seen comparing wildtype MCF7 cells to PTK7-EGFP expressing cells. We investigated the impact of PTK7 on cell migration in wound scratch assays using the doxycycline-inducible PTK7-EGFP expression in MCF7 cells. In this setting the polarized cell migration on a 2D surface was assayed and no difference was detectable between PTK7 overexpressing and wildtype MCF7 cells. This could indicate that PTK7 does not increase the efficiency of 2D migration on the plastic surface of cell culture dishes. In vivo analysis of mouse embryonic wound repair showed PTK7 as essential for the process of wound healing (Caddy et al., 2010). Here one could argue that in vivo wound repair is less artificial than $2 \mathrm{D}$ wound repair in a culture dish and therefore more likely represents the endogenous function. We carried out additional functional studies using Boyden chamber transwell 
assays which test for the ability of cells to invade extracellular matrix proteins in a similar composition to the basement membrane. Invasive migration behavior of cells is required for cancer metastasis. Our results demonstrate that overexpression of PTK7 is sufficient to increase the invasiveness 2.5 times in the non-invasive breast cancer cell line MCF7. The gain in invasiveness is comparable to the stimulation with recombinant Wnt5a protein (Pukrop et al., 2006). Combination of Wnt5a stimulation and PTK7 overexpression leads to a 3.4 fold increased invasiveness compared to the unstimulated wildtype MCF7 cells. Considering these results we can conclude that PTK7 indeed has a function in cancer cell invasion. Due to the fact that PTK7 does not influence the migratory behavior in $2 \mathrm{D}$ migration assays it is most likely that the overexpression of PTK7 provides advantages to the cells required for invading the basement membranelike ECM in transwell assays, but not in 2D polarized cell migration on cell culture dishes. This conclusion suggests that PTK7 gain of function is associated with an increased activity of ECM modulating proteases. Our preliminary experiments addressed this possibility. Immunofluorescence staining of the membrane-localized MT1MMP showed co-localized expression of PTK7 and MT1MMP at the protrusion sites. PTK7 gain of function did not affect MT1MMP expression or activity. Golubkov et al. identified a MT1MMP specific cleavage site in the extracellular domain of PTK7, which is essential for the invasiveness of HT1080 and knockdown of MT1MMP or overexpression of the full-length PTK7, which can abolish the invasive effect. The group proposed that a balanced ratio of full-length and cleaved secreted PTK7 is important for proper function of PTK7 in cells (Golubkov et al., 2010). In a further study the same group analyzed the previously described PTK7 mutant chuzoi (Paudyal et al., 2010). They detected an additional insertion of MT1MMP cleavage site closer to the N-terminus of the PTK7 extracellular domain, which results in an approximately $10 \mathrm{kDa}$ smaller fragment after cleavage. This shorter fragment was even more potent to induce invasiveness in HT1080 cells than the wild type secreted PTK7 (Golubkov et al., 2011). Our own preliminary data also showed an increased invasiveness in Boyden chamber assays when the cells were incubated with secreted PTK7 containing supernatant compared to mock supernatant. One possible explanation for the increasing effect of secreted PTK7 on invasiveness could be the fact that PTK7 mediates homophilic binding and by binding of the secreted extracellular domain to the membrane-bound full-length PTK7 pathway activation could occur. This is contradictory to the finding of Shin et al. and Prebet et al. who showed an inhibitory effect of the secreted PTK7 on cell migration and invasion (Prebet et al., 2010; Shin et al., 2008), but as they were using different types of cells the outcomes can be diverse due to co-receptor variations in different cell types. Comparing our findings for overexpression of the full-length PTK7 to published data, our results verify what was also 
seen for leukemia cell lines. In leukemia cells overexpression of PTK7, increased invasiveness through fibronectin-coated membranes while shRNA-mediated knockdown of PTK7 results in an impairment of invasiveness, which could be rescued by expression of PTK7 (Prebet et al., 2010). Contrary data exist for HT1080 cells showing an inhibitory effect of PTK7 overexpression on invasiveness in collagen coated transwell assays (Golubkov et al., 2010). Currently, the molecular mechanism of PTK7 mediated invasiveness remains unknown and needs to be further analyzed.

\subsection{PTK7 is a Wnt co-receptor}

PTK7 functions as a Wnt receptor in Xenopus and Drosophila development, but it was unclear whether it has a similar role in mammalian cells and whether the binding is direct. Here we could confirm that PTK7 is a co-receptor for Wnt ligands. As we could not detect a direct interaction and we knew that PTK7 is part of an Fz7/Dsh complex and PTK7 is necessary for Fz7-mediated Dsh recruitment (Shnitsar and Borchers, 2008), we detected the interaction of PTK7 and Fz7. Using combinations of secreted PTK7, secreted Fz7 and recombinant Wnt3a in co-precipitation revealed that Fz7 is required for PTK7 Wnt3a binding. These findings show that PTK7, known as a regulator of PCP, is a receptor for a Wnt ligand that is described to activate $\beta$-catenin dependent Wnt signaling. In functional Xenopus double axis assays, PTK7 was found to inhibit Wnt3a-mediated $\beta$-catenin dependent Wnt signaling (Peradziryi et al., 2011). We analyzed whether the function of PTK7 is also conserved in mammalian cells by performing luciferase reporter assays using the TOPflash luciferase reporter in HEK293 cells. Indeed, we could show that PTK7 inhibits the Wnt3a-induced activation of the luciferase reporter suggesting that PTK7 binds Wnt3a and thereby prevents activation of $\beta$-catenin dependent Wnt signaling. siRNA-mediated knockdown of PTK7 in HEK293 cells revealed that PTK7 is not required for activation of the Wnt signaling pathway and validates what was also found in Xenopus ectodermal explants of embryos undergoing morpholino-induced PTK7 knockdown (Peradziryi et al., 2011). Other authors report an increase of $\beta$-catenin signaling upon PTK7 overexpression, which could be explained by binding of PTK7 to $\beta$-catenin that might prevent $\beta$-catenin from degradation and thereby activating gene transcription (Puppo et al., 2011). Our results for the first time describe PTK7 as a co-receptor for Wnt ligand binding and its function in regulating canonical Wnt signaling. Furthermore, this is conserved in Xenopus and mammalian cells. 


\subsection{PTK7 activates PCP downstream signaling}

PTK7 was previously identified as a regulator of PCP signaling (Lu et al., 2004), but its downstream signaling remains elusive. Therefore, we wanted to investigate its contribution to PCP downstream signaling. Our results show an activation of RhoA and Rac1 by PTK7 expression. An important part of downstream PCP signaling is fulfilled by the small GTPases RhoA and Rac1 (Eaton et al., 1996; Fanto et al., 2000; Habas et al., 2003; Strutt et al., 1997; Tahinci and Symes, 2003). In order to investigate whether PTK7 as a regulator of PCP can activate small GTPase signaling we performed RhoA and Rac1 activation assays. Active GTPases are present in a GTP-bound state that can be probed using the corresponding binding proteins. The CRIB-domain of p21 activated kinase (PAK1B) was used to probe GTP-bound Rac1 (Sander et al., 1998) and the Rho binding domain of Rhotekin was used to probe RhoA-GTP (Ren and Schwartz, 2000). Our analysis of activated RhoA and Rac1 revealed that transient overexpression of PTK7 indeed activates RhoA and Rac1. This finding is an indication for activation of PCP downstream signaling through PTK7 to provoke cytoskeleton rearrangement. Results from the fibrosarcoma cell line HT1080 show that not the full-length PTK7 but the secreted extracellular domain of PTK7 can induce active GTP-bound RhoA (Golubkov et al., 2011; Golubkov et al., 2010).

An additional readout for active PCP signaling is to look for gene transcription upon pathway activation. The N-terminal c-jun kinase JNK is activated by active RhoA and Rac1, which in turn activates $\mathrm{c}$-jun and promotes transcriptional activation. To check for active phosphorylated JNK we performed Western blots detecting phosphorylated JNK in comparison to total JNK using lysates of HEK293 cells that were transfected with different putative activators of PCP signaling. Using this setting it was not possible to detect any increase in JNK phosphorylation in the case of PTK7 overexpression. As the stimulation with recombinant Wnt5a, overexpression of Ror2 and MKK7, which were published to activate JNK (Schambony and Wedlich, 2007; Yamanaka et al., 2002), show a slight increase in phosphorylated JNK, we assume that the experimental setting was correctly chosen. Previously we published that phosphorylated JNK could be detected at the nuclei of Xenopus ectodermal explants of embryos injected with PTK7 mRNA (Shnitsar and Borchers, 2008). Nuclear localization of phosphorylated JNK is an indicator of activated JNK signaling downstream of the PCP signaling cascade (Kaempchen et al., 2003; Tahinci et al., 2007). A further tool to measure activity of PCP downstream signaling is the Activating Transcription Factor2 (ATF2) luciferease reporter (Ohkawara 
and Niehrs, 2011). ATF2 is a downstream target of Wnt5a/Ror2 signaling that belongs to a group of transcription factors, which are activated by JNK (Schambony and Wedlich, 2007). In Peradziryi et al. we could show that in Xenopus embryo lysates overexpression of PTK7 induces ATF2 activity (Peradziryi et al., 2011). Also the receptor tyrosine kinase Ror2 activates ATF2 (Schambony and Wedlich, 2007), which hints at a possible common activity of PTK7 and Ror2. Taken together our results provide reasonable evidence that PTK7 activates PCP downstream signaling.

\subsection{PTK7/Ror2 interaction}

\subsubsection{Biochemical evidence for PTK7/Ror2 interaction}

PTK7 and Ror2 share the same phenotype and both interact with each other in coimmunoprecipitation assays. Overexpression of PTK7 could increase the formation of filopodia-like structures in MCF7 cells. A very similar phenotype was known for the overexpression of Ror2, which binds the actin scaffold protein filamin A with its C-terminal proline rich domain (PRD) to regulate polarized cell migration (Nishita et al., 2006). Furthermore, PTK7 and Ror2 transmembrane proteins are active in convergent extension movement regulation through non-canonical Wnt signaling (Hikasa et al., 2002; Lu et al., 2004; Paudyal et al., 2010; Yen et al., 2009) and bind Wnt proteins (Hikasa et al., 2002; Peradziryi et al., 2011). In the breast cancer cell line MCF7 the overexpression of either PTK7 or Ror2 or their combinaton increases filopodia formation. For further analysis we performed co-immunuoprecipitation approaches, which showed binding of full-length and $\Delta$ kinase domain PTK7 with the full-length Ror2. As we already knew, that the kinase function of PTK7 is impaired due to a mutation in the active center of the kinase domain (Mossie et al., 1995). We speculated that Ror2 could be the kinase, which mediates phosphorylation of the C-terminus of PTK7 in case of signal transmission. However, for binding of the two candidates to each other the C-terminal part of PTK7 is apparently not required. To map the interaction domains, deletion constructs of mouse Ror2 were used to test for the binding to full-length PTK7. All tested Ror2 constructs could bind PTK7. As all of them contain the transmembrane domain, we speculated whether the transmembrane domains of both proteins are required for mediating the interaction. The PTK7 transmembrane domain has a typical GXXXG protein interaction motif at its $\mathrm{N}$ terminal part. Flemming and Kobus predict a function in transmembrane helix-helix interactions for this motif. GXXXG motifs have been described as a driving force for 
protein dimerization of glycophorin alpha (Fleming et al., 1997; Fleming and Engelman, 2001; Fleming et al., 2004). Kobus and Flemming used an SDS PAGE-based approach as well as sedimentation equilibrium analytical ultracentrifugation to study the strength of transmembrane self-association of the PTK7 transmembrane domain and found that it lacks a preferential self-association affinity (Kobus and Fleming, 2005). Furthermore our sequence analysis revealed that in the transmembrane domain of Ror2, the GXXXG motif is not present. Additional tests showed that Ror2 binds secreted PTK7, which is an indication that the transmembrane domain might not be required for the interaction. Our current results demonstrate biochemical interaction of PTK7 and Ror2, but a conclusion of defined binding sites between PTK7 and Ror2 so far cannot be drawn. It also could be the case that the interaction of PTK7 and Ror2 is mediated by an additional interaction partner like Fz. To finally analyze this aspect further experiments are required.

\subsubsection{PTK7 and Ror2 interact functionally in Xenopus neural crest migration}

Endogenous interaction of PTK7 and Ror2 could be demonstrated by the finding that Ror2 modulates PTK7 mediated neural crest migration in functional assays in Xenopus laevis embryos. After we could biochemically show that PTK7 and Ror2 interact in coimmunoprecipitations we wondered whether we could also find evidence for functional interaction in a model organism. PTK7 and Ror2 are required during neural tube closure for convergent extension movements (Hikasa et al., 2002; Lu et al., 2004; Paudyal et al., 2010; Yen et al., 2009). Furthermore, the function of PTK7 is necessary during Xenopus neural crest migration (Shnitsar and Borchers, 2008) and both proteins are expressed in the area of the migrating neural crest cells during development (Hikasa et al., 2002; Shnitsar and Borchers, 2008). These facts led us to ask whether we could identify a genetic interaction of PTK7 and Ror2 in the migrating neural crest cells. To address this question we analyzed the migrating neural crest cells of microinjected Xenopus embryos. The overexpression of Ror2 mRNA, similar to the overexpression of PTK7, could not induce any changes in neural crest migration. Therefore, we injected antisense morpholino oligonucleotides targeting the PTK7 expression to induce a neural crest migration phenotype as previously described (Shnitsar and Borchers, 2008). Co-injection of Ror2 mRNA rescued the PTK7 loss of function phenotype in neural crest cell migration significantly. This finding confirms that the transmembrane receptor tyrosine kinases 
PTK7 and Ror2 share a function in the regulation of neural crest migration, while the molecular mechanism remains unclear. One can only speculate that the active kinase Ror2 might be required for signal transduction downstream of PTK7. However, phosphorylated PTK7 could not be detected when Ror2 was overexpressed.

As we showed that PTK7 is a Fz co-receptor for Wnt and additonally binds Ror2, which is known to interact with Fz (Yamamoto et al., 2008) we speculate that PTK7, Ror2 and Fz could form a triple complex to activate PCP signaling over canonical Wnt signaling.

Our findings also raise the question as to whether the PTK7/Ror2 interaction also plays a role in tumor cell migration and invasion. In this study we show that overexpression of PTK7 in non-invasive MCF7 breast cancer cells induces invasiveness and Ror2 overexpression in NIH3T3 cells drives the polarization and MTOC reorientation (Nomachi et al., 2008). Therefore, it would be interesting to see whether the co-expression of Ror2 in the PTK7 overexpressing MCF7 cells could increase their ability to close cell layer wounds in wound scratch assays compared to PTK7 expression alone. 


\section{Summary and Conclusions}

In summary, our study demonstrates a function of PTK7 in cancer cell invasion; it describes PTK7 as a Wnt co-receptor to inhibit $\beta$-catenin dependent Wnt signaling and identifies Ror2 as a new interaction partner for PTK7 to regulate neural crest migration. These findings show conservation in Xenopus and mammalian cells. Thereby the results of our study provide insights into the role of different Wnt signaling pathways in cell migration during embryogenesis and tumor progression. With the established inducible PTK7 expression in MCF7 cells we offer a useful tool to analyze further aspects of invasive tumor cell migration. 


\section{Supplement}

\section{Detailed protocol of Whole-mount in situ hybridization (WISH)}

Whole-mount in situ hybridization (WISH)

Whole-mount in situ hybridization (WISH) was performed as described (Harland, 1991). All the steps were performed at room temperature with mild agitation.

\section{WISH day 1.}

Rehydration of embryos

Prior to WISH embryos were rehydrated, as described below.

\section{Rehydration of embryos}

\begin{tabular}{|c|l|c|}
\hline $\begin{array}{c}\text { Step } \\
\text { Number }\end{array}$ & Solution & $\begin{array}{c}\text { Incubation } \\
\text { time }\end{array}$ \\
\hline 1 & $100 \%$ ethanol & $3 \mathrm{~min}$ \\
\hline 2 & $75 \%$ ethanol in water & $3 \mathrm{~min}$ \\
\hline 3 & $50 \%$ ethanol in water & $3 \mathrm{~min}$ \\
\hline 4 & $25 \%$ ethanol in PTw & $3 \mathrm{~min}$ \\
\hline 5 & PTw & $3 \mathrm{~min}$ \\
\hline
\end{tabular}

\section{Proteinase K treatment}

To make the embryos accessible for RNA probes, they were treated with proteinase $\mathrm{K}$ (10 $\mu \mathrm{g} / \mathrm{ml}$ ) in PTw. The proteinase $\mathrm{K}$ incubation time was chosen depending on the embryo stage.

\section{Proteinase K treatment procedure}

\begin{tabular}{|l|l|l|}
\hline $\begin{array}{l}\text { Developmental } \\
\text { stage } \\
\text { Xenopus } \\
\text { embryos }\end{array}$ & $\begin{array}{l}\text { Incubation time } \\
\text { (min) }\end{array}$ & Temperature \\
\hline $9-10.5$ & $6-8$ & room temperature \\
\hline $14-16$ & $8-10$ & room temperature \\
\hline $20-25$ & $15-18$ & room temperature \\
\hline 36 & $22-25$ & room temperature \\
\hline 40 & $17-20$ & $37^{\circ} \mathrm{C}$ \\
\hline $42-43$ & $27-30$ & $37^{\circ} \mathrm{C}$ \\
\hline 46 & $32-35$ & $37^{\circ} \mathrm{C}$ \\
\hline
\end{tabular}

Acetylation and refixation

Acetylation of embryos was performed as described below. 
Acetylation of Xenopus embryos

\begin{tabular}{|l|l|l|}
\hline $\begin{array}{l}\text { Step } \\
\text { Number }\end{array}$ & Buffer & $\begin{array}{l}\text { Incubation } \\
\text { time }\end{array}$ \\
\hline 1 & 1 M Triethanolamine chlorid, pH 7.0 (TEA) & $2 \times 5 \mathrm{~min}$ \\
\hline 2 & $1 \mathrm{M}$ TEA with $0.3 \%$ acetic anhydride & $5 \mathrm{~min}$ \\
\hline 3 & $1 \mathrm{M}$ TEA with $0.6 \%$ acetic anhydride & $5 \mathrm{~min}$ \\
\hline 4 & PTw & $5 \mathrm{~min}$ \\
\hline
\end{tabular}

Upon acetylation, embryos were fixed for 20 minutes in PTw containing 4\% (v/v) formaldehyde and washed 5 times with PTw buffer.

\section{Hybridization}

After the last washing step approximately $1 \mathrm{ml}$ of PTw was left in the tubes and $250 \mu \mathrm{l} \mathrm{Hyb-Mix}$ was added. The solution was replaced immediately by $500 \mu \mathrm{l}$ of fresh Hyb-Mix and incubated for 10 minutes at $60^{\circ} \mathrm{C}$. Hyb-Mix was exchanged again and embryos were incubated $4-5 \mathrm{~h}$ at $60^{\circ} \mathrm{C}$. The Hyb-Mix was replaced with the desired labeled RNA probe, diluted in Hyb-Mix solution. The hybridization took place overnight at $60^{\circ} \mathrm{C}$.

\section{WISH day 2.}

\section{Washing and RNAse treatment}

To remove unbound RNA probes, the samples were washed and digested with RNAse A (10 $\mu \mathrm{g} / \mathrm{ml})$ and RNAse $\mathrm{T} 1(10 \mathrm{U} / \mathrm{ml})$ as described in the table below.

Washing and RNAse treatment of Xenopus embryos

\begin{tabular}{|l|l|l|}
\hline $\begin{array}{l}\text { Step } \\
\text { Number }\end{array}$ & Solution & Incubation temperature and time \\
\hline 1 & Hyb Mix & $60^{\circ} \mathrm{C}, 10 \mathrm{~min}$ \\
\hline 2 & $2 \times \mathrm{SSC}$ & $60^{\circ} \mathrm{C}, 3 \times 15 \mathrm{~min}$ \\
\hline 3 & RNAses in $2 \times \mathrm{SSC}$ & $37^{\circ} \mathrm{C}, 60 \mathrm{~min}$ \\
\hline 4 & $2 \times \mathrm{SSC}$ & room temperature, 5 min \\
\hline 5 & $0.2 \times \mathrm{SSC}$ & $60^{\circ} \mathrm{C}, 2 \times 30$ min \\
\hline 6 & $\mathrm{MAB}$ & room temperature, $2 \times 15 \mathrm{~min}$ \\
\hline
\end{tabular}


Embryos were blocked with MAB buffer, containing the Boehringer Mannheim Blocking Reagent (BMB) and horse serum, and incubated with Sheep Alkaline phosphatase-coupled anti-Dig antibody (Sigma) according to the table below.

Blocking and antibody incubation

\begin{tabular}{|l|l|l|}
\hline $\begin{array}{l}\text { Step } \\
\text { Number }\end{array}$ & \multicolumn{1}{|c|}{ Solution } & \multicolumn{1}{|c|}{$\begin{array}{l}\text { Incubation temperature and } \\
\text { time }\end{array}$} \\
\hline 1 & $\mathrm{MAB} / 2 \% \mathrm{BMB}$ & room temperature, $10 \mathrm{~min}$ \\
\hline 2 & $\mathrm{MAB} / 2 \% \mathrm{BMB} / 20 \%$ Horse serum & room temperature, 30 min \\
\hline 3 & $\begin{array}{l}\mathrm{MAB} / 2 \% \mathrm{BMB} / 20 \% \text { Horse serum } \\
1: 5000 \mathrm{\alpha}-\mathrm{DIG} \text { antibodies }\end{array}$ & room temperature, 4 hours \\
\hline 4 & $\mathrm{MAB}$ & room temperature, 3x $10 \mathrm{~min}$ \\
\hline 5 & $\mathrm{MAB}$ & $4^{\circ} \mathrm{C}$, overnight \\
\hline
\end{tabular}

WISH day 3.

Staining reaction

The alkaline phosphatase staining reaction was performed as described in the table below.

Alkaline phosphatase staining reaction

\begin{tabular}{|l|l|l|}
\hline Step Number & Solution & Incubation time \\
\hline 1 & MAB & $5 \times 5$ min, room ttemperature \\
\hline 2 & APB & $3 \times 5$ min, room ttemperature \\
\hline 3 & $\begin{array}{l}\text { APB with } 80 \mu \mathrm{g} / \mathrm{ml} \mathrm{NBT}, \\
175 \mu \mathrm{g} / \mathrm{ml} \mathrm{BCIP}\end{array}$ & Up to three days, $4^{\circ} \mathrm{C}$ \\
\hline
\end{tabular}

Upon staining, albino embryos were fixed in MEMFA, washed with PTw, documented and stored in $100 \%$ ethanol. Pigmented embryos were bleached as described in section 2.10.3 to remove the pigment, which can interfere with the specific WISH signal. 


\section{Bleaching}

The bleaching of pigmented embryos was performed as described in the table below.

\section{Bleaching of pigmented Xenopus embryos}

\begin{tabular}{|l|l|l|}
\hline $\begin{array}{l}\text { Step } \\
\text { Number }\end{array}$ & \multicolumn{1}{|c|}{ Solution } & \multicolumn{1}{|c|}{ Incubation time } \\
\hline 1 & $2 \times$ SSC & $3 \times 5$ min \\
\hline 2 & $2 \times S S C$ with $50 \%$ formamide, $1 \% \mathrm{H}_{2} \mathrm{O}_{2}$, & Until embryos loose pigment \\
\hline 3 & MEMFA & 30 min \\
\hline 4 & PTw & $3 \times 5$ min \\
\hline
\end{tabular}

Bleached embryos were documented and stored in $100 \%$ ethanol. 


\section{Bibliography}

Aaku-Saraste, E., Hellwig, A. and Huttner, W.B., 1996. Loss of occludin and functional tight junctions, but not ZO-1, during neural tube closure--remodeling of the neuroepithelium prior to neurogenesis. Dev Biol. 180, 664-79.

Aberle, H., Bauer, A., Stappert, J., Kispert, A. and Kemler, R., 1997. beta-catenin is a target for the ubiquitin-proteasome pathway. Embo J. 16, 3797-804.

Akbarzadeh, S., Wheldon, L.M., Sweet, S.M., Talma, S., Mardakheh, F.K. and Heath, J.K., 2008. The deleted in brachydactyly B domain of ROR2 is required for receptor activation by recruitment of Src. PLoS One. 3, e1873.

Alahari, S.K., Reddig, P.J. and Juliano, R.L., 2002. Biological aspects of signal transduction by cell adhesion receptors. Int Rev Cytol. 220, 145-84.

Albini, A., Iwamoto, Y., Kleinman, H.K., Martin, G.R., Aaronson, S.A., Kozlowski, J.M. and McEwan, R.N., 1987. A rapid in vitro assay for quantitating the invasive potential of tumor cells. Cancer Res. 47, 3239-45.

Aman, A. and Piotrowski, T., 2010. Cell migration during morphogenesis. Dev Biol. 341, 2033.

Angers, S. and Moon, R.T., 2009. Proximal events in Wnt signal transduction. Nat Rev Mol Cell Biol. 10, 468-77.

Ataliotis, P. and Mercola, M., 1997. Distribution and functions of platelet-derived growth factors and their receptors during embryogenesis. Int Rev Cytol. 172, 95-127.

Aybar, M.J., Nieto, M.A. and Mayor, R., 2003. Snail precedes slug in the genetic cascade required for the specification and migration of the Xenopus neural crest. Development. 130, 483-94.

Banga, S.S., Ozer, H.L., Park, S.K. and Lee, S.T., 1997. Assignment of PTK7 encoding a receptor protein tyrosine kinase-like molecule to human chromosome 6p21.1-->p12.2 by fluorescence in situ hybridization. Cytogenet Cell Genet. 76, 43-4.

Barembaum, M. and Bronner-Fraser, M., 2005. Early steps in neural crest specification. Semin Cell Dev Biol. 16, 642-6.

Bastock, R., Strutt, H. and Strutt, D., 2003. Strabismus is asymmetrically localised and binds to Prickle and Dishevelled during Drosophila planar polarity patterning. Development. 130, 3007-14.

Batlle, E., Sancho, E., Franci, C., Dominguez, D., Monfar, M., Baulida, J. and Garcia De Herreros, A., 2000. The transcription factor snail is a repressor of E-cadherin gene expression in epithelial tumour cells. Nat Cell Biol. 2, 84-9.

Bayly, R. and Axelrod, J.D., 2011. Pointing in the right direction: new developments in the field of planar cell polarity. Nat Rev Genet. 12, 385-91.

Behrens, J., von Kries, J.P., Kuhl, M., Bruhn, L., Wedlich, D., Grosschedl, R. and Birchmeier, W., 1996. Functional interaction of beta-catenin with the transcription factor LEF-1. Nature. 382, 638-42.

Bhanot, P., Brink, M., Samos, C.H., Hsieh, J.C., Wang, Y., Macke, J.P., Andrew, D., Nathans, J. and Nusse, R., 1996. A new member of the frizzled family from Drosophila functions as a Wingless receptor. Nature. 382, 225-30.

Billiard, J., Way, D.S., Seestaller-Wehr, L.M., Moran, R.A., Mangine, A. and Bodine, P.V., 2005. The orphan receptor tyrosine kinase Ror2 modulates canonical Wnt signaling in osteoblastic cells. Mol Endocrinol. 19, 90-101.

Bonstein, L., Elias, S. and Frank, D., 1998. Paraxial-fated mesoderm is required for neural crest induction in Xenopus embryos. Dev Biol. 193, 156-68. 
Boutros, M., Paricio, N., Strutt, D.I. and Mlodzik, M., 1998. Dishevelled activates JNK and discriminates between JNK pathways in planar polarity and wingless signaling. Cell. 94, 109-18.

Brown, C.B., Feiner, L., Lu, M.M., Li, J., Ma, X., Webber, A.L., Jia, L., Raper, J.A. and Epstein, J.A., 2001. PlexinA2 and semaphorin signaling during cardiac neural crest development. Development. 128, 3071-80.

Buccione, R., Caldieri, G. and Ayala, I., 2009. Invadopodia: specialized tumor cell structures for the focal degradation of the extracellular matrix. Cancer Metastasis Rev. 28, 13749.

Cabrera, C.V., Alonso, M.C., Johnston, P., Phillips, R.G. and Lawrence, P.A., 1987. Phenocopies induced with antisense RNA identify the wingless gene. Cell. 50, 65963.

Caddy, J., Wilanowski, T., Darido, C., Dworkin, S., Ting, S.B., Zhao, Q., Rank, G., Auden, A., Srivastava, S., Papenfuss, T.A., Murdoch, J.N., Humbert, P.O., Parekh, V., Boulos, N., Weber, T., Zuo, J., Cunningham, J.M. and Jane, S.M., 2010. Epidermal wound repair is regulated by the planar cell polarity signaling pathway. Dev Cell. 19, 138-47.

Cano, A., Perez-Moreno, M.A., Rodrigo, I., Locascio, A., Blanco, M.J., del Barrio, M.G., Portillo, F. and Nieto, M.A., 2000. The transcription factor snail controls epithelialmesenchymal transitions by repressing E-cadherin expression. Nat Cell Biol. 2, 7683.

Cantrell, V.A. and Jessen, J.R., 2010. The planar cell polarity protein Van Gogh-Like 2 regulates tumor cell migration and matrix metalloproteinase-dependent invasion. Cancer Lett. 287, 54-61.

Carl, T.F., Dufton, C., Hanken, J. and Klymkowsky, M.W., 1999. Inhibition of neural crest migration in Xenopus using antisense slug RNA. Dev Biol. 213, 101-15.

Carmona-Fontaine, C., Matthews, H.K., Kuriyama, S., Moreno, M., Dunn, G.A., Parsons, M., Stern, C.D. and Mayor, R., 2008. Contact inhibition of locomotion in vivo controls neural crest directional migration. Nature. 456, 957-61.

Carter, S.B., 1965. Principles of cell motility: the direction of cell movement and cancer invasion. Nature. 208, 1183-7.

Carver, E.A., Jiang, R., Lan, Y., Oram, K.F. and Gridley, T., 2001. The mouse snail gene encodes a key regulator of the epithelial-mesenchymal transition. Mol Cell Biol. 21, 8184-8.

Cavallo, R.A., Cox, R.T., Moline, M.M., Roose, J., Polevoy, G.A., Clevers, H., Peifer, M. and Bejsovec, A., 1998. Drosophila Tcf and Groucho interact to repress Wingless signalling activity. Nature. 395, 604-8.

Chambers, A.F., Groom, A.C. and MacDonald, I.C., 2002. Dissemination and growth of cancer cells in metastatic sites. Nat Rev Cancer. 2, 563-72.

Chen, W.T., 1989. Proteolytic activity of specialized surface protrusions formed at rosette contact sites of transformed cells. J Exp Zool. 251, 167-85.

Chou, Y.H. and Hayman, M.J., 1991. Characterization of a member of the immunoglobulin gene superfamily that possibly represents an additional class of growth factor receptor. Proc Natl Acad Sci U S A. 88, 4897-901.

Ciruna, B. and Rossant, J., 2001. FGF signaling regulates mesoderm cell fate specification and morphogenetic movement at the primitive streak. Dev Cell. 1, 37-49.

Clevers, H., 2006. Wnt/beta-catenin signaling in development and disease. Cell. 127, 46980.

Cotran, R.a., 2005. Pathologic Basis of Disease 7/E, in: Kumar, A., Fausto (Ed.), Pathologic Basis of Disease. Elsevier Inc., Philadelphia Pennsylvania

Coyle, R.C., Latimer, A. and Jessen, J.R., 2008. Membrane-type 1 matrix metalloproteinase regulates cell migration during zebrafish gastrulation: evidence for an interaction with non-canonical Wnt signaling. Exp Cell Res. 314, 2150-62.

Dabdoub, A., Donohue, M.J., Brennan, A., Wolf, V., Montcouquiol, M., Sassoon, D.A., Hseih, J.C., Rubin, J.S., Salinas, P.C. and Kelley, M.W., 2003. Wnt signaling mediates 
reorientation of outer hair cell stereociliary bundles in the mammalian cochlea. Development. 130, 2375-84.

Dabdoub, A. and Kelley, M.W., 2005. Planar cell polarity and a potential role for a Wnt morphogen gradient in stereociliary bundle orientation in the mammalian inner ear. $\mathrm{J}$ Neurobiol. 64, 446-57.

Damianitsch, K., Melchert, J. and Pieler, T., 2009. XsFRP5 modulates endodermal organogenesis in Xenopus laevis. Dev Biol. 329, 327-37.

Davidson, G., Wu, W., Shen, J., Bilic, J., Fenger, U., Stannek, P., Glinka, A. and Niehrs, C., 2005. Casein kinase 1 gamma couples Wnt receptor activation to cytoplasmic signal transduction. Nature. 438, 867-72.

Davy, A., Aubin, J. and Soriano, P., 2004. Ephrin-B1 forward and reverse signaling are required during mouse development. Genes Dev. 18, 572-83.

De Calisto, J., Araya, C., Marchant, L., Riaz, C.F. and Mayor, R., 2005. Essential role of noncanonical Wnt signalling in neural crest migration. Development. 132, 2587-97.

De Smet, F., Segura, I., De Bock, K., Hohensinner, P.J. and Carmeliet, P., 2009. Mechanisms of vessel branching: filopodia on endothelial tip cells lead the way. Arterioscler Thromb Vasc Biol. 29, 639-49.

DeLuca, S.M., Gerhart, J., Cochran, E., Simak, E., Blitz, J., Mattiacci-Paessler, M., Knudsen, K. and George-Weinstein, M., 1999. Hepatocyte growth factor/scatter factor promotes a switch from E- to N-cadherin in chick embryo epiblast cells. Exp Cell Res. 251, 315.

Dickson, B.J. and Gilestro, G.F., 2006. Regulation of commissural axon pathfinding by slit and its Robo receptors. Annu Rev Cell Dev Biol. 22, 651-75.

Diz-Munoz, A., Krieg, M., Bergert, M., Ibarlucea-Benitez, I., Muller, D.J., Paluch, E. and Heisenberg, C.P., 2010. Control of directed cell migration in vivo by membrane-tocortex attachment. PLoS Biol. 8, e1000544.

Dominguez, I., Itoh, K. and Sokol, S.Y., 1995. Role of glycogen synthase kinase 3 beta as a negative regulator of dorsoventral axis formation in Xenopus embryos. Proc Natl Acad Sci U S A. 92, 8498-502.

Dower, W.J., Miller, J.F. and Ragsdale, C.W., 1988. High efficiency transformation of E. coli by high voltage electroporation. Nucleic Acids Res. 16, 6127-45.

Du, S.J., Purcell, S.M., Christian, J.L., McGrew, L.L. and Moon, R.T., 1995. Identification of distinct classes and functional domains of Wnts through expression of wild-type and chimeric proteins in Xenopus embryos. Mol Cell Biol. 15, 2625-34.

Easty, D.J., Mitchell, P.J., Patel, K., Florenes, V.A., Spritz, R.A. and Bennett, D.C., 1997. Loss of expression of receptor tyrosine kinase family genes PTK7 and SEK in metastatic melanoma. Int J Cancer. 71, 1061-5.

Eaton, S., Wepf, R. and Simons, K., 1996. Roles for Rac1 and Cdc42 in planar polarization and hair outgrowth in the wing of Drosophila. J Cell Biol. 135, 1277-89.

Eickholt, B.J., Mackenzie, S.L., Graham, A., Walsh, F.S. and Doherty, P., 1999. Evidence for collapsin-1 functioning in the control of neural crest migration in both trunk and hindbrain regions. Development. 126, 2181-9.

Elbashir, S.M., Harborth, J., Lendeckel, W., Yalcin, A., Weber, K. and Tuschl, T., 2001. Duplexes of 21-nucleotide RNAs mediate RNA interference in cultured mammalian cells. Nature. 411, 494-8.

Elloul, S., Elstrand, M.B., Nesland, J.M., Trope, C.G., Kvalheim, G., Goldberg, I., Reich, R. and Davidson, B., 2005. Snail, Slug, and Smad-interacting protein 1 as novel parameters of disease aggressiveness in metastatic ovarian and breast carcinoma. Cancer. 103, 1631-43.

Emsley, J., Knight, C.G., Farndale, R.W., Barnes, M.J. and Liddington, R.C., 2000. Structural basis of collagen recognition by integrin alpha2beta1. Cell. 101, 47-56.

Endoh, H., Tomida, S., Yatabe, Y., Konishi, H., Osada, H., Tajima, K., Kuwano, H., Takahashi, T. and Mitsudomi, T., 2004. Prognostic model of pulmonary adenocarcinoma by expression profiling of eight genes as determined by quantitative real-time reverse transcriptase polymerase chain reaction. J Clin Oncol. 22, 811-9. 
Enomoto, M., Hayakawa, S., Itsukushima, S., Ren, D.Y., Matsuo, M., Tamada, K., Oneyama, C., Okada, M., Takumi, T., Nishita, M. and Minami, Y., 2009. Autonomous regulation of osteosarcoma cell invasiveness by Wnt5a/Ror2 signaling. Oncogene. 28, 3197208.

Etienne-Manneville, S. and Hall, A., 2002. Rho GTPases in cell biology. Nature. 420, 629-35.

Fanto, M., Weber, U., Strutt, D.I. and Mlodzik, M., 2000. Nuclear signaling by Rac and Rho GTPases is required in the establishment of epithelial planar polarity in the Drosophila eye. Curr Biol. 10, 979-88.

Felgner, P.L., Gadek, T.R., Holm, M., Roman, R., Chan, H.W., Wenz, M., Northrop, J.P., Ringold, G.M. and Danielsen, M., 1987. Lipofection: a highly efficient, lipid-mediated DNA-transfection procedure. Proc Natl Acad Sci U S A. 84, 7413-7.

Fisher, M.P. and Dingman, C.W., 1971. Role of molecular conformation in determining the electrophoretic properties of polynucleotides in agarose-acrylamide composite gels. Biochemistry. 10, 1895-9.

Fleming, K.G., Ackerman, A.L. and Engelman, D.M., 1997. The effect of point mutations on the free energy of transmembrane alpha-helix dimerization. J Mol Biol. 272, 266-75.

Fleming, K.G. and Engelman, D.M., 2001. Specificity in transmembrane helix-helix interactions can define a hierarchy of stability for sequence variants. Proc Natl Acad Sci U S A. 98, 14340-4.

Fleming, K.G., Ren, C.C., Doura, A.K., Eisley, M.E., Kobus, F.J. and Stanley, A.M., 2004. Thermodynamics of glycophorin A transmembrane helix dimerization in $\mathrm{C} 14$ betaine micelles. Biophys Chem. 108, 43-9.

Forrester, W.C., Kim, C. and Garriga, G., 2004. The Caenorhabditis elegans Ror RTK CAM1 inhibits EGL-20/Wnt signaling in cell migration. Genetics. 168, 1951-62.

Friedl, P. and Gilmour, D., 2009. Collective cell migration in morphogenesis, regeneration and cancer. Nat Rev Mol Cell Biol. 10, 445-57.

Friedl, P., Hegerfeldt, Y. and Tusch, M., 2004. Collective cell migration in morphogenesis and cancer. Int J Dev Biol. 48, 441-9.

Friedl, P., Noble, P.B., Walton, P.A., Laird, D.W., Chauvin, P.J., Tabah, R.J., Black, M. and Zanker, K.S., 1995. Migration of coordinated cell clusters in mesenchymal and epithelial cancer explants in vitro. Cancer Res. 55, 4557-60.

Friedl, P. and Weigelin, B., 2008. Interstitial leukocyte migration and immune function. Nat Immunol. 9, 960-9.

Friedl, P. and Wolf, K., 2003. Tumour-cell invasion and migration: diversity and escape mechanisms. Nat Rev Cancer. 3, 362-74.

Fukui, A., Goto, T., Kitamoto, J., Homma, M. and Asashima, M., 2007. SDF-1 alpha regulates mesendodermal cell migration during frog gastrulation. Biochem Biophys Res Commun. 354, 472-7.

Giancotti, F.G. and Ruoslahti, E., 1999. Integrin signaling. Science. 285, 1028-32.

Gitler, A.D., Lu, M.M. and Epstein, J.A., 2004. PlexinD1 and semaphorin signaling are required in endothelial cells for cardiovascular development. Dev Cell. 7, 107-16.

Glading, A., Lauffenburger, D.A. and Wells, A., 2002. Cutting to the chase: calpain proteases in cell motility. Trends Cell Biol. 12, 46-54.

Golubkov, V.S., Aleshin, A.E. and Strongin, A.Y., 2011. Potential Relation of Aberrant Proteolysis of Human Protein Tyrosine Kinase 7 (PTK7) chuzhoi by Membrane Type 1 Matrix Metalloproteinase (MT1-MMP) to Congenital Defects. J Biol Chem. 286, 20970-6.

Golubkov, V.S., Chekanov, A.V., Cieplak, P., Aleshin, A.E., Chernov, A.V., Zhu, W., Radichev, I.A., Zhang, D., Dong, P.D. and Strongin, A.Y., 2010. The Wnt/planar cell polarity protein-tyrosine kinase-7 (PTK7) is a highly efficient proteolytic target of membrane type-1 matrix metalloproteinase: implications in cancer and embryogenesis. J Biol Chem. 285, 35740-9.

Goodrich, L.V., 2008. The plane facts of PCP in the CNS. Neuron. 60, 9-16. 
Gorringe, K.L., Boussioutas, A. and Bowtell, D.D., 2005. Novel regions of chromosomal amplification at $6 \mathrm{p} 21,5 \mathrm{p} 13$, and $12 \mathrm{q} 14$ in gastric cancer identified by array comparative genomic hybridization. Genes Chromosomes Cancer. 42, 247-59.

Graham, F.L., Smiley, J., Russell, W.C. and Nairn, R., 1977. Characteristics of a human cell line transformed by DNA from human adenovirus type 5. J Gen Virol. 36, 59-74.

Green, J.L., Inoue, T. and Sternberg, P.W., 2007. The C. elegans ROR receptor tyrosine kinase, CAM-1, non-autonomously inhibits the Wnt pathway. Development. 134, 4053-62.

Green, J.L., Kuntz, S.G. and Sternberg, P.W., 2008. Ror receptor tyrosine kinases: orphans no more. Trends Cell Biol. 18, 536-44.

Grose, R., Hutter, C., Bloch, W., Thorey, I., Watt, F.M., Fassler, R., Brakebusch, C. and Werner, S., 2002. A crucial role of beta 1 integrins for keratinocyte migration in vitro and during cutaneous wound repair. Development. 129, 2303-15.

Gubb, D. and Garcia-Bellido, A., 1982. A genetic analysis of the determination of cuticular polarity during development in Drosophila melanogaster. J Embryol Exp Morphol. 68, 37-57.

Guger, K.A. and Gumbiner, B.M., 1995. beta-Catenin has Wnt-like activity and mimics the Nieuwkoop signaling center in Xenopus dorsal-ventral patterning. Dev Biol. 172, 11525.

Habas, R., Dawid, I.B. and He, X., 2003. Coactivation of Rac and Rho by Wnt/Frizzled signaling is required for vertebrate gastrulation. Genes Dev. 17, 295-309.

Habas, R., Kato, Y. and He, X., 2001. Wnt/Frizzled activation of Rho regulates vertebrate gastrulation and requires a novel Formin homology protein Daam1. Cell. 107, 843-54.

Hagemann, T., Robinson, S.C., Schulz, M., Trumper, L., Balkwill, F.R. and Binder, C., 2004. Enhanced invasiveness of breast cancer cell lines upon co-cultivation with macrophages is due to TNF-alpha dependent up-regulation of matrix metalloproteases. Carcinogenesis. 25, 1543-9.

Hammerschmidt, M. and Wedlich, D., 2008. Regulated adhesion as a driving force of gastrulation movements. Development. 135, 3625-41.

Hanahan, D. and Weinberg, R.A., 2011. Hallmarks of cancer: the next generation. Cell. 144, 646-74.

Harland, R.M., 1991. In situ hybridization: an improved whole-mount method for Xenopus embryos. Methods Cell Biol. 36, 685-95.

Hazel L. Sive, R.G., Richard M. Harland, 2000. Early Development of Xenopus laevis A Laboratory Manual, Cold Spring Harbour Laboratory Press,

Cold Spring Harbour, New York.

He, X., Saint-Jeannet, J.P., Woodgett, J.R., Varmus, H.E. and Dawid, I.B., 1995. Glycogen synthase kinase-3 and dorsoventral patterning in Xenopus embryos. Nature. 374, 617-22.

Hegerfeldt, Y., Tusch, M., Brocker, E.B. and Friedl, P., 2002. Collective cell movement in primary melanoma explants: plasticity of cell-cell interaction, beta1-integrin function, and migration strategies. Cancer Res. 62, 2125-30.

Heisenberg, C.P., Tada, M., Rauch, G.J., Saude, L., Concha, M.L., Geisler, R., Stemple, D.L., Smith, J.C. and Wilson, S.W., 2000. Silberblick/Wnt11 mediates convergent extension movements during zebrafish gastrulation. Nature. 405, 76-81.

Helling, R.B., Goodman, H.M. and Boyer, H.W., 1974. Analysis of endonuclease R-EcoRI fragments of DNA from lambdoid bacteriophages and other viruses by agarose-gel electrophoresis. J Virol. 14, 1235-44.

Hendey, B., Klee, C.B. and Maxfield, F.R., 1992. Inhibition of neutrophil chemokinesis on vitronectin by inhibitors of calcineurin. Science. 258, 296-9.

Hikasa, H., Shibata, M., Hiratani, I. and Taira, M., 2002. The Xenopus receptor tyrosine kinase Xror2 modulates morphogenetic movements of the axial mesoderm and neuroectoderm via Wnt signaling. Development. 129, 5227-39.

Hillen, W. and Berens, C., 1994. Mechanisms underlying expression of Tn10 encoded tetracycline resistance. Annu Rev Microbiol. 48, 345-69. 
Hillen, W., Gatz, C., Altschmied, L., Schollmeier, K. and Meier, I., 1983. Control of expression of the Tn10-encoded tetracycline resistance genes. Equilibrium and kinetic investigation of the regulatory reactions. J Mol Biol. 169, 707-21.

Hopwood, N.D., Pluck, A. and Gurdon, J.B., 1989. MyoD expression in the forming somites is an early response to mesoderm induction in Xenopus embryos. Embo J. 8, 340917.

Hynes, R.O., 1992. Integrins: versatility, modulation, and signaling in cell adhesion. Cell. 69, 11-25.

Itoh, K., Antipova, A., Ratcliffe, M.J. and Sokol, S., 2000. Interaction of dishevelled and Xenopus axin-related protein is required for wnt signal transduction. Mol Cell Biol. 20, 2228-38.

Itoh, R.E., Kurokawa, K., Ohba, Y., Yoshizaki, H., Mochizuki, N. and Matsuda, M., 2002. Activation of rac and cdc42 video imaged by fluorescent resonance energy transferbased single-molecule probes in the membrane of living cells. Mol Cell Biol. 22, 658291.

Jenny, A., Reynolds-Kenneally, J., Das, G., Burnett, M. and Mlodzik, M., 2005. Diego and Prickle regulate Frizzled planar cell polarity signalling by competing for Dishevelled binding. Nat Cell Biol. 7, 691-7.

Jessen, J.R., Topczewski, J., Bingham, S., Sepich, D.S., Marlow, F., Chandrasekhar, A. and Solnica-Krezel, L., 2002. Zebrafish trilobite identifies new roles for Strabismus in gastrulation and neuronal movements. Nat Cell Biol. 4, 610-5.

Jia, L., Cheng, L. and Raper, J., 2005. Slit/Robo signaling is necessary to confine early neural crest cells to the ventral migratory pathway in the trunk. Dev Biol. 282, 411-21.

Jones, C. and Chen, P., 2007. Planar cell polarity signaling in vertebrates. Bioessays. 29, 120-32.

Joyce, J.A. and Pollard, J.W., 2009. Microenvironmental regulation of metastasis. Nat Rev Cancer. 9, 239-52.

Julius, M.A., Schelbert, B., Hsu, W., Fitzpatrick, E., Jho, E., Fagotto, F., Costantini, F. and Kitajewski, J., 2000. Domains of axin and disheveled required for interaction and function in wnt signaling. Biochem Biophys Res Commun. 276, 1162-9.

Jung, J.W., Shin, W.S., Song, J. and Lee, S.T., 2004. Cloning and characterization of the fulllength mouse Ptk7 cDNA encoding a defective receptor protein tyrosine kinase. Gene. 328, 75-84.

Kaempchen, K., Mielke, K., Utermark, T., Langmesser, S. and Hanemann, C.O., 2003. Upregulation of the Rac1/JNK signaling pathway in primary human schwannoma cells. Hum Mol Genet. 12, 1211-21.

Kani, S., Oishi, I., Yamamoto, H., Yoda, A., Suzuki, H., Nomachi, A., lozumi, K., Nishita, M., Kikuchi, A., Takumi, T. and Minami, Y., 2004. The receptor tyrosine kinase Ror2 associates with and is activated by casein kinase lepsilon. J Biol Chem. 279, 501029.

Karner, C., Wharton, K.A., Jr. and Carroll, T.J., 2006. Planar cell polarity and vertebrate organogenesis. Semin Cell Dev Biol. 17, 194-203.

Keller, R., 2002. Shaping the vertebrate body plan by polarized embryonic cell movements. Science. 298, 1950-4.

Keller, R., 2005. Cell migration during gastrulation. Curr Opin Cell Biol. 17, 533-41.

Keller, R., Davidson, L., Edlund, A., Elul, T., Ezin, M., Shook, D. and Skoglund, P., 2000. Mechanisms of convergence and extension by cell intercalation. Philos Trans R Soc Lond B Biol Sci. 355, 897-922.

Keller, R., Davidson, L.A. and Shook, D.R., 2003. How we are shaped: the biomechanics of gastrulation. Differentiation. 71, 171-205.

Keller, R.E., 1980. The cellular basis of epiboly: an SEM study of deep-cell rearrangement during gastrulation in Xenopus laevis. J Embryol Exp Morphol. 60, 201-34.

Kessenbrock, K., Plaks, V. and Werb, Z., 2010. Matrix metalloproteinases: regulators of the tumor microenvironment. Cell. 141, 52-67. 
Kinbara, K., Goldfinger, L.E., Hansen, M., Chou, F.L. and Ginsberg, M.H., 2003. Ras GTPases: integrins' friends or foes? Nat Rev Mol Cell Biol. 4, 767-76.

Kishida, S., Yamamoto, H., Hino, S., Ikeda, S., Kishida, M. and Kikuchi, A., 1999. DIX domains of $\mathrm{Dvl}$ and axin are necessary for protein interactions and their ability to regulate beta-catenin stability. Mol Cell Biol. 19, 4414-22.

Klein, T.J. and Mlodzik, M., 2004. A conserved signaling cassette regulates hair patterning from Drosophila to man. Proc Natl Acad Sci U S A. 101, 9173-4.

Klein, T.J. and Mlodzik, M., 2005. Planar cell polarization: an emerging model points in the right direction. Annu Rev Cell Dev Biol. 21, 155-76.

Knecht, A.K. and Bronner-Fraser, M., 2002. Induction of the neural crest: a multigene process. Nat Rev Genet. 3, 453-61.

Kobus, F.J. and Fleming, K.G., 2005. The GxxxG-containing transmembrane domain of the CCK4 oncogene does not encode preferential self-interactions. Biochemistry. 44, 1464-70.

Kolodkin, A.L., 1998. Semaphorin-mediated neuronal growth cone guidance. Prog Brain Res. 117, 115-32.

Kolsch, V., Charest, P.G. and Firtel, R.A., 2008. The regulation of cell motility and chemotaxis by phospholipid signaling. J Cell Sci. 121, 551-9.

Korff, T. and Augustin, H.G., 1999. Tensional forces in fibrillar extracellular matrices control directional capillary sprouting. J Cell Sci. 112 ( Pt 19), 3249-58.

Korinek, V., Barker, N., Morin, P.J., van Wichen, D., de Weger, R., Kinzler, K.W., Vogelstein, B. and Clevers, H., 1997. Constitutive transcriptional activation by a beta-catenin-Tcf complex in APC-/- colon carcinoma. Science. 275, 1784-7.

Kricka, J.L. and Thorpe, G.H., 1985. Recent progress in bioluminescence and chemiluminescence. Ann Biol Clin (Paris). 43, 457-62.

Kuhnert, F., Davis, C.R., Wang, H.T., Chu, P., Lee, M., Yuan, J., Nusse, R. and Kuo, C.J., 2004. Essential requirement for Wnt signaling in proliferation of adult small intestine and colon revealed by adenoviral expression of Dickkopf-1. Proc Natl Acad Sci U S A. 101, 266-71.

Kuphal, S., Bauer, R. and Bosserhoff, A.K., 2005. Integrin signaling in malignant melanoma. Cancer Metastasis Rev. 24, 195-222.

Kuriyama, S. and Mayor, R., 2008. Molecular analysis of neural crest migration. Philos Trans $R$ Soc Lond B Biol Sci. 363, 1349-62.

Kurosaka, S. and Kashina, A., 2008. Cell biology of embryonic migration. Birth Defects Res C Embryo Today. 84, 102-22.

LaBonne, C. and Bronner-Fraser, M., 2000. Snail-related transcriptional repressors are required in Xenopus for both the induction of the neural crest and its subsequent migration. Dev Biol. 221, 195-205.

Laemmli, U.K., 1970. Cleavage of structural proteins during the assembly of the head of bacteriophage T4. Nature. 227, 680-5.

Lara, E., Calvanese, V., Huidobro, C., Fernandez, A.F., Moncada-Pazos, A., Obaya, A.J., Aguilera, O., Gonzalez-Sancho, J.M., Sanchez, L., Astudillo, A., Munoz, A., LopezOtin, C., Esteller, M. and Fraga, M.F., 2010. Epigenetic repression of ROR2 has a Wnt-mediated, pro-tumourigenic role in colon cancer. Mol Cancer. 9, 170.

Larsen, M., Tremblay, M.L. and Yamada, K.M., 2003. Phosphatases in cell-matrix adhesion and migration. Nat Rev Mol Cell Biol. 4, 700-11.

Lauffenburger, D.A. and Horwitz, A.F., 1996. Cell migration: a physically integrated molecular process. Cell. 84, 359-69.

Lee, J., Ishihara, A., Oxford, G., Johnson, B. and Jacobson, K., 1999. Regulation of cell movement is mediated by stretch-activated calcium channels. Nature. 400, 382-6.

Lepore, J.J., Mericko, P.A., Cheng, L., Lu, M.M., Morrisey, E.E. and Parmacek, M.S., 2006. GATA-6 regulates semaphorin $3 \mathrm{C}$ and is required in cardiac neural crest for cardiovascular morphogenesis. J Clin Invest. 116, 929-39.

Ley, K., Laudanna, C., Cybulsky, M.I. and Nourshargh, S., 2007. Getting to the site of inflammation: the leukocyte adhesion cascade updated. Nat Rev Immunol. 7, 678-89. 
Li, D. and Mrsny, R.J., 2000. Oncogenic Raf-1 disrupts epithelial tight junctions via downregulation of occludin, J Cell Biol. pp. 791-800.

Li, L., Yuan, H., Weaver, C.D., Mao, J., Farr, G.H., 3rd, Sussman, D.J., Jonkers, J., Kimelman, D. and Wu, D., 1999a. Axin and Frat1 interact with dvl and GSK, bridging Dvl to GSK in Wnt-mediated regulation of LEF-1. Embo J. 18, 4233-40.

Li, L., Yuan, H., Xie, W., Mao, J., Caruso, A.M., McMahon, A., Sussman, D.J. and Wu, D., 1999b. Dishevelled proteins lead to two signaling pathways. Regulation of LEF-1 and C-Jun N-terminal kinase in mammalian cells. J Biol Chem. 274, 129-34.

Liu, Y., Ross, J.F., Bodine, P.V. and Billiard, J., 2007. Homodimerization of Ror2 tyrosine kinase receptor induces 14-3-3(beta) phosphorylation and promotes osteoblast differentiation and bone formation. Mol Endocrinol. 21, 3050-61.

Liu, Y., Rubin, B., Bodine, P.V. and Billiard, J., 2008. Wnt5a induces homodimerization and activation of Ror2 receptor tyrosine kinase. J Cell Biochem. 105, 497-502.

Lo, C.M., Wang, H.B., Dembo, M. and Wang, Y.L., 2000. Cell movement is guided by the rigidity of the substrate. Biophys J. 79, 144-52.

Lo, C.W., Cohen, M.F., Huang, G.Y., Lazatin, B.O., Patel, N., Sullivan, R., Pauken, C. and Park, S.M., 1997. Cx43 gap junction gene expression and gap junctional communication in mouse neural crest cells. Dev Genet. 20, 119-32.

Logan, C.Y. and Nusse, R., 2004. The Wnt signaling pathway in development and disease. Annu Rev Cell Dev Biol. 20, 781-810.

Lu, X., Borchers, A.G., Jolicoeur, C., Rayburn, H., Baker, J.C. and Tessier-Lavigne, M., 2004. PTK7/CCK-4 is a novel regulator of planar cell polarity in vertebrates. Nature. 430, 93-8.

Mancilla, A. and Mayor, R., 1996. Neural crest formation in Xenopus laevis: mechanisms of Xslug induction. Dev Biol. 177, 580-9.

Mandel, M. and Higa, A., 1970. Calcium-dependent bacteriophage DNA infection. J Mol Biol. 53, 159-62.

Matthews, H.K., Marchant, L., Carmona-Fontaine, C., Kuriyama, S., Larrain, J., Holt, M.R., Parsons, M. and Mayor, R., 2008. Directional migration of neural crest cells in vivo is regulated by Syndecan-4/Rac1 and non-canonical Wnt signaling/RhoA. Development. 135, 1771-80.

Mayor, R., Guerrero, N., Young, R.M., Gomez-Skarmeta, J.L. and Cuellar, C., 2000. A novel function for the Xslug gene: control of dorsal mesendoderm development by repressing BMP-4. Mech Dev. 97, 47-56.

Mayor, R., Morgan, R. and Sargent, M.G., 1995. Induction of the prospective neural crest of Xenopus. Development. 121, 767-77.

McMahon, A.P. and Moon, R.T., 1989. Ectopic expression of the proto-oncogene int-1 in Xenopus embryos leads to duplication of the embryonic axis. Cell. 58, 1075-84.

Meng, L., Sefah, K., O'Donoghue, M.B., Zhu, G., Shangguan, D., Noorali, A., Chen, Y., Zhou, L. and Tan, W., 2010. Silencing of PTK7 in colon cancer cells: caspase-10-dependent apoptosis via mitochondrial pathway. PLoS One. 5, e14018.

Mikels, A., Minami, Y. and Nusse, R., 2009. Ror2 receptor requires tyrosine kinase activity to mediate Wnt5A signaling. J Biol Chem. 284, 30167-76.

Mikels, A.J. and Nusse, R., 2006. Purified Wnt5a protein activates or inhibits beta-cateninTCF signaling depending on receptor context. PLoS Biol. 4, e115.

Miller, M.A. and Steele, R.E., 2000. Lemon encodes an unusual receptor protein-tyrosine kinase expressed during gametogenesis in Hydra. Dev Biol. 224, 286-98.

Minami, Y., Oishi, I., Endo, M. and Nishita, M., 2010. Ror-family receptor tyrosine kinases in noncanonical Wnt signaling: their implications in developmental morphogenesis and human diseases. Dev Dyn. 239, 1-15.

Molenaar, M., van de Wetering, M., Oosterwegel, M., Peterson-Maduro, J., Godsave, S., Korinek, V., Roose, J., Destree, O. and Clevers, H., 1996. XTcf-3 transcription factor mediates beta-catenin-induced axis formation in Xenopus embryos. Cell. 86, 391-9.

Molyneaux, K. and Wylie, C., 2004. Primordial germ cell migration. Int J Dev Biol. 48, 537-44. 
Molyneaux, K.A., Stallock, J., Schaible, K. and Wylie, C., 2001. Time-lapse analysis of living mouse germ cell migration. Dev Biol. 240, 488-98.

Montcouquiol, M., Crenshaw, E.B., 3rd and Kelley, M.W., 2006. Noncanonical Wnt signaling and neural polarity. Annu Rev Neurosci. 29, 363-86.

Montell, D.J., 2008. Morphogenetic cell movements: diversity from modular mechanical properties. Science. 322, 1502-5.

Mosmann, T., 1983. Rapid colorimetric assay for cellular growth and survival: application to proliferation and cytotoxicity assays. J Immunol Methods. 65, 55-63.

Mossie, K., Jallal, B., Alves, F., Sures, I., Plowman, G.D. and Ullrich, A., 1995. Colon carcinoma kinase-4 defines a new subclass of the receptor tyrosine kinase family. Oncogene. 11, 2179-84.

Muller-Tidow, C., Schwable, J., Steffen, B., Tidow, N., Brandt, B., Becker, K., Schulze-Bahr, E., Halfter, H., Vogt, U., Metzger, R., Schneider, P.M., Buchner, T., Brandts, C., Berdel, W.E. and Serve, H., 2004. High-throughput analysis of genome-wide receptor tyrosine kinase expression in human cancers identifies potential novel drug targets. Clin Cancer Res. 10, 1241-9.

Mullins, R.D. and Pollard, T.D., 1999a. Rho-family GTPases require the Arp2/3 complex to stimulate actin polymerization in Acanthamoeba extracts. Curr Biol. 9, 405-15.

Mullins, R.D. and Pollard, T.D., 1999b. Structure and function of the Arp2/3 complex. Curr Opin Struct Biol. 9, 244-9.

Nabeshima, K., Inoue, T., Shimao, Y., Okada, Y., Itoh, Y., Seiki, M. and Koono, M., 2000. Front-cell-specific expression of membrane-type 1 matrix metalloproteinase and gelatinase A during cohort migration of colon carcinoma cells induced by hepatocyte growth factor/scatter factor. Cancer Res. 60, 3364-9.

Nabzdyk, C.S., Chun, M., Pradhan, L. and Logerfo, F.W., 2011. High throughput RNAi assay optimization using adherent cell cytometry. J Transl Med. 9, 48.

Nagel, M., Tahinci, E., Symes, K. and Winklbauer, R., 2004. Guidance of mesoderm cell migration in the Xenopus gastrula requires PDGF signaling. Development. 131, 272736.

Nieuwkoop, P.D.F., J. , 1991. Normal table of Xenopus laevis. (Daudin) (North-Holland, Amsterdam, 1967)

Nishita, M., Yoo, S.K., Nomachi, A., Kani, S., Sougawa, N., Ohta, Y., Takada, S., Kikuchi, A. and Minami, Y., 2006. Filopodia formation mediated by receptor tyrosine kinase Ror2 is required for Wnt5a-induced cell migration. $\mathrm{J}$ Cell Biol. 175, 555-62.

Nobes, C.D. and Hall, A., 1999. Rho GTPases control polarity, protrusion, and adhesion during cell movement. J Cell Biol. 144, 1235-44.

Nomachi, A., Nishita, M., Inaba, D., Enomoto, M., Hamasaki, M. and Minami, Y., 2008. Receptor tyrosine kinase Ror2 mediates Wnt5a-induced polarized cell migration by activating C-Jun $\mathrm{N}$-terminal kinase via actin-binding protein filamin $\mathrm{A}$. J Biol Chem. 283, 27973-81.

Nomura, H., Sato, H., Seiki, M., Mai, M. and Okada, Y., 1995. Expression of membrane-type matrix metalloproteinase in human gastric carcinomas. Cancer Res. 55, 3263-6.

Noordermeer, J., Klingensmith, J., Perrimon, N. and Nusse, R., 1994. dishevelled and armadillo act in the wingless signalling pathway in Drosophila. Nature. 367, 80-3.

Nusse, R. and Varmus, H.E., 1982. Many tumors induced by the mouse mammary tumor virus contain a provirus integrated in the same region of the host genome. Cell. 31 , 99-109.

Nusslein-Volhard, C. and Wieschaus, E., 1980. Mutations affecting segment number and polarity in Drosophila. Nature. 287, 795-801.

O'Connell, M.P., Fiori, J.L., Baugher, K.M., Indig, F.E., French, A.D., Camilli, T.C., Frank, B.P., Earley, R., Hoek, K.S., Hasskamp, J.H., Elias, E.G., Taub, D.D., Bernier, M. and Weeraratna, A.T., 2009. Wnt5A activates the calpain-mediated cleavage of filamin A. J Invest Dermatol. 129, 1782-9.

Ohkawara, B. and Niehrs, C., 2011. An ATF2-based luciferase reporter to monitor noncanonical Wnt signaling in Xenopus embryos. Dev Dyn. 240, 188-94. 
Oishi, I., Suzuki, H., Onishi, N., Takada, R., Kani, S., Ohkawara, B., Koshida, I., Suzuki, K., Yamada, G., Schwabe, G.C., Mundlos, S., Shibuya, H., Takada, S. and Minami, Y., 2003. The receptor tyrosine kinase Ror2 is involved in non-canonical Wnt5a/JNK signalling pathway. Genes Cells. 8, 645-54.

Olson, D.J. and Papkoff, J., 1994. Regulated expression of Wnt family members during proliferation of C57mg mammary cells. Cell Growth Differ. 5, 197-206.

Parent, C.A., Blacklock, B.J., Froehlich, W.M., Murphy, D.B. and Devreotes, P.N., 1998. G protein signaling events are activated at the leading edge of chemotactic cells. Cell. 95, 81-91.

Park, M. and Moon, R.T., 2002. The planar cell-polarity gene stbm regulates cell behaviour and cell fate in vertebrate embryos. Nat Cell Biol. 4, 20-5.

Paudyal, A., Damrau, C., Patterson, V.L., Ermakov, A., Formstone, C., Lalanne, Z., Wells, S., Lu, X., Norris, D.P., Dean, C.H., Henderson, D.J. and Murdoch, J.N., 2010. The novel mouse mutant, chuzhoi, has disruption of Ptk7 protein and exhibits defects in neural tube, heart and lung development and abnormal planar cell polarity in the ear. BMC Dev Biol. 10, 87.

Peifer, M., Sweeton, D., Casey, M. and Wieschaus, E., 1994. wingless signal and Zestewhite 3 kinase trigger opposing changes in the intracellular distribution of Armadillo. Development. 120, 369-80.

Peradziryi, H., Kaplan, N.A., Podleschny, M., Liu, X., Wehner, P., Borchers, A. and Tolwinski, N.S., 2011. PTK7/Otk interacts with Wnts and inhibits canonical Wnt signalling. Embo J.

Peters, J.M., McKay, R.M., McKay, J.P. and Graff, J.M., 1999. Casein kinase I transduces Wnt signals. Nature. 401, 345-50.

Petrie, R.J., Doyle, A.D. and Yamada, K.M., 2009. Random versus directionally persistent cell migration. Nat Rev Mol Cell Biol. 10, 538-49.

Pinson, K.I., Brennan, J., Monkley, S., Avery, B.J. and Skarnes, W.C., 2000. An LDLreceptor-related protein mediates Wnt signalling in mice. Nature. 407, 535-8.

Pinto, D., Gregorieff, A., Begthel, H. and Clevers, H., 2003. Canonical Wnt signals are essential for homeostasis of the intestinal epithelium. Genes Dev. 17, 1709-13.

Poincloux, R., Lizarraga, F. and Chavrier, P., 2009. Matrix invasion by tumour cells: a focus on MT1-MMP trafficking to invadopodia. J Cell Sci. 122, 3015-24.

Pollard, J.W., 2004. Tumour-educated macrophages promote tumour progression and metastasis. Nat Rev Cancer. 4, 71-8.

Pollard, T.D., 2000. Reflections on a quarter century of research on contractile systems. Trends Biochem Sci. 25, 607-11.

Pollard, T.D., 2007. Regulation of actin filament assembly by Arp2/3 complex and formins. Annu Rev Biophys Biomol Struct. 36, 451-77.

Pollard, T.D. and Borisy, G.G., 2003. Cellular motility driven by assembly and disassembly of actin filaments. Cell. 112, 453-65.

Prebet, T., Lhoumeau, A.C., Arnoulet, C., Aulas, A., Marchetto, S., Audebert, S., Puppo, F., Chabannon, C., Sainty, D., Santoni, M.J., Sebbagh, M., Summerour, V., Huon, Y., Shin, W.S., Lee, S.T., Esterni, B., Vey, N. and Borg, J.P., 2010. The cell polarity PTK7 receptor acts as a modulator of the chemotherapeutic response in acute myeloid leukemia and impairs clinical outcome. Blood. 116, 2315-23.

Price, M.A., 2006. CKI, there's more than one: caseine kinase I family members in Wnt and Hedegehog signaling. Genes Dev. 20, 399-410.

Pukrop, T., Klemm, F., Hagemann, T., Gradl, D., Schulz, M., Siemes, S., Trumper, L. and Binder, C., 2006. Wnt 5a signaling is critical for macrophage-induced invasion of breast cancer cell lines. Proc Natl Acad Sci U S A. 103, 5454-9.

Pulido, D., Campuzano, S., Koda, T., Modolell, J. and Barbacid, M., 1992. Dtrk, a Drosophila gene related to the trk family of neurotrophin receptors, encodes a novel class of neural cell adhesion molecule. Embo J. 11, 391-404.

Puppo, F., Thome, V., Lhoumeau, A.C., Cibois, M., Gangar, A., Lembo, F., Belotti, E., Marchetto, S., Lecine, P., Prebet, T., Sebbagh, M., Shin, W.S., Lee, S.T., 
Kodjabachian, L. and Borg, J.P., 2011. Protein tyrosine kinase 7 has a conserved role in Wnt/beta-catenin canonical signalling. EMBO Rep. 12, 43-9.

Qian, B.Z. and Pollard, J.W., 2010. Macrophage diversity enhances tumor progression and metastasis. Cell. 141, 39-51.

Qian, D., Jones, C., Rzadzinska, A., Mark, S., Zhang, X., Steel, K.P., Dai, X. and Chen, P., 2007. Wnt5a functions in planar cell polarity regulation in mice. Dev Biol. 306, 121-33.

Raible, D.W. and Ragland, J.W., 2005. Reiterated Wnt and BMP signals in neural crest development. Semin Cell Dev Biol. 16, 673-82.

Ramos, J.W., Whittaker, C.A. and DeSimone, D.W., 1996. Integrin-dependent adhesive activity is spatially controlled by inductive signals at gastrulation. Development. 122, 2873-83.

Raven, C.P.K., J. , 1945. Induction by medial and lateral pieces of the archenteron roof with special reference to the determination of the neural crest. Acta Neerl. Morphol. 4, 348-362.

Ren, X.D. and Schwartz, M.A., 2000. Determination of GTP loading on Rho. Methods Enzymol. 325, 264-72.

Ridley, A.J., 2011. Life at the leading edge. Cell. 145, 1012-22.

Ridley, A.J., Schwartz, M.A., Burridge, K., Firtel, R.A., Ginsberg, M.H., Borisy, G., Parsons, J.T. and Horwitz, A.R., 2003. Cell migration: integrating signals from front to back. Science. 302, 1704-9.

Rijsewijk, F., Schuermann, M., Wagenaar, E., Parren, P., Weigel, D. and Nusse, R., 1987. The Drosophila homolog of the mouse mammary oncogene int- 1 is identical to the segment polarity gene wingless. Cell. 50, 649-57.

Robinson, D.R., Wu, Y.M. and Lin, S.F., 2000. The protein tyrosine kinase family of the human genome. Oncogene. 19, 5548-57.

Rodriguez, O.C., Schaefer, A.W., Mandato, C.A., Forscher, P., Bement, W.M. and Waterman-Storer, C.M., 2003. Conserved microtubule-actin interactions in cell movement and morphogenesis. Nat Cell Biol. 5, 599-609.

Roose, J., Molenaar, M., Peterson, J., Hurenkamp, J., Brantjes, H., Moerer, P., van de Wetering, M., Destree, O. and Clevers, H., 1998. The Xenopus Wnt effector XTcf-3 interacts with Groucho-related transcriptional repressors. Nature. 395, 608-12.

Rothbacher, U., Laurent, M.N., Deardorff, M.A., Klein, P.S., Cho, K.W. and Fraser, S.E., 2000. Dishevelled phosphorylation, subcellular localization and multimerization regulate its role in early embryogenesis. Embo J. 19, 1010-22.

Rupp, R.A., Snider, L. and Weintraub, H., 1994. Xenopus embryos regulate the nuclear localization of XMyoD. Genes Dev. 8, 1311-23.

Russel, S.a., 2001. Molecular Cloning: a laboratory manual 3rd ed. Cold Spring Harbour Laboratory Press,

Cold Spring Harbour, New York

Saha, S., Bardelli, A., Buckhaults, P., Velculescu, V.E., Rago, C., St Croix, B., Romans, K.E., Choti, M.A., Lengauer, C., Kinzler, K.W. and Vogelstein, B., 2001. A phosphatase associated with metastasis of colorectal cancer. Science. 294, 1343-6.

Sakanaka, C., Leong, P., Xu, L., Harrison, S.D. and Williams, L.T., 1999. Casein kinase iepsilon in the wnt pathway: regulation of beta-catenin function. Proc Natl Acad Sci U S A. 96, 12548-52.

Sammar, M., Stricker, S., Schwabe, G.C., Sieber, C., Hartung, A., Hanke, M., Oishi, I., Pohl, J., Minami, Y., Sebald, W., Mundlos, S. and Knaus, P., 2004. Modulation of GDF5/BRI-b signalling through interaction with the tyrosine kinase receptor Ror2. Genes Cells. 9, 1227-38.

Sander, E.E., van Delft, S., ten Klooster, J.P., Reid, T., van der Kammen, R.A., Michiels, F. and Collard, J.G., 1998. Matrix-dependent Tiam1/Rac signaling in epithelial cells promotes either cell-cell adhesion or cell migration and is regulated by phosphatidylinositol 3-kinase. J Cell Biol. 143, 1385-98.

Sanger, F., Nicklen, S. and Coulson, A.R., 1977. DNA sequencing with chain-terminating inhibitors. Proc Natl Acad Sci U S A. 74, 5463-7. 
Sato, M., Tsai, H.J. and Yost, H.J., 2006. Semaphorin3D regulates invasion of cardiac neural crest cells into the primary heart field. Dev Biol. 298, 12-21.

Savory, J.G., Mansfield, M., Rijli, F.M. and Lohnes, D., 2011. Cdx mediates neural tube closure through transcriptional regulation of the planar cell polarity gene Ptk7. Development. 138, 1361-70.

Schambony, A. and Wedlich, D., 2007. Wnt-5A/Ror2 regulate expression of XPAPC through an alternative noncanonical signaling pathway. Dev Cell. 12, 779-92.

Scherson, T., Serbedzija, G., Fraser, S. and Bronner-Fraser, M., 1993. Regulative capacity of the cranial neural tube to form neural crest. Development. 118, 1049-62.

Schlessinger, J., 2000. Cell signaling by receptor tyrosine kinases. Cell. 103, 211-25.

Schoumacher, M., Goldman, R.D., Louvard, D. and Vignjevic, D.M., 2010. Actin, microtubules, and vimentin intermediate filaments cooperate for elongation of invadopodia. J Cell Biol. 189, 541-56.

Schoumacher, M., Louvard, D. and Vignjevic, D., 2011. Cytoskeleton networks in basement membrane transmigration. Eur J Cell Biol. 90, 93-9.

Seifert, J.R. and Mlodzik, M., 2007. Frizzled/PCP signalling: a conserved mechanism regulating cell polarity and directed motility. Nat Rev Genet. 8, 126-38.

Seiki, M., 2002. The cell surface: the stage for matrix metalloproteinase regulation of migration. Curr Opin Cell Biol. 14, 624-32.

Seiki, M., Mori, H., Kajita, M., Uekita, T. and Itoh, Y., 2003. Membrane-type 1 matrix metalloproteinase and cell migration. Biochem Soc Symp. 253-62.

Selleck, M.A. and Bronner-Fraser, M., 1995. Origins of the avian neural crest: the role of neural plate-epidermal interactions. Development. 121, 525-38.

Serbedzija, G.N., Bronner-Fraser, M. and Fraser, S.E., 1989. A vital dye analysis of the timing and pathways of avian trunk neural crest cell migration. Development. 106, 809-16.

Serbedzija, G.N., Bronner-Fraser, M. and Fraser, S.E., 1992. Vital dye analysis of cranial neural crest cell migration in the mouse embryo. Development. 116, 297-307.

Serbedzija, G.N., Fraser, S.E. and Bronner-Fraser, M., 1990. Pathways of trunk neural crest cell migration in the mouse embryo as revealed by vital dye labelling. Development. 108, 605-12.

Servant, G., Weiner, O.D., Herzmark, P., Balla, T., Sedat, J.W. and Bourne, H.R., 2000. Polarization of chemoattractant receptor signaling during neutrophil chemotaxis. Science. 287, 1037-40.

Sharp, P.A., Sugden, B. and Sambrook, J., 1973. Detection of two restriction endonuclease activities in Haemophilus parainfluenzae using analytical agarose--ethidium bromide electrophoresis. Biochemistry. 12, 3055-63.

Shimizu, H., Julius, M.A., Giarre, M., Zheng, Z., Brown, A.M. and Kitajewski, J., 1997. Transformation by Wnt family proteins correlates with regulation of beta-catenin. Cell Growth Differ. 8, 1349-58.

Shin, W.S., Maeng, Y.S., Jung, J.W., Min, J.K., Kwon, Y.G. and Lee, S.T., 2008. Soluble PTK7 inhibits tube formation, migration, and invasion of endothelial cells and angiogenesis. Biochem Biophys Res Commun. 371, 793-8.

Shnitsar, I. and Borchers, A., 2008. PTK7 recruits dsh to regulate neural crest migration. Development. 135, 4015-24.

Siegfried, E., Chou, T.B. and Perrimon, N., 1992. wingless signaling acts through zeste-white 3 , the Drosophila homolog of glycogen synthase kinase-3, to regulate engrailed and establish cell fate. Cell. 71, 1167-79.

Smalley, M.J., Sara, E., Paterson, H., Naylor, S., Cook, D., Jayatilake, H., Fryer, L.G., Hutchinson, L., Fry, M.J. and Dale, T.C., 1999. Interaction of axin and Dvl-2 proteins regulates Dvl-2-stimulated TCF-dependent transcription. Embo J. 18, 2823-35.

Smith, W.C. and Harland, R.M., 1991. Injected Xwnt-8 RNA acts early in Xenopus embryos to promote formation of a vegetal dorsalizing center. Cell. 67, 753-65.

Solnica-Krezel, L., 2006. Gastrulation in zebrafish -- all just about adhesion? Curr Opin Genet Dev. 16, 433-41. 
Springman, E.B., Angleton, E.L., Birkedal-Hansen, H. and Van Wart, H.E., 1990. Multiple modes of activation of latent human fibroblast collagenase: evidence for the role of a Cys73 active-site zinc complex in latency and a "cysteine switch" mechanism for activation. Proc Natl Acad Sci U S A. 87, 364-8.

Srinivasan, S., Wang, F., Glavas, S., Ott, A., Hofmann, F., Aktories, K., Kalman, D. and Bourne, H.R., 2003. Rac and Cdc42 play distinct roles in regulating PI(3,4,5)P3 and polarity during neutrophil chemotaxis. J Cell Biol. 160, 375-85.

Stahle, M., Veit, C., Bachfischer, U., Schierling, K., Skripczynski, B., Hall, A., Gierschik, P. and Giehl, K., 2003. Mechanisms in LPA-induced tumor cell migration: critical role of phosphorylated ERK. J Cell Sci. 116, 3835-46.

Stetler-Stevenson, W.G., Krutzsch, H.C. and Liotta, L.A., 1989. Tissue inhibitor of metalloproteinase (TIMP-2). A new member of the metalloproteinase inhibitor family. J Biol Chem. 264, 17374-8.

Steventon, B., Carmona-Fontaine, C. and Mayor, R., 2005. Genetic network during neural crest induction: from cell specification to cell survival. Semin Cell Dev Biol. 16, 64754.

Strutt, D.I., Weber, U. and Mlodzik, M., 1997. The role of RhoA in tissue polarity and Frizzled signalling. Nature. 387, 292-5.

Tada, M. and Kai, M., 2009. Noncanonical Wnt/PCP signaling during vertebrate gastrulation. Zebrafish. 6, 29-40.

Tahinci, E. and Symes, K., 2003. Distinct functions of Rho and Rac are required for convergent extension during Xenopus gastrulation. Dev Biol. 259, 318-35.

Tahinci, E., Thorne, C.A., Franklin, J.L., Salic, A., Christian, K.M., Lee, L.A., Coffey, R.J. and Lee, E., 2007. Lrp6 is required for convergent extension during Xenopus gastrulation. Development. 134, 4095-106.

Taira, M., Otani, H., Saint-Jeannet, J.P. and Dawid, I.B., 1994. Role of the LIM class homeodomain protein Xlim-1 in neural and muscle induction by the Spemann organizer in Xenopus. Nature. 372, 677-9.

Tamai, K., Semenov, M., Kato, Y., Spokony, R., Liu, C., Katsuyama, Y., Hess, F., SaintJeannet, J.P. and He, X., 2000. LDL-receptor-related proteins in Wnt signal transduction. Nature. 407, 530-5.

Teddy, J.M. and Kulesa, P.M., 2004. In vivo evidence for short- and long-range cell communication in cranial neural crest cells. Development. 131, 6141-51.

Theveneau, E., Marchant, L., Kuriyama, S., Gull, M., Moepps, B., Parsons, M. and Mayor, R., 2010. Collective chemotaxis requires contact-dependent cell polarity. Dev Cell. 19, 39-53.

Theveneau, E. and Mayor, R., 2011. Collective cell migration of the cephalic neural crest: the art of integrating information. Genesis. 49, 164-76.

Thorpe, G.H. and Kricka, L.J., 1986. Enhanced chemiluminescent reactions catalyzed by horseradish peroxidase. Methods Enzymol. 133, 331-53.

Thorpe, G.H., Kricka, L.J., Gillespie, E., Moseley, S., Amess, R., Baggett, N. and Whitehead, T.P., 1985. Enhancement of the horseradish peroxidase-catalyzed chemiluminescent oxidation of cyclic diacyl hydrazides by 6-hydroxybenzothiazoles. Anal Biochem. 145, 96-100.

Towbin, H. and Gordon, J., 1984. Immunoblotting and dot immunobinding--current status and outlook. J Immunol Methods. 72, 313-40.

Towbin, H., Staehelin, T. and Gordon, J., 1979. Electrophoretic transfer of proteins from polyacrylamide gels to nitrocellulose sheets: procedure and some applications. Proc Natl Acad Sci U S A. 76, 4350-4.

Towbin, H., Staehelin, T. and Gordon, J., 1992. Electrophoretic transfer of proteins from polyacrylamide gels to nitrocellulose sheets: procedure and some applications. 1979. Biotechnology. 24, 145-9.

Trainor, P.A., 2005. Specification of neural crest cell formation and migration in mouse embryos. Semin Cell Dev Biol. 16, 683-93. 
Turner, C.E., West, K.A. and Brown, M.C., 2001. Paxillin-ARF GAP signaling and the cytoskeleton. Curr Opin Cell Biol. 13, 593-9.

Turner, D.L. and Weintraub, H., 1994. Expression of achaete-scute homolog 3 in Xenopus embryos converts ectodermal cells to a neural fate. Genes Dev. 8, 1434-47.

van Amerongen, R. and Berns, A., 2008. Targeted anticancer therapies: mouse models help uncover the mechanisms of tumor escape. Cancer Cell. 13, 5-7.

van de Wetering, M., Cavallo, R., Dooijes, D., van Beest, M., van Es, J., Loureiro, J., Ypma, A., Hursh, D., Jones, T., Bejsovec, A., Peifer, M., Mortin, M. and Clevers, H., 1997. Armadillo coactivates transcription driven by the product of the Drosophila segment polarity gene dTCF. Cell. 88, 789-99.

Van Haastert PJ, D.P., 2004. Chemotaxis: Signalling the way forward. Nat Rev Mol Cell Biol. 5, 626-634.

Vasilyev, A., Liu, Y., Mudumana, S., Mangos, S., Lam, P.Y., Majumdar, A., Zhao, J., Poon, K.L., Kondrychyn, I., Korzh, V. and Drummond, I.A., 2009. Collective cell migration drives morphogenesis of the kidney nephron. PLoS Biol. 7, e9.

Vaughan, R.B. and Trinkaus, J.P., 1966. Movements of epithelial cell sheets in vitro. J Cell Sci. 1, 407-13.

Wallar, B.J. and Alberts, A.S., 2003. The formins: active scaffolds that remodel the cytoskeleton. Trends Cell Biol. 13, 435-46.

Wallingford, J.B., Fraser, S.E. and Harland, R.M., 2002. Convergent extension: the molecular control of polarized cell movement during embryonic development. Dev Cell. 2, 695706.

Wallingford, J.B. and Habas, R., 2005. The developmental biology of Dishevelled: an enigmatic protein governing cell fate and cell polarity. Development. 132, 4421-36.

Wallingford, J.B. and Harland, R.M., 2002. Neural tube closure requires Dishevelleddependent convergent extension of the midline. Development. 129, 5815-25.

Wang, W., Goswami, S., Lapidus, K., Wells, A.L., Wyckoff, J.B., Sahai, E., Singer, R.H., Segall, J.E. and Condeelis, J.S., 2004. Identification and testing of a gene expression signature of invasive carcinoma cells within primary mammary tumors. Cancer Res. 64, 8585-94.

Wang, W., Goswami, S., Sahai, E., Wyckoff, J.B., Segall, J.E. and Condeelis, J.S., 2005. Tumor cells caught in the act of invading: their strategy for enhanced cell motility. Trends Cell Biol. 15, 138-45.

Wang, W., Wyckoff, J.B., Frohlich, V.C., Oleynikov, Y., Huttelmaier, S., Zavadil, J., Cermak, L., Bottinger, E.P., Singer, R.H., White, J.G., Segall, J.E. and Condeelis, J.S., 2002. Single cell behavior in metastatic primary mammary tumors correlated with gene expression patterns revealed by molecular profiling. Cancer Res. 62, 6278-88.

Wang, Y. and Nathans, J., 2007. Tissue/planar cell polarity in vertebrates: new insights and new questions. Development. 134, 647-58.

Wehner, P., Shnitsar, I., Urlaub, H. and Borchers, A., 2010. RACK1 is a novel interaction partner of PTK7 that is required for neural tube closure. Development. 138, 1321-7.

Wehrli, M., Dougan, S.T., Caldwell, K., O'Keefe, L., Schwartz, S., Vaizel-Ohayon, D., Schejter, E., Tomlinson, A. and DiNardo, S., 2000. arrow encodes an LDL-receptorrelated protein essential for Wingless signalling. Nature. 407, 527-30.

Werner, S. and Grose, R., 2003. Regulation of wound healing by growth factors and cytokines. Physiol Rev. 83, 835-70.

Whitehead, T.P., Kricka, L.J., Carter, T.J. and Thorpe, G.H., 1979. Analytical luminescence: its potential in the clinical laboratory. Clin Chem. 25, 1531-46.

Willert, K., Brink, M., Wodarz, A., Varmus, H. and Nusse, R., 1997. Casein kinase 2 associates with and phosphorylates dishevelled. Embo J. 16, 3089-96.

Winberg, M.L., Tamagnone, L., Bai, J., Comoglio, P.M., Montell, D. and Goodman, C.S., 2001. The transmembrane protein Off-track associates with Plexins and functions downstream of Semaphorin signaling during axon guidance. Neuron. 32, 53-62.

Winklbauer, R., Medina, A., Swain, R.K. and Steinbeisser, H., 2001. Frizzled-7 signalling controls tissue separation during Xenopus gastrulation. Nature. 413, 856-60. 
Winklbauer, R. and Nagel, M., 1991. Directional mesoderm cell migration in the Xenopus gastrula. Dev Biol. 148, 573-89.

Witzel, S., Zimyanin, V., Carreira-Barbosa, F., Tada, M. and Heisenberg, C.P., 2006. Wnt11 controls cell contact persistence by local accumulation of Frizzled 7 at the plasma membrane. J Cell Biol. 175, 791-802.

Wodarz, A. and Nusse, R., 1998. Mechanisms of Wnt signaling in development. Annu Rev Cell Dev Biol. 14, 59-88.

Wolf, K., Wu, Y.I., Liu, Y., Geiger, J., Tam, E., Overall, C., Stack, M.S. and Friedl, P., 2007. Multi-step pericellular proteolysis controls the transition from individual to collective cancer cell invasion. Nat Cell Biol. 9, 893-904.

Wong, L.L. and Adler, P.N., 1993. Tissue polarity genes of Drosophila regulate the subcellular location for prehair initiation in pupal wing cells. J Cell Biol. 123, 209-21.

Worthylake, R.A. and Burridge, K., 2003. RhoA and ROCK promote migration by limiting membrane protrusions. J Biol Chem. 278, 13578-84.

Wyckoff, J., Wang, W., Lin, E.Y., Wang, Y., Pixley, F., Stanley, E.R., Graf, T., Pollard, J.W., Segall, J. and Condeelis, J., 2004. A paracrine loop between tumor cells and macrophages is required for tumor cell migration in mammary tumors. Cancer Res. 64, 7022-9.

Xu, J., Wang, F., Van Keymeulen, A., Herzmark, P., Straight, A., Kelly, K., Takuwa, Y., Sugimoto, N., Mitchison, T. and Bourne, H.R., 2003. Divergent signals and cytoskeletal assemblies regulate self-organizing polarity in neutrophils. Cell. 114, 201-14.

Yamaguchi, H., Wyckoff, J. and Condeelis, J., 2005. Cell migration in tumors. Curr Opin Cell Biol. 17, 559-64.

Yamamoto, S., Nishimura, O., Misaki, K., Nishita, M., Minami, Y., Yonemura, S., Tarui, H. and Sasaki, H., 2008. Cthrc1 selectively activates the planar cell polarity pathway of Wnt signaling by stabilizing the Wnt-receptor complex. Dev Cell. 15, 23-36.

Yamanaka, H., Moriguchi, T., Masuyama, N., Kusakabe, M., Hanafusa, H., Takada, R., Takada, S. and Nishida, E., 2002. JNK functions in the non-canonical Wnt pathway to regulate convergent extension movements in vertebrates. EMBO Rep. 3, 69-75.

Yao, F., Svensjo, T., Winkler, T., Lu, M., Eriksson, C. and Eriksson, E., 1998. Tetracycline repressor, tetR, rather than the tetR-mammalian cell transcription factor fusion derivatives, regulates inducible gene expression in mammalian cells. Hum Gene Ther. 9, 1939-50.

Yen, W.W., Williams, M., Periasamy, A., Conaway, M., Burdsal, C., Keller, R., Lu, X. and Sutherland, A., 2009. PTK7 is essential for polarized cell motility and convergent extension during mouse gastrulation. Development. 136, 2039-48.

Yost, C., Torres, M., Miller, J.R., Huang, E., Kimelman, D. and Moon, R.T., 1996. The axisinducing activity, stability, and subcellular distribution of beta-catenin is regulated in Xenopus embryos by glycogen synthase kinase 3. Genes Dev. 10, 1443-54.

Yu, H.H., Araj, H.H., Ralls, S.A. and Kolodkin, A.L., 1998. The transmembrane Semaphorin Sema I is required in Drosophila for embryonic motor and CNS axon guidance. Neuron. 20, 207-20.

Zallen, J.A., 2007. Planar polarity and tissue morphogenesis. Cell. 129, 1051-63.

Zeng, X., Tamai, K., Doble, B., Li, S., Huang, H., Habas, R., Okamura, H., Woodgett, J. and $\mathrm{He}, \mathrm{X} ., 2$ 2005. A dual-kinase mechanism for Wnt co-receptor phosphorylation and activation. Nature. 438, 873-7. 